JEFFREY D. SACHS

Columbia University and UN Millennium Project

J OHN W. MCARTHUR, GUIDO SCHMIDT - TRAUB, MARGARET KRUK, CHANDRIKA BAHADUR, MICHAEL FAYE, AND GORDON MCCORD UN Millennium Project

\title{
Ending Africa's Poverty Trap
}

Africa's DEVElopment CRISIS is unique. Not only is Africa the poorest region in the world, but it was also the only major developing region with negative growth in income per capita during 1980-2000 (table 1). Some African countries grew during the 1990s, but for the most part this growth recovered ground lost during the 1980s. Moreover, Africa's health conditions are by far the worst on the planet. The AIDS pandemic is wreaking havoc, as is the resurgence of malaria due to rising drug resistance and the lack of effective public health systems. Africa's population continues to soar, adding ecological stresses to the economic strains. Policy-based development lending to Africa over the past twenty years, known as structural adjustment lending, did not solve the problem. A heavy debt burden is evidenced by the 155 Paris Club restructurings of African countries' debt between 1980 and 2001, much more than for any other region. In general, Africa remains mired in poverty and debt.

This paper focuses on the tropical sub-Saharan African countries with populations of at least 2 million people in 2001. We leave out North Africa (Algeria, Egypt, Libya, Morocco, and Tunisia,), southernmost Africa (Botswana, Lesotho, Namibia, South Africa, and Swaziland), and a number of very small economies (Cape Verde, Comoros, Djibouti, Equatorial Guinea, Gabon, The Gambia, Guinea-Bissau, Mauritius, São Tomé and Principe, and Seychelles). Both nontropical ends of Africa are much richer

We would like to thank our colleagues in the UN Millennium Project, an advisory project to UN Secretary-General Kofi Annan, and especially the Task Force coordinators and members, for ample advice and consultations. We especially thank Vijay Modi for his detailed assistance on issues regarding energy and transport infrastructure. 
Table 1. Selected Development Indicators for Major Developing Regions ${ }^{\mathrm{a}}$

\begin{tabular}{|c|c|c|c|c|c|}
\hline Region & $\begin{array}{c}G N I \\
\text { per capita, } \\
2001 \\
(\text { dollars })^{\mathrm{b}}\end{array}$ & $\begin{array}{c}\text { Average } \\
\text { annual } \\
\text { growth } \\
\text { in GDP } \\
\text { per capita, } \\
\text { 1980-2000 } \\
\text { (percent) }\end{array}$ & $\begin{array}{c}\text { Life } \\
\text { expectancy } \\
\text { at birth, } \\
2001 \\
\text { (years) }\end{array}$ & $\begin{array}{l}\text { Under-five } \\
\text { mortality } \\
\text { rate, } 2001 \\
\text { (deaths } \\
\text { per } 1,000 \\
\text { live births) }\end{array}$ & $\begin{array}{c}\text { Average } \\
\text { annual } \\
\text { growth in } \\
\text { population, } \\
2001 \\
\text { (percent) }\end{array}$ \\
\hline $\begin{array}{l}\text { Tropical sub-Saharan } \\
\text { Africa }^{\mathrm{c}}\end{array}$ & 271 & -1.1 & 46.0 & 172.5 & 2.3 \\
\hline South Asia & 449 & 3.3 & 62.6 & 95.3 & 1.7 \\
\hline Latin America & 3,669 & 0.5 & 70.6 & 32.7 & 1.4 \\
\hline $\begin{array}{l}\text { East Asia and } \\
\text { the Pacific }\end{array}$ & 3,710 & 6.4 & 70.2 & 38.3 & 0.8 \\
\hline $\begin{array}{l}\text { Middle East and } \\
\text { North Africa }\end{array}$ & 2,207 & 0.9 & 68.4 & 49.8 & 2.0 \\
\hline
\end{tabular}

than tropical Africa. They grow temperate crops, escape the worst of malaria, enjoy (in the south) vast deposits per capita of gold and diamonds, and (in the north) benefit from proximity to EU markets. The smallest economies present idiosyncrasies that would distract more than inform the analysis.

The thirty-three sub-Saharan African countries on which we focus (and which are listed in table 2) had a combined population of 617 million in 2001 , with a population-weighted average annual income of $\$ 271$ per person, or a mere 74 cents a day. Every country on the list is a low-income country according to World Bank country classifications, and twenty-six are among the forty-nine Least Developed Countries in the world by the United Nations classification. Of the four countries with income per capita of $\$ 500$ or more, three (Angola, Cameroon, and Congo) are oil exporters, and only Côte d'Ivoire, which is currently in a vertiginous political and economic collapse, is a non-oil exporter. Every country on the list has a life expectancy at birth below sixty years, and in all but Ghana, Madagascar, and Sudan life expectancy at birth is below fifty-five years. Child mortality rates (deaths before the age of five per 1,000 live births) are above 100 in every country.

The standard diagnosis is that Africa is suffering from a governance crisis. With highly visible examples of profoundly poor governance, for 
Table 2. Governance Ratings and Household Consumption in Tropical Sub-Saharan Africa

\begin{tabular}{|c|c|c|c|c|}
\hline Country & $\begin{array}{c}\text { Rating } \\
\text { based on } \\
\text { World Bank } \\
\text { governance } \\
\text { indicators, } \\
\text { 2002 }\end{array}$ & 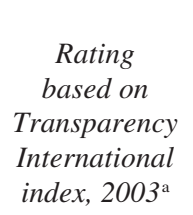 & $\begin{array}{c}\text { Freedom } \\
\text { House } \\
\text { rating, } 2003\end{array}$ & $\begin{array}{c}\text { Household } \\
\text { final } \\
\text { consumption } \\
\text { expenditure } \\
\text { per capita, 2000 } \\
(1980=100)\end{array}$ \\
\hline Benin & Good & n.a. & Free & 98.9 \\
\hline Burkina Faso & Good & n.a. & Partly free & 111.0 \\
\hline Ghana & Good & Average & Free & 92.8 \\
\hline Madagascar & Good & Good & Partly free & 64.0 \\
\hline Malawi & Good & Good & Partly free & 111.2 \\
\hline Mali & Good & Good & Free & 95.3 \\
\hline Mauritania & Good & Good & Partly free & 104.8 \\
\hline Senegal & Good & Good & Free & 99.6 \\
\hline Cameroon & Average & Average & Not free & 102.5 \\
\hline Central African Rep. & Average & n.a. & Partly free & n.a. \\
\hline Chad & Average & n.a. & Not free & n.a. \\
\hline Congo, Rep. of & Average & Average & n.a. & 80.5 \\
\hline Côte d'Ivoire & Average & Average & Not free & 78.2 \\
\hline Eritrea & Average & n.a. & Not free & n.a. \\
\hline Ethiopia & Average & Good & Partly free & n.a. \\
\hline Guinea & Average & n.a. & Not free & n.a. \\
\hline Kenya & Average & Average & Partly free & 100.7 \\
\hline Mozambique & Average & Good & Partly free & 79.4 \\
\hline Niger & Average & n.a. & Partly free & n.a. \\
\hline Nigeria & Average & Average & Partly free & n.a. \\
\hline Rwanda & Average & n.a. & Not free & 83.9 \\
\hline Sierra Leone & Average & Good & Partly free & 43.9 \\
\hline Tanzania & Average & Good & Partly free & n.a. \\
\hline Togo & Average & n.a. & Not free & 112.4 \\
\hline Uganda & Average & Average & Partly free & n.a. \\
\hline Zambia & Average & Good & Partly free & 47.0 \\
\hline Angola & Poor & Poor & Not free & n.a. \\
\hline Burundi & Poor & n.a. & Not free & 65.0 \\
\hline Congo, Dem. Rep. of & Poor & n.a. & Not free & 45.1 \\
\hline Sudan & Poor & Average & Not free & n.a. \\
\hline Zimbabwe & Poor & Average & Not free & 88.4 \\
\hline Liberia & n.a. & n.a. & Not free & n.a. \\
\hline Somalia & n.a. & n.a. & Not free & n.a. \\
\hline
\end{tabular}

Sources: Kaufmann, Kraay, and Mastruzzi (2003); Radelet (2004); authors' calculations using data in Transparency International (2004); Freedom House (2003); World Bank (2003a).

n.a., not available.

a. Determined from the residuals of a regression of countries' governance indicators or scores on income per capita (at purchasing power parity); countries with residuals more than 1 standard deviation above or 1 standard deviation below the predicted value are categorized as "good" or "poor," respectively, and those with residuals within 1 standard deviation as "average." For the first column, the World Bank governance indicators are those calculated by Kaufmann, Kraay, and Mastruzzi (2003). For the second column, Transparency International's Corruption Perceptions Index is used, which relates to the degree of corruption in the country as perceived by business people, academics, and risk analysts and ranges between 10 (highly clean) and 0 (highly corrupt). 
example in Zimbabwe, and widespread war and violence, as in Angola, the Democratic Republic of the Congo, Liberia, Sierra Leone, and Sudan, the impression of a continent-wide governance crisis is understandable. Yet it is wrong. Many parts of Africa are well governed even though stuck in poverty. Governance is a problem, but Africa's development challenges run much deeper.

Using our thirty-three-country sample, table 2 reports some common governance indicators that make this point. The first column presents a ranking of African governance compiled by Steven Radelet, ${ }^{1}$ who regresses a set of widely used World Bank governance indicators due to Daniel Kaufmann, Aart Kraay, and Massimo Mastruzzi on GDP per capita, ${ }^{2}$ and ranks countries according to the residuals from that regression, thereby standardizing the measurement of governance by level of income. This procedure recognizes that poorer countries have systematically poorer governance measures than richer countries, since good governance itself requires real resources. Well-governed African countries are defined as those with residuals at least 1 standard error above, and poorly governed countries as those with residuals at least 1 standard error below, the regression line. "Average" countries are those with residuals within 1 standard error on either side of the regression line. The table shows that, by this ranking, many countries are well governed. Nor is there evidence that Africa's governance, on average, is worse than elsewhere once we control for income levels: a regression (not reported in this paper) of several different governance indicators on the logarithm of GDP per capita (measured at purchasing power parity) and a dummy for tropical sub-Saharan Africa results in a statistically insignificant coefficient for the dummy variable.

The second column of table 2 repeats the same procedure using the Corruption Perceptions Index of Transparency International. ${ }^{3}$ All but one of the African countries in our sample for which scores are available receive scores of "good" (that is, low corruption) or "average" after we control for income. The third column reminds us as well that many African countries have become democracies in recent years, and thus are scored as "free" or "partly free" by the well-known Freedom House ranking. ${ }^{4}$ The final col-

1. Radelet (2004).

2. Kaufmann, Kraay, and Mastruzzi (2003).

3. Transparency International (2004).

4. Freedom House (2003). 
Table 3. Regressions Explaining Economic Growth in Tropical Sub-Saharan Africa with Governance Indicators ${ }^{\mathrm{a}}$

\begin{tabular}{|c|c|c|c|c|c|}
\hline Independent variable & $3-1$ & $3-2$ & $3-3$ & $3-4$ & $3-5$ \\
\hline $\begin{array}{l}\text { Dummy variable for tropical } \\
\text { sub-Saharan Africa }^{\mathrm{b}}\end{array}$ & $\begin{array}{l}-3.28 \\
(-6.56)\end{array}$ & $\begin{array}{l}-3.06 \\
(-6.50)\end{array}$ & $\begin{array}{l}-2.68 \\
(-6.11)\end{array}$ & $\begin{array}{l}-3.43 \\
(-7.05)\end{array}$ & $\begin{array}{l}-3.40 \\
(-6.46)\end{array}$ \\
\hline $\begin{array}{l}\text { Corruption Perceptions } \\
\text { Index, } 2003^{c}\end{array}$ & $\begin{array}{c}0.83 \\
(5.23)\end{array}$ & $\ldots$ & $\ldots$ & $\ldots$ & $\ldots$ \\
\hline $\begin{array}{l}\text { Index of Economic Freedom, } \\
2001^{\mathrm{d}}\end{array}$ & $\ldots$ & $\begin{array}{l}-0.96 \\
(-2.75)\end{array}$ & $\ldots$ & $\cdots$ & $\cdots$ \\
\hline $\begin{array}{l}\text { Average Kaufmann, Kraay, } \\
\text { Zoido-Lobaton indicators, } \\
2000^{\mathrm{e}}\end{array}$ & $\cdots$ & $\ldots$ & $\begin{array}{c}1.89 \\
(5.91)\end{array}$ & $\cdots$ & $\cdots$ \\
\hline $\begin{array}{l}\text { Average ICRG indicators, } \\
\text { 1982-97 }\end{array}$ & $\ldots$ & $\cdots$ & $\ldots$ & $\begin{array}{l}1.56 \\
(5.29)\end{array}$ & $\ldots$ \\
\hline Average ICRG indicators, $1982^{\mathrm{f}}$ & $\cdots$ & $\cdots$ & . . & $\ldots$ & $\begin{array}{c}0.68 \\
(3.78)\end{array}$ \\
\hline $\begin{array}{l}\text { Logarithm of GDP per capita } \\
\text { (at purchasing power } \\
\text { parity), } 1980\end{array}$ & $\begin{array}{l}-2.07 \\
(-7.02)\end{array}$ & $\begin{array}{l}-1.65 \\
(-6.06)\end{array}$ & $\begin{array}{l}-1.75 \\
(-7.07)\end{array}$ & $\begin{array}{l}-2.00 \\
(-7.01)\end{array}$ & $\begin{array}{l}-1.82 \\
(-5.84)\end{array}$ \\
\hline$R^{2}$ & 0.58 & 0.46 & 0.59 & 0.59 & 0.54 \\
\hline No. of observations & 60 & 71 & 78 & 65 & 52 \\
\hline
\end{tabular}

Sources: Authors' regressions using data from Transparency International (2004); Miles, Feulner, and O'Grady (2004); Kaufmann, Kraay, and Zoido-Lobaton (2002); PSR Group (2004); World Bank (2003a).

a. The dependent variable is average annual growth of GDP per capita, 1980-2000. The sample consists of ninety-two countries worldwide, excluding high-income countries and former republics of the Soviet Union. All regressions are ordinary least squares and include a constant term (not reported). Numbers in parentheses are $t$ statistics; all coefficients reach statistical significance at the 1 percent level.

b. Variable equals 1 if the country is one of the thirty-three countries listed in table 2

c. See table 2 for description.

d. The index is published by the Heritage Foundation and the Wall Street Journal and ranges from 1 to 5 , where 5 indicates the greatest government interference in the economy and the least economic freedom.

e. Average of six World Bank governance indicators measured in units ranging from about -2.5 to 2.5 , with higher values corresponding to better governance outcomes.

f. Average of six governance indicators from the International Country Risk Guide, with values ranging from 1 to 6 , with higher values reflecting better governance.

umn, however, shows real consumption expenditure per capita in 2000, as a percentage of its 1980 level, to point out that many of the relatively well governed African countries have been unable to increase the material well-being of their populations. Table 3 makes this point more systematically in a cross-country regression, which shows that, after we control for initial income in 1980 and the quality of governance (according to several alternative measures), sub-Saharan African countries grew more slowly than other developing countries, by around 3 percentage points a year. Africa's crisis requires a better explanation than governance alone.

Our explanation is that tropical Africa, even the well-governed parts, is stuck in a poverty trap, too poor to achieve robust, high levels of 
economic growth and, in many places, simply too poor to grow at all. ${ }^{5}$ More policy or governance reform, by itself, will not be sufficient to overcome this trap. Specifically, Africa's extreme poverty leads to low national saving rates, which in turn lead to low or negative economic growth rates. Low domestic saving is not offset by large inflows of private foreign capital, for example foreign direct investment, because Africa's poor infrastructure and weak human capital discourage such inflows. With very low domestic saving and low rates of market-based foreign capital inflows, there is little in Africa's current dynamics that promotes an escape from poverty. Something new is needed.

We argue that what is needed is a "big push" in public investments to produce a rapid "step" increase in Africa's underlying productivity, both rural and urban. The intervention of foreign donors will be critical to achieving this step increase. In particular, we argue that well-governed African countries should be offered a substantial increase in official development assistance (ODA) to enable them to achieve the Millennium Development Goals (MDGs), the internationally agreed targets for poverty reduction, by $2015 .{ }^{6}$ The goals are useful intermediate targets for breaking Africa's poverty trap, because they address the key sectors in which major productivity improvements are both needed and achievable, and because the rich countries have repeatedly committed themselves to help-

5. The concept of a low-level poverty trap is, of course, a long-standing hypothesis in the theories of economic growth and development. The earliest mathematical formalization was by Nelson (1956). The theoretical possibility of poverty traps in the neoclassical growth model is covered briefly in the economic growth textbook by Barro and Sala-iMartin (1998), which also discusses briefly the possible case for large-scale development assistance to overcome such traps. The connection of a low-level trap to subsistence consumption needs is spelled out in Ben-David (1998), and connections to agriculture and education are described in the World Economic and Social Survey 2000. Two recent empirical studies claiming that such poverty traps exist in very poor countries are UNCTAD (2002) and Bloom, Canning, and Sevilla (2003).

6. Adopted by the world's leaders in September 2000, the UN Millennium Declaration committed their nations to stronger global efforts to reduce poverty, improve health, and promote peace, human rights, and environmental sustainability. The MDGs that emerged from the declaration are specific, measurable targets, summarized by the following eight goals: eradicate extreme poverty and hunger; achieve universal primary education; promote gender equality and empower women; reduce child mortality; improve maternal health; combat HIV/AIDS, malaria, and other diseases; ensure environmental sustainability; and develop a global partnership for development. More information is available at www. unmillenniumproject.org and www.un.org/millenniumgoals. 
ing Africa achieve these goals, with more funding if necessary. ${ }^{7}$ However, the rich countries have not yet delivered on that promise.

We begin by outlining our theory of Africa's poverty trap. This is followed by a discussion of the structural conditions and history that have led the continent into such a trap. Following that, we identify how a big push in key investments could enable Africa to meet the MDGs, and how that, in turn, would help to extricate Africa from its current development trap. We then estimate the financial costs required to meet the MDGs, and we suggest how those costs could be allocated between domestic resources in Africa (both public and private) and increased ODA. Finally, we propose a new framework for donor-African relations to underpin a big push designed to meet the MDGs.

\section{The Theory of Africa's Poverty Trap}

Consider a standard neoclassical growth model in which output per capita $q$ is produced by a production function $A \mathrm{f}(k)$, where $A$ is total factor productivity and $k$ is the capital-labor ratio. For the moment we take $A$ to be constant. The national saving rate is $s$, and $d$ is the rate of capital depreciation, with $n$ denoting the rate of population growth. The rate of capital accumulation $\mathrm{d} k / \mathrm{d} t$ is given by

$$
\mathrm{d} k / \mathrm{d} t=s A \mathrm{f}(k)-(n+d) k .
$$

A change in the capital-labor ratio is called capital deepening. The term $(n+d) k$ is called capital widening and is equal to the amount of saving per capita that is needed to hold the capital-labor ratio constant in the face of population growth and depreciation. Equation 1 says that capital deepening equals saving per capita minus capital widening.

7. Perhaps the clearest commitment is in the 2002 Monterrey Consensus of the International Conference on Financing for Development, where in paragraph 42 all countries (including the United States, the European Union, and other donors) adopted the following position: "[W]e urge developed countries that have not done so to make concrete efforts towards the target of 0.7 per cent of gross national product (GNP) as ODA to developing countries and 0.15 to 0.20 per cent of GNP of developed countries to least developed countries ...” (pp. 9-10). ODA was 0.23 percent of the combined gross national income of donor countries (members of the OECD's Development Assistance Committee) in 2002, a shortfall of approximately $\$ 120$ billion a year on a combined donor GNP of around $\$ 25$ trillion. 
Figure 1. Standard Neoclassical Growth Model

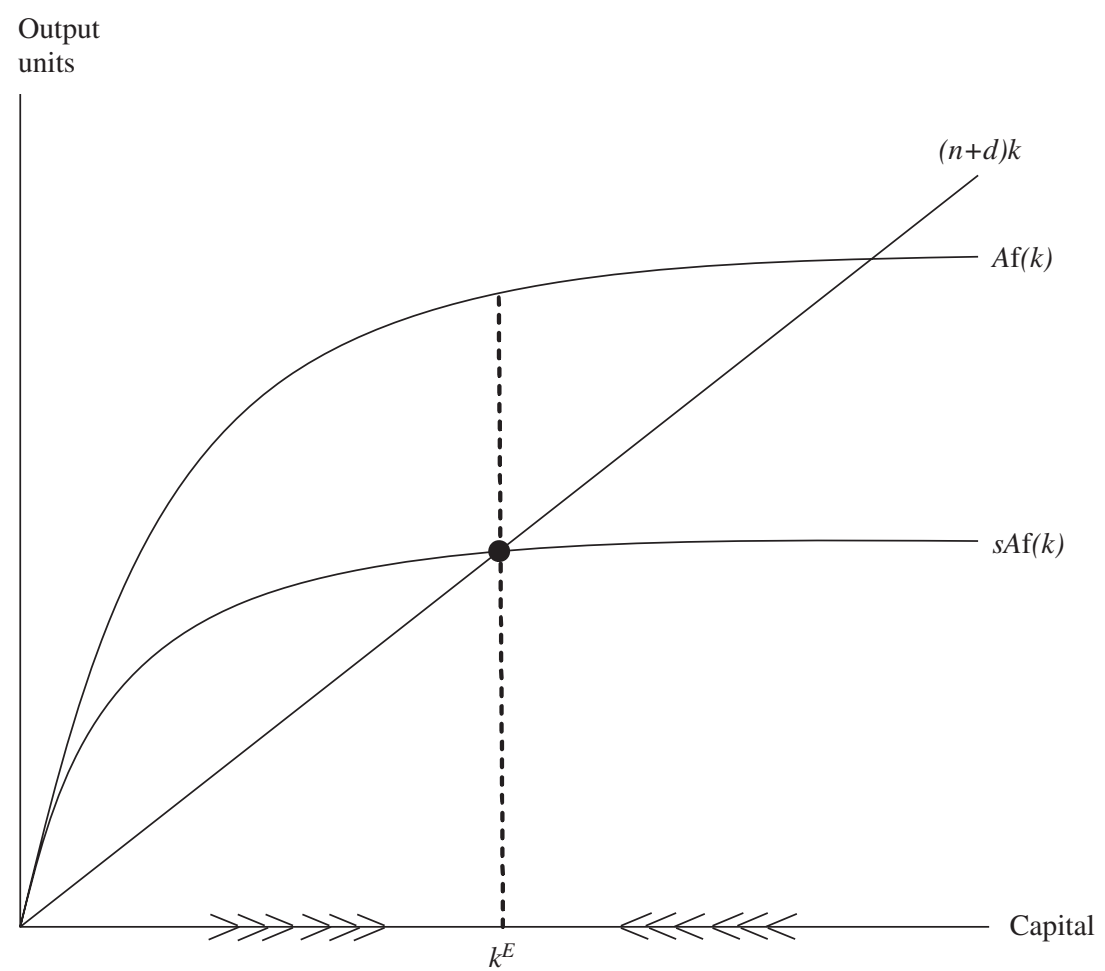

Source: Authors' model described in the text.

The economy grows in per capita terms as long as saving per capita exceeds capital widening. If saving is lower than capital widening, the economy experiences a decline in output per capita. The standard neoclassical model is typically presented as if the economy necessarily grows when $k$ is very low, in the famous diagram reproduced in figure 1 . In the figure, $s A \mathrm{f}(k)$ is assumed to be very steep at the origin and, in particular, steeper than the $(n+d) k$ ray from the origin. In that case, when $k$ is low, $\mathrm{d} k / \mathrm{d} t$ is positive, since it is equal to the vertical distance between the $s A \mathrm{f}(k)$ curve and the $(n+d) k$ ray. Indeed, starting at a very low capitallabor ratio, $k$ and $q$ rise asymptotically to a unique, positive steady-state equilibrium at $k^{E}$ and $q^{E}=A \mathrm{f}\left(k^{E}\right)$.

Actually, figure 1 is a special case, and a not very plausible one at that. When $k$ is very low, two other things tend to be true. First, the marginal 
productivity of capital also tends to be very low (instead of nearly infinite, as the standard theory assumes), because a minimum threshold of capital is needed before modern production processes can be started. Factory production requires, for example, a basic infrastructure of electricity, roads, and a functioning port, as well as a literate and numerate labor force. When these basic conditions are not present, small increments of $k$ may have little effect. However, once the basic infrastructure and human capital are in place, the marginal productivity of capital may indeed become very high in a low-income country. The capital threshold can be seen in figure 2: small increments of $k$ below a threshold $k^{T}$ might do little to raise production, and the $s A \mathrm{f}(k)$ curve might be very flat near the origin. It then becomes steep in a middle range before flattening out once again at high levels of $k$. In short, there is an early period of increasing returns to scale in capital before the more traditional constant or decreasing returns to scale set in.

\section{Figure 2. Growth Model with Minimum Capital Stock Threshold}

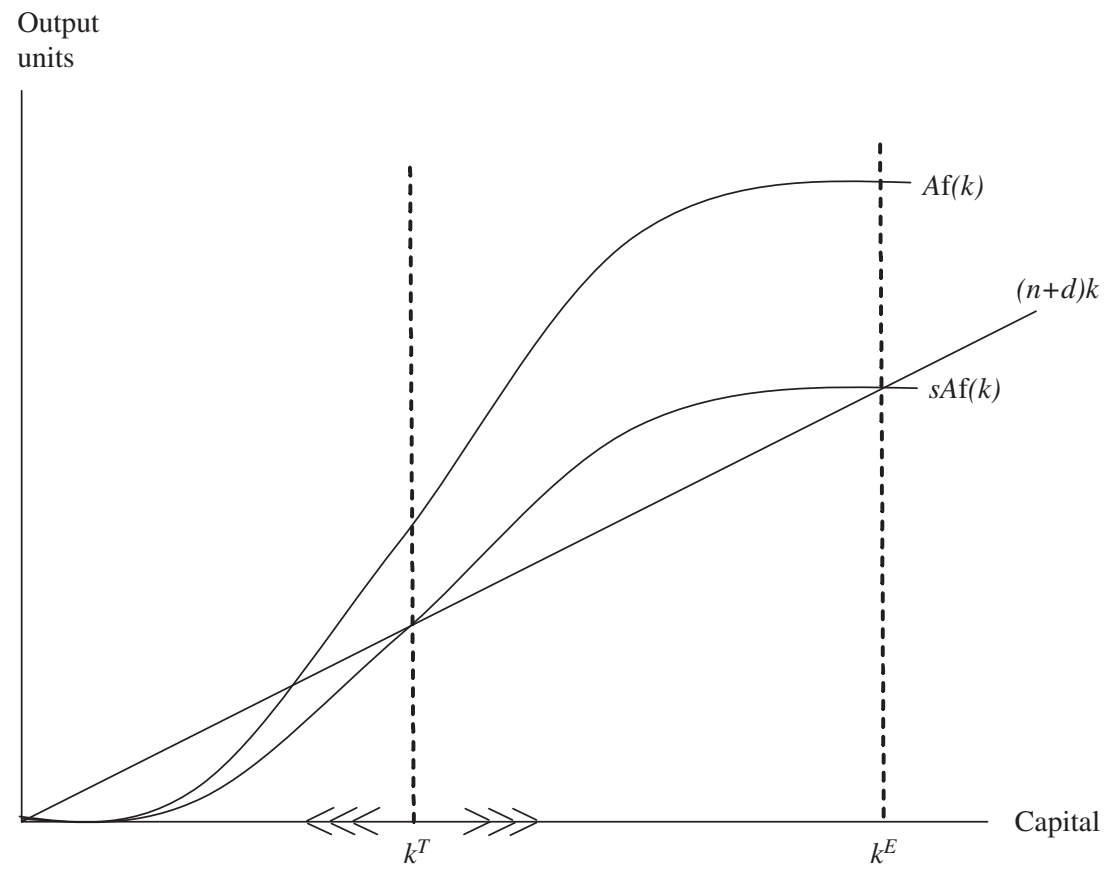


Figure 3. Saving Trap

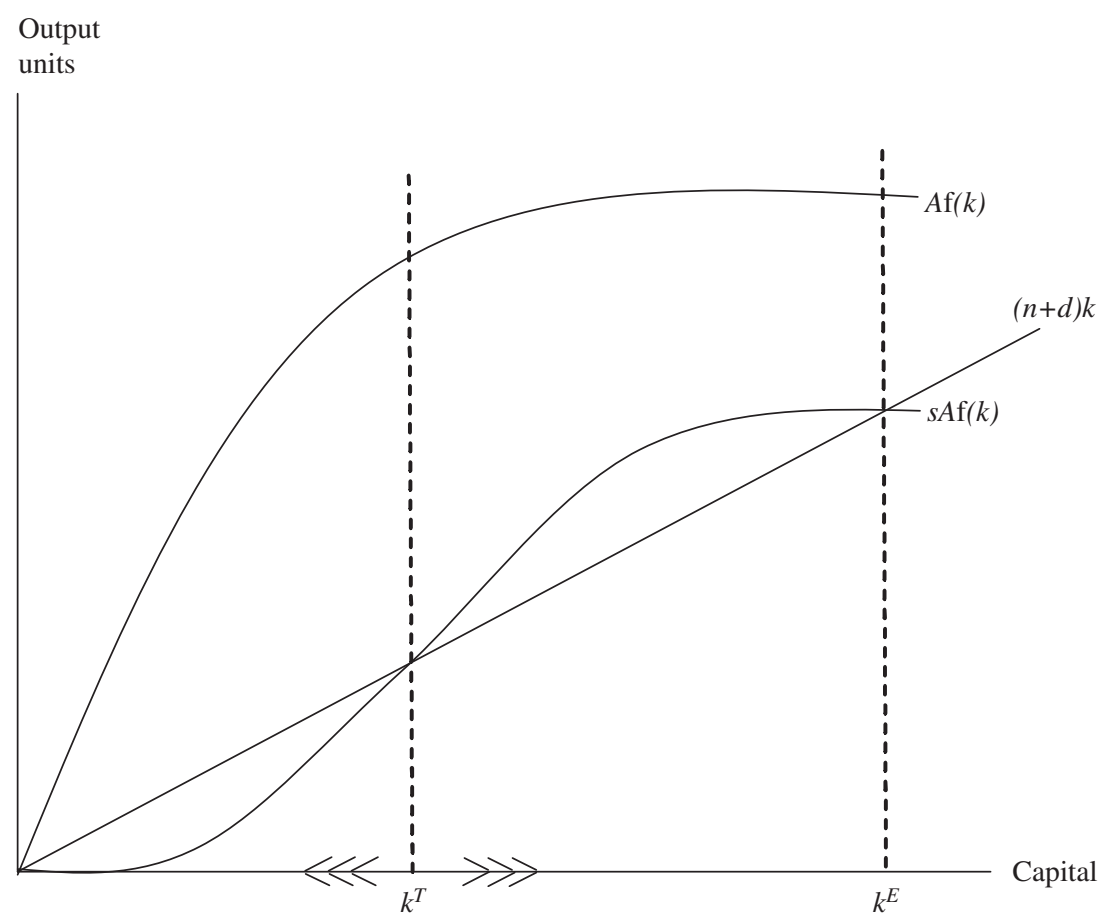

Source: Authors' model described in the text.

Second, the saving rate can become very low or even negative when $k$ is very low, because impoverished households do not save, but rather must use all (or more than all) of their current income in the struggle just to stay alive. Once basic needs are met, poor households may save quite a lot of income, but not before. The saving trap leads to a picture like figure 3 , in which $s A \mathrm{f}(k)$ is less steep than $(n+d) k$ when $k$ is very low, and then turns steeper in an intermediate range. Note that $s A \mathrm{f}(k)$ looks as it does in figure 2 even without assuming a threshold level of capital. The key implication of figures 2 and 3 is that $\mathrm{d} k / \mathrm{d} t$ is negative when $k<k^{T}$. When an economy begins with very low capital, both the capital-labor ratio and output per capita tend to decline over time. The very poor indeed get poorer, pushed into more extreme poverty by the lack of capital accu- 
mulation coupled with population growth. Only when an economy has a capital-labor ratio above a minimum threshold $k^{T}$ does it tend to achieve economic growth and converge to the steady-state $k^{E}$ and $q^{E}$.

To formalize these ideas using the simplest version of the neoclassical model, we can use the Harrod-Domar or AK model, in which $q=A k$. In this case, equation 1 becomes

$$
\mathrm{d} k / \mathrm{d} t=s A k-(n+d) k .
$$

The proportionate growth rate of the economy is given by

$$
\gamma=(l / q) \mathrm{d} q / \mathrm{d} t=s A-(n+d) .
$$

The economy grows if $s A>(n+d)$ and declines if $s A<(n+d)$. As is well known, the AK model does not have a steady-state equilibrium. The economy either grows or declines at a constant rate.

Let us now see how a poverty trap arises in the AK model, beginning with a capital threshold. Suppose that $A$ is low $\left(A^{L}\right)$ until a threshold level of infrastructure capital $k^{T}$ (the minimum capital needed for roads, ports, electric power, and human capital) is reached, and then becomes high $\left(A^{H}>A^{L}\right)$. If it is the case that $s A^{L}<n+d$ while $s A^{H}>n+d$, the economy can get stuck in a poverty trap. Specifically, if the capital stock starts below $k^{T}$, the economy shrinks at the rate $s A^{L}-(n+d)<0$, whereas if $k$ starts above $k^{T}$, the economy grows at the rate $s A^{H}-(n+d)>0$. The picture is similar to figure 2 , with a relatively flat $s A \mathrm{f}(k)$ curve near the origin, but with a vertical segment at $k=k^{T}$ as the economy transits from $A^{L}$ to $A^{H}$, and then a relatively steep segment for $k>k^{T}$.

Consider alternatively the case of the saving trap, in which the saving rate is very low or negative when $k$ is very low. As an illustration, suppose that households save a constant fraction $\sigma$ not of total income but of discretionary income, which we define as income after deducting the costs of meeting basic needs. Poor countries calculate basic needs according to an estimate of the minimum caloric intake necessary for a healthy and productive life, plus ancillary essential needs of clothing, shelter, cooking fuel, and a few other basic amenities. Let these minimum needs be represented by the poverty line $q^{P}=A k^{P}$. Discretionary income is then $q^{d}=q-$ $q^{P}$ if $q>q^{p}$ and $q^{d}=0$ otherwise. We assume that saving per capita $s q$ is equal to $\sigma q^{d}$. The saving function is therefore 


$$
\begin{aligned}
& s=0 \text { for } q<q^{P}\left(\text { or } k<k^{P}\right) \\
& s=\sigma\left(1-k^{P} / k\right) \text { for } q>q^{P}\left(\text { or } k>k^{P}\right) .
\end{aligned}
$$

This kind of saving function gives rise to a poverty trap. Specifically, in the AK model, the capital stock must be greater than or equal to $k^{T}=$ $\sigma A k^{P} /[\sigma A-(n+d)]$ to achieve positive economic growth. The growth rate is easily calculated to be as follows:

$$
\begin{aligned}
& \gamma=-(n+d), \text { for } k<k^{P} \\
& \gamma=\sigma A\left(1-k^{P} / k\right)-(n+d)<0, \text { for } k^{P}<k<k^{T} \\
& \gamma=\sigma A\left(1-k^{P} / k\right)-(n+d)>0, \text { for } k>k^{T} .
\end{aligned}
$$

There is a long theoretical tradition and strong empirical evidence to support the proposition that the saving rate is very low at low income levels and rises as income rises above the poverty threshold. Simon Kuznets remarked, in his classic study on Modern Economic Growth: Rate, Structure, and Spread, that "It is hardly surprising that with the much lower per capita product in the underdeveloped countries, their gross or net capital formation proportions - which represent gross or net national saving rates - are distinctly lower than those of industrial countries." Loayza, Klaus Schmidt-Hebbel, and Luís Servén find that, in developing countries, a doubling of private income raises the long-run private saving rate by 10 percentage points. ${ }^{9}$ Many other studies have shown that saving rates rise at low levels of income. ${ }^{10}$ In an interesting unpublished survey of rural Ugandan households, only 23.8 percent indicated that they had undertaken any saving, and "the most common reason given for not saving was low income (85.4 percent), although a number of non-saving respondents also referred to the poor access to financial institutions." 11

A third factor that can push an economy into a poverty trap is very rapid population growth at low levels of $k$. Very poor people do not save much, if anything, in the form of reproducible capital or even human cap-

8. Kuznets (1966, p. 427).

9. Loayza, Schmidt-Hebbel, and Servén (2000).

10. For example, Ogaki, Ostry, and Reinhart (1996).

11. Musinguzi and Smith (2000, p. 9). 
Figure 4. Demographic Trap

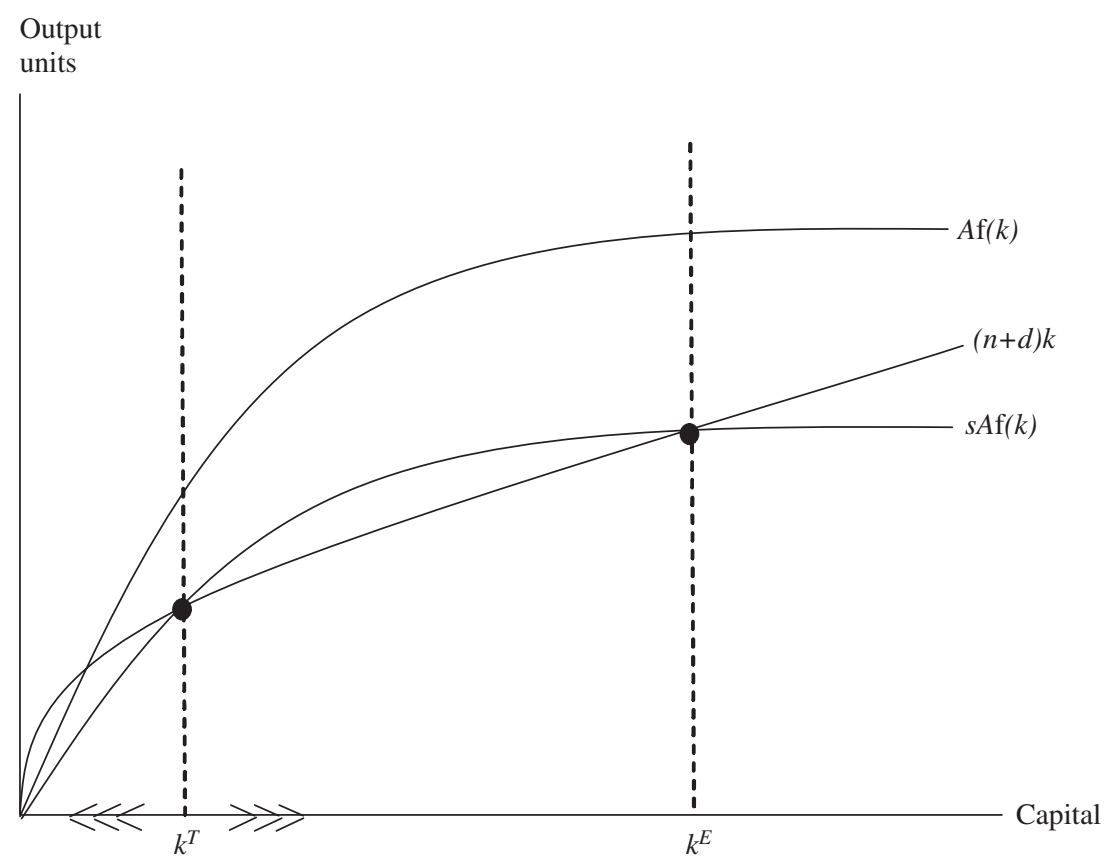

Source: Authors' model described in the text.

ital, but they do save in the form of progeny. Since $n$ is a function of $k$, it is quite possible that $s A<n+d$ when $k$ is low and $n$ is high, whereas $s A>$ $n+d$ when $k$ is high and hence $n$ is low. This is diagrammed in figure 4 . The highest fertility rates in the world are observed among the world's poorest people. This initially seems paradoxical, since the poorest people have the least chance to actually care for and invest in such large families. But ample research on fertility choices in low-income settings has explained this paradoxical situation very well. First, children are net economic assets from an early age in rural areas where most poor people live (or, in a less extreme version, they are a much smaller net cost than children in urban areas). They collect fuel wood and water and tend to the animals and other household chores. Second, the children of the poor are more likely than other children to die, and so risk-averse poor parents have large numbers of children to compensate, and indeed a much larger number than needed simply to break even in an actuarial sense. Third, parents 
view children as old-age security in the absence of a well-functioning and reliable private or public old-age financing scheme. Fourth, poor families lack access to contraceptives and family planning services, so there is considerable unmet desire to limit childbearing: about 17 percent of married women in developing countries would prefer to avoid a pregnancy but are not using any form of family planning. ${ }^{12}$

These three factors - capital thresholds, saving traps, and demographic traps-all interact. It is quite possible that no one of them would be sufficient by itself to cause a poverty trap, but that they do so in combination. For example, a country with substandard infrastructure may find itself with a low level of productivity $A^{L}$, which by itself would not create a trap, but does so when combined with the low saving rate and high population growth rate caused by the low productivity.

In any case, positive growth in income per capita is more likely if there is rapid technological change. When $A$ is rising, the growth equation (equation 3) becomes

$$
\gamma=s A-(n+d)+(1 / A)(\mathrm{d} A / \mathrm{d} t)
$$

We shall see, alas, that Africa suffers not only from low $A$, low $s$, and high $n$, but also from very slow growth in total factor productivity. The slow rise or stagnation of $A$ is mainly for structural rather than governance reasons, as we discuss later.

\section{Why Has Africa Suffered the Most Persistent Poverty Trap?}

The simple theory outlined above explains how a country or region can get stuck in a poverty trap. It does not explain, however, why sub-Saharan Africa has been the region most prone to getting stuck. We propose five structural reasons that have made sub-Saharan Africa the most vulnerable region in the world to a persistent poverty trap:

— very high transport costs and small market size

-low-productivity agriculture

— a very high disease burden

12. Ross and Winfrey (2002), who estimate the corresponding figure to be highest in sub-Saharan Africa, at 24 percent. 
—adverse geopolitics

— very slow diffusion of technology from abroad.

In combination, these produce the confluence of low $A$, low $s$, and high $n$ that characterizes Africa.

\section{High Transport Costs and Small Market Size}

To a remarkable extent, Africans live in the interior of the continent and face enormous transport costs in shipping goods between coastal ports and the places where they live and work. Moreover, the Sahara effectively cuts sub-Saharan Africa off from high-volume overland trade with its major high-income trading partner, Europe, and this fact increases the high costs of transport. Problems of isolation are compounded by small market size. Small developing countries with little access to global trade tend to grow more slowly than countries with large internal markets, or than countries that have easy access to trade (such as Singapore). ${ }^{13}$

There are several reasons why Africans tend to live away from the coast: the soils are often better and rainfall is more plentiful in the interior highland regions; the burden of malaria is intrinsically lower there; and centuries of slave trade made it dangerous for Africans to live near the coast. This problem would not be so severe if the rivers from the interior to the coast of Africa were navigable by oceangoing vessels, but they are not. Economists are gradually returning to the wisdom of Adam Smith, who recognized, in The Wealth of Nations, the long-standing low levels of development in Africa and the fundamental role of transport costs in impeding prosperity in the region:

There are in Africa none of those great inlets, such as the Baltic and Adriatic seas in Europe, the Mediterranean and Euxine [Black] seas in both Europe and Asia, and the gulphs of Arabia, Persia, India, Bengal, and Siam, in Asia, to carry maritime commerce into the interior parts of that great continent; and the great rivers of Africa are at too great a distance from one another to give occasion to any considerable inland navigation. ${ }^{14}$

Recent evidence underscores the extremely high transport costs in subSaharan Africa and their severe impact on trade. Figure 5 compares the much higher transport costs in sub-Saharan Africa relative to those in

13. Sachs (forthcoming).

14. Smith (1776/1976, Book I, Chapter iii, para. 8). 
Figure 5. Transport Costs in Typical Sub-Saharan African and Asian Countries

Dollars per ton per kilometer

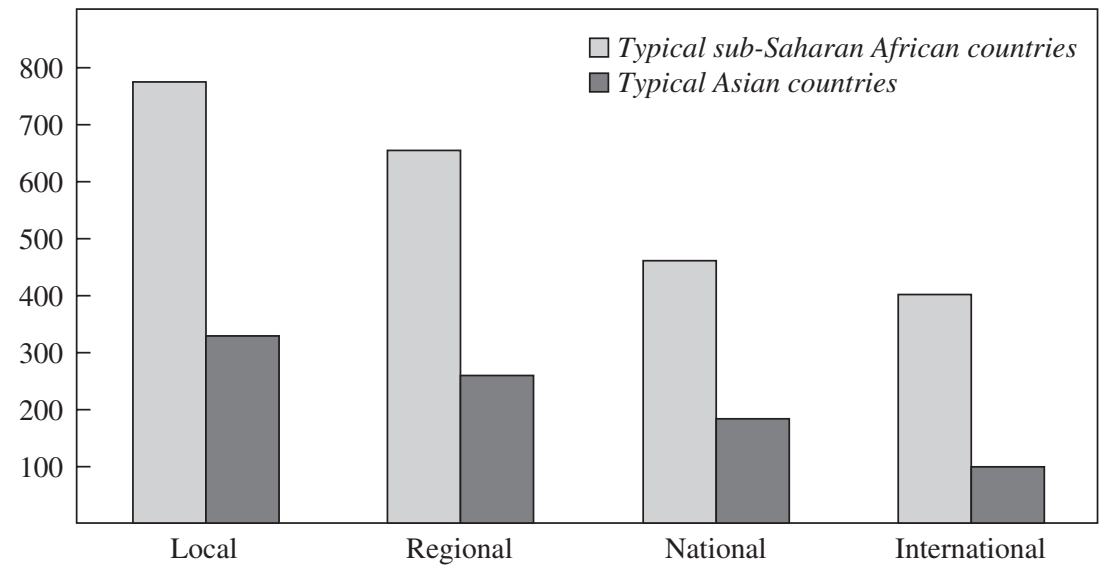

Source: Starkey and others (2002).

Asia; Nuno Limao and Anthony J. Venables estimate that halving transport costs could increase the volume of transport by a factor of five. ${ }^{15}$ Before high-intensity modern trade can get started, Africa needs an extensive road system both from the coast to the interior and within the interior, where the highest population concentrations are found. These roads, however, are very expensive to build and maintain.

In terms of our simple model with $A^{L}$ and $A^{H}$, we can say that Africa could have the same $A^{H}$ as other regions, but it must invest in very costly transport infrastructure to be on a par with other developing regions that have lower transport costs. These transport costs therefore cause Africa to be stuck with $A^{L}$, which in turn contributes to the low-level poverty trap.

\section{Low-Productivity Agriculture}

Africa gets no break on food productivity. Most Africans live in the subhumid or arid tropics, with few rivers to provide irrigation and a lack of the

15. Limao and Venables (1999). Other relevant evidence includes that provided by Rizet and Hine (1993), who found that long-distance freight tariffs in francophone West Africa were over five times higher than comparable tariffs in India, Pakistan, and Vietnam between 1986 and 1988. More recently, Hine and Ellis (2001) have found that long-distance freight rates in Tanzania are three times higher than in Indonesia. 
large alluvial plains typical of much of South and East Asia that permit cheap irrigation. As a result, Africa has the lowest share of irrigated cropland of any major region of the developing world. ${ }^{16}$ Moreover, rainfall in much of the continent is erratic, vulnerable to high seasonal and year-toyear fluctuations, and the land is subject to high rates of evapotranspiration, due also to high temperatures. Indeed, of all major regions, Africa loses the largest share of its precipitation to evapotranspiration. ${ }^{17}$ In addition, rainfall in the Sahel (the semiarid region just south of the Sahara) has been persistently low during the past thirty years, in a phenomenon that may be linked to long-term climate change and to rising sea-surface temperatures in the Indian Ocean. High transport costs also mean that African farmers can afford little fertilizer, since by the time they cover the cost of bringing fertilizer to their farms and farm output to market, fertilizers are no longer cost effective. Consequently, farmers are farming on soils increasingly depleted of nutrients, and without modern methods of water management, in increasingly densely populated communities that are therefore too impoverished to finance roads and water infrastructure that could dramatically raise farm yields. Finally, as discussed below, the new seed varieties that sparked the Green Revolution in Asia and Latin America are poorly suited to African farming conditions.

\section{Very High Disease Burden}

Africa carries a disease burden that is unique in the world in its severity. In recent years the most prominent disease in the region has been HIV/ AIDS. Tropical sub-Saharan Africa's HIV prevalence in 2001 was 7.3 percent; in every other world region it is below 1 percent. Africa is also home to numerous endemic tropical diseases, especially vector-borne diseases. Among these, malaria is by far the most consequential. Of the 1 million to 3 million malaria-related deaths every year, it is estimated that 90 percent occur in sub-Saharan Africa, the great majority of them among children. ${ }^{18}$ Many casual observers mistakenly assume that because the United States and Europe once were burdened by malaria and got rid of it, Africa's ongoing malaria crisis is a symptom of its poverty and weak institutions rather than a deep cause. In other words, many ask how malaria could have

16. World Bank (2003a).

17. Global Environmental Monitoring and Research Center (1995).

18. World Health Organization and United Nations Children's Fund (2003). 
played any more of a causal and intractable role in Africa's development than it did in the southern United States, southern Europe, and other regions that have since eliminated the disease. The answer lies in the disease's ecology.

Africa's malaria is much less tractable than that in other regions for a combination of climatic and biological reasons. The continent's temperatures, mosquito species, and humidity give Africa the world's highest malaria burden, as captured in the malaria ecology index developed by Anthony Kiszewski, Jeffrey Sachs, and others; this index is a measure of the strength of malarial transmission based solely on ecological factors. ${ }^{19}$ Unlike in other parts of the world, Africa's malaria mosquitoes are almost exclusively human-biters, and this fact enhances the chain of human-to-human transmission. Africa is also the only major world region where the most malignant human malaria species, Plasmodium falciparum, predominates..$^{20}$ The combination of high year-round temperatures, adequate precipitation for mosquito breeding, and human-biting anopheles mosquitoes has made Africa the global epicenter of malaria from time immemorial. The genetic code of African populations provides evidence: the sickle-cell hemoglobin allele, which partially protects individuals against malaria when inherited heterozygously, is extraordinarily prevalent in Africa compared with other regions of the world. ${ }^{21}$

Malaria contributes to a classic poverty trap. With enough investment, even Africa's high malaria morbidity and mortality could be controlled, although not eliminated, with current technologies. But that would require substantially more money than Africa can afford. Thus Africa is too poor to control malaria, and meanwhile malaria reduces productivity, frustrates foreign investment, and (by contributing to very high child mortality rates) delays or stops the demographic transition, thereby helping to keep Africa poor.

To highlight Africa's unique challenges in terms of high transport costs, low agricultural productivity, and high disease burden, table 4 presents difference-of-means tests for a series of geographic variables and results of simple regressions with agricultural productivity, infrastructure,

19. Kiszewski and others (2004).

20. World Health Organization (1992).

21. The Hardy-Weinberg equation can be used to link the high prevalence of the hemoglobin $\mathrm{S}$ allele and the historically high death rates from malaria in Africa. 
Sachs, McArthur, Schmidt-Traub, Kruk, Bahadur, Faye, and McCord 135

Table 4. Selected Geographic and Health Indicators for

Tropical Sub-Saharan Africa

Percent except where stated otherwise

\begin{tabular}{|c|c|c|c|}
\hline Indicator & $\begin{array}{c}\text { Tropical } \\
\text { sub-Saharan } \\
\text { Africa }^{\mathrm{a}}\end{array}$ & $\begin{array}{c}\text { Rest of } \\
\text { developing } \\
\text { world average }\end{array}$ & $\begin{array}{c}\text { Level of } \\
\text { statistical } \\
\text { significance }^{\mathrm{c}}\end{array}$ \\
\hline \multicolumn{4}{|l|}{ Population distribution } \\
\hline $\begin{array}{l}\text { Share of population } \\
\text { within } 100 \text { kilometers of coast }\end{array}$ & 24.9 & 66.3 & 1 percent \\
\hline $\begin{array}{l}\text { Share of population in } \\
\text { tropical ecozones }\end{array}$ & 62.0 & 34.9 & 1 percent \\
\hline $\begin{array}{l}\text { Share of population in subhumid and } \\
\text { arid ecozones }\end{array}$ & 81.9 & 38.7 & 1 percent \\
\hline $\begin{array}{l}\text { Share of population living at low } \\
\text { density }^{\mathrm{d}}\end{array}$ & 45.2 & 26.5 & 1 percent \\
\hline \multicolumn{4}{|l|}{ Agriculture } \\
\hline $\begin{array}{l}\text { Irrigated land as share of total } \\
\text { agricultural land }\end{array}$ & 0.5 & 10.6 & 1 percent \\
\hline Cereal yield (kilograms per hectare) & $1,102.0$ & $2,364.6$ & 1 percent \\
\hline $\begin{array}{l}\text { Fertilizer consumption (100 grams per } \\
\text { hectare of arable land) }\end{array}$ & 95.0 & $1,606.2$ & 1 percent \\
\hline \multicolumn{4}{|l|}{ Infrastructure } \\
\hline $\begin{array}{l}\text { Paved roads (kilometers per } 1,000 \\
\text { population) }\end{array}$ & $<0.1$ & 4.2 & $\begin{array}{l}\text { Not } \\
\text { significant }\end{array}$ \\
\hline $\begin{array}{l}\text { Traditional fuel use as } \\
\text { share of total energy use }\end{array}$ & 76.3 & 29.2 & 1 percent \\
\hline \multicolumn{4}{|l|}{ Health } \\
\hline Index of malaria ecology $\mathrm{f}^{\mathrm{f}}$ & 13.0 & 2.5 & 1 percent \\
\hline $\begin{array}{l}\text { Infant mortality rate } \\
\quad \text { (deaths per } 1,000 \text { live births) }\end{array}$ & 107.6 & 43.7 & 5 percent \\
\hline $\begin{array}{l}\text { Under-five mortality rate } \\
\text { (deaths per } 1,000 \text { live births) }\end{array}$ & 176.9 & 58.1 & 1 percent \\
\hline Total fertility rate (number of children) ${ }^{\mathrm{g}}$ & 5.4 & 3.4 & 5 percent \\
\hline
\end{tabular}

Sources: World Bank (2003a); Center for International Earth Science Information Network, Columbia University (2002); Kiszewski and others (2004); and authors' regressions.

a. Thirty-three countries listed in table 2 . Data are averages not weighted by population.

b. Former republics of the Soviet Union are excluded. Data are averages not weighted by population.

c. For the population distribution variables, statistical significance of the difference in the two averages; for other variables, statistical significance of the dummy variable in the following regression:

\footnotetext{
dependent variable $=a+b_{1}(\log$ of 2001 GDP per capita at PPP $)+b_{2}$ (dummy variable for tropical sub-Saharan Africa)
}

A tobit regression is used when the dependent variable is a percentage; otherwise ordinary least squares is used, with the dependent variable expressed as a natural logarithm.

d. Percent of the population living in areas with density below 50 persons per square kilometer.

e. Estimated consumption of fuel wood, charcoal, bagasse (sugar cane waste), and animal and vegetable wastes.

f. From Kiszewski and others (2004). Index measures the stability of malaria transmission based on ecological factors and the biological properties of the anopheline (mosquito) species of that region. The variable is measured at a highly disaggregated level and averaged to the country level using population weighting.

g. Number of children that a woman would have borne if she survived her childbearing years and bore children in accordance with age-specific fertility rates. 
and health measures as dependent variables. The geographic variables show a statistically significant difference of means between sub-Saharan Africa and the rest of the developing world, and the agriculture, infrastructure, and health variables are significantly worse in Africa even after controlling for income per capita.

\section{Adverse Geopolitics}

On top of the structural challenges already mentioned, Africa suffered brutally at the hands of European powers for almost five centuries, and the record with Arab powers was little better. A massive slave trade helped undermine the formation of nation-states and may have depopulated Africa's coastal regions. In the nineteenth century the slave trade was replaced by direct colonial rule and a century of exploitation by European imperial powers. At the end of the colonial period, most of Africa was left with tragically little infrastructure and education, far less than in postcolonial Asia. ${ }^{22}$ In contrast to much of Asia, Africa's borders were drawn up without regard to ethnic and political units, with little infrastructure connecting them. In addition, differences in colonial languages and customs further fragmented many parts of Africa, particularly in West Africa. Independence, ironically, was followed by the continued manipulation of African countries as proxies in the cold war and continued depredations by rich countries in exploiting Africa's natural resources. No doubt many African leaders played into these abuses and exacerbated them through corrupt and authoritarian rule, but if it is true that these leaders hanged themselves and their fellow citizens, the rich countries often provided the rope.

22. It is worth quoting at length an excellent paper by Torero and Chowdhury (2004, p. 4): "Unlike Asia and Latin America, Africa inherited a highly dispersed and unevenly distributed infrastructure from its colonial past. There was little, if any, improvement of infrastructure during the colonial era, and, according to [Baland and] Platteau (1996), 'in some important respects, it can even be said that colonial policy reinforced the handicaps of

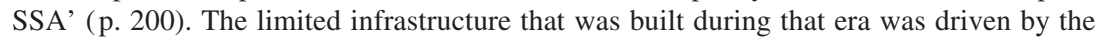
objective of connecting natural resources to export markets. For example, Platteau noted that 'two-thirds of the African railways built in the colonial period connected mines to a coastal harbor' ( p. 200). The rest of the continent was virtually ignored and, according to Boserup (1981), 'only the Union of South Africa with mass immigration of Europeans had more than six meters of railways per square kilometer in 1970 and six countries had no railways at all' (p. 148)." 
Even when the major powers were not exploiting Africa, they were rarely helping it, or at least not very much. Africa is not a strategic focus of either the United States or Europe, in contradistinction, for example, to the United States' relationships with East Asia, the Middle East, or Latin America, and Western Europe's relationships with Eastern Europe, the Middle East, and North Africa. Sub-Saharan Africa is too far away and too negligible a market to elicit a priority concern. The result is that whereas Europe, Asia, Latin America, and the Middle East have all, at times, been the object of U.S. financial largesse, Africa has not. Africa has also ranked as a low priority in both trade and debt negotiations. Following the 1982 developing country debt crisis, Latin American countries received debt cancellation well before Africa did, and trade discrimination against Africa has persisted for decades despite repeated promises to remove limits on Africa's access to U.S. and European markets. Even new initiatives to expand access to the U.S. market, such as the African Growth and Opportunity Act, remain heavily constrained by rules-of-origin and other limits to African exports.

\section{Slow Diffusion of Technology from Abroad}

Africa has been the world's great laggard in technological advance, notably in the areas of agriculture and health. For instance, most of the developing world experienced a Green Revolution-a surge in crop yields in the 1970s through the 1990s as a result of scientific breeding that produced high-yield varieties (HYVs), combined with increased use of fertilizers and irrigation. Africa's uptake of HYVs was the lowest in the developing world. The reasons are very clear. The Green Revolution HYVs were designed for the conditions of Latin America and Asia and did not easily transfer to the agronomic and economic conditions of Africa's rainfed, fertilizer-scarce, subhumid and arid tropics. Whereas HYV research focused mainly on wheat, maize, and paddy rice, Africa produces maize but little wheat and paddy rice. It depends much more on sorghum, millet, and tubers (cassava, coco yams, and sweet potatoes). As discussed above, high transport costs and the combination of unfavorable geohydrology and topography hindered increases in the use of fertilizers and irrigation. The absence of a Green Revolution in Africa had clear implications for food productivity, as shown in table 5. Sub-Saharan Africa has by far the lowest cereal yield per hectare of any major region and has 


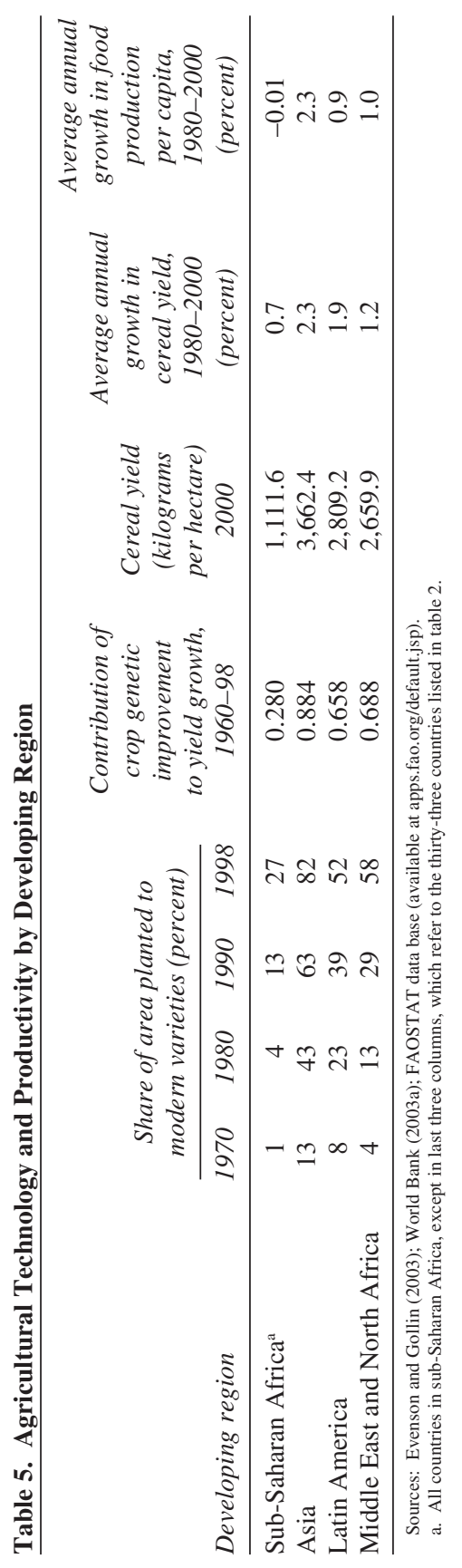


experienced the slowest gain in yields during the last two decades. Indeed, it is the only major region to have recorded a (slight) decline in food production per capita during 1980-2000.

In highlighting these points, we are certainly not arguing for any geographical determinism. Indeed, the whole point of the paper is the opposite: Africa's structural impediments can be overcome, if they are compensated by an intensive investment program that directly confronts the continent's high transport costs, low agricultural productivity, heavy disease burden, colonial legacy of poor educational attainment, and the like. We are arguing, however, that Africa's structural problems help to account for its current trap. Each of the factors mentioned has made it much harder for Africa to lift itself up by its bootstraps. Rural and inland Africa, plagued by disease, huge transport costs, and low agricultural yields, was unable to generate enough of an economic surplus above survival levels that could be invested sufficiently to overcome these conditions. Poor governance no doubt complicated the task-many natural resource rents were squandered - but the poor governance itself was as much symptom as cause. ${ }^{23}$ To break out of the poverty trap, Africa needs help, and it has not yet gotten it in the form and to the extent that is necessary.

The delay in getting this help, moreover, has greatly complicated the task that lies ahead. Because the world has waited so long to help Africa break free of its structural constraints, the situation is vastly more complicated today than even a generation ago. First, there is AIDS, a pandemic unrivaled in ferocity in modern history, which the rich countries have allowed to run almost unabated in Africa since its recognition twentythree years ago. Second, the massive population growth in rural areas has led to a sharp fall in the size of the average household farm. In turn, the increased population pressure has not led to agricultural intensification as Ester Boserup predicted, ${ }^{24}$ but has caused massive environmental degra-

23. Even in clear cases of squandered wealth, such as Nigeria with its oil earnings, the extent of the loss is often exaggerated. Nigeria is not, contrary to popular view, a rich country that squandered vast wealth. Rather, it is a poor country that squandered a modest inheritance. A simple calculation explains why. Nigeria produces around 2 million barrels of oil a day, at a price of roughly $\$ 25$ per barrel in recent years, or $\$ 50$ million a day. Perhaps 60 percent of this, or $\$ 30$ million a day, stays with Nigeria after production sharing with foreign companies and covering the costs of extraction. Given that there are approximately 130 million Nigerians, oil revenue would be around 23 cents per Nigerian per day, or around $\$ 84$ a year. Nigeria, in short, is not oil rich on a per capita basis.

24. Boserup (1965). 
Table 6. Decomposition of Growth by Region, 1980-90 and 1990-2000

\begin{tabular}{|c|c|c|c|c|}
\hline \multirow[b]{2}{*}{ Region and period } & \multirow{2}{*}{$\begin{array}{l}\text { Growth in output } \\
\text { per worker } \\
\text { (percent a year) }\end{array}$} & \multicolumn{3}{|c|}{$\begin{array}{l}\text { Contribution to growth in output } \\
\text { per worker (percentage points) }\end{array}$} \\
\hline & & $\begin{array}{l}\text { Physical capital } \\
\text { per worker }\end{array}$ & $\begin{array}{l}\text { Education } \\
\text { per worker }\end{array}$ & $\begin{array}{l}\text { Total factor } \\
\text { productivity }\end{array}$ \\
\hline \multicolumn{5}{|l|}{ Africa $^{\mathrm{a}}$} \\
\hline $1980-90$ & -1.1 & -0.1 & 0.4 & -1.4 \\
\hline 1990-2000 & -0.2 & -0.1 & 0.4 & -0.5 \\
\hline \multicolumn{5}{|l|}{ Latin America } \\
\hline 1980-90 & -1.8 & 0.0 & 0.5 & -2.3 \\
\hline 1990-2000 & 0.9 & 0.2 & 0.3 & 0.4 \\
\hline \multicolumn{5}{|l|}{ Middle East } \\
\hline 1980-90 & 1.1 & 0.6 & 0.5 & 0.1 \\
\hline 1990-2000 & 0.8 & 0.3 & 0.5 & 0.0 \\
\hline \multicolumn{5}{|l|}{ East Asia } \\
\hline 1980-90 & 4.4 & 2.4 & 0.6 & 1.3 \\
\hline 1990-2000 & 3.4 & 2.3 & 0.5 & 0.5 \\
\hline \multicolumn{5}{|l|}{ China } \\
\hline 1980-90 & 6.8 & 2.1 & 0.4 & 4.2 \\
\hline 1990-2000 & 8.8 & 3.2 & 0.3 & 5.1 \\
\hline \multicolumn{5}{|l|}{ Industrial countries } \\
\hline $1980-90$ & 1.8 & 0.7 & 0.2 & 0.9 \\
\hline 1990-2000 & 1.5 & 0.8 & 0.2 & 0.5 \\
\hline
\end{tabular}

Source: Bosworth and Collins (2003).

a. Nineteen African countries with populations above 1 million for which data were available.

dation instead. In Boserup's theory, higher population density should have led to intensive cultivation, with large investments in fertilizers, water management, seed breeding, and the like. Instead soil nutrients have been depleted, with hardly any replacement by chemical fertilizers or nitrogenfixing plants, and forests have been cut down, yet food production remains at subsistence levels, with almost no modern inputs.

\section{Some Growth Accounting}

Africa's poverty trap is evident empirically through simple growth accounting. We look at this in two ways. The first is the standard Solow decomposition of growth, as recently implemented on a cross-country basis by Barry Bosworth and Susan Collins. ${ }^{25}$ The second is the AK

25. Bosworth and Collins (2003). 
Table 7. Economic Growth Predicted from National Saving, Population Growth, and Capital Consumption, by Developing Region, 1980-2001

Percent $^{\mathrm{a}}$

\begin{tabular}{|c|c|c|c|c|c|}
\hline \multirow[b]{2}{*}{ Region } & \multirow{2}{*}{$\begin{array}{c}\text { Gross } \\
\text { national } \\
\text { saving as } \\
\text { share of } \\
\text { gross } \\
\text { national } \\
\text { income }^{\mathrm{a}}\end{array}$} & \multirow{2}{*}{$\begin{array}{l}\text { Growth in } \\
\text { population }^{\mathrm{a}}\end{array}$} & \multirow[t]{2}{*}{$\begin{array}{l}\text { Consumption } \\
\text { of fixed } \\
\text { capital as } \\
\text { share of } \\
\text { gross } \\
\text { national } \\
\text { income }^{\text {a }}\end{array}$} & \multicolumn{2}{|c|}{$\begin{array}{c}\text { Annual } \\
\text { growth in output } \\
\text { per capita }\end{array}$} \\
\hline & & & & Predicted & Actual \\
\hline $\begin{array}{l}\text { Tropical sub-Saharan } \\
\text { Africa }^{\text {b }}\end{array}$ & 11.1 & 2.7 & 9.9 & -2.3 & -0.4 \\
\hline South Asia & 20.0 & 2.0 & 8.7 & 1.8 & 3.3 \\
\hline Latin America & 18.7 & 1.8 & 9.8 & 1.2 & 0.4 \\
\hline $\begin{array}{l}\text { East Asia and } \\
\text { Pacific }\end{array}$ & 35.1 & 1.3 & 9.6 & 7.2 & 6.4 \\
\hline $\begin{array}{l}\text { Middle East and } \\
\text { North Africa }\end{array}$ & 23.5 & 2.4 & 9.2 & 2.3 & 1.0 \\
\hline
\end{tabular}

model approach, which assumes a fixed incremental capital-labor ratio and which does not require us to construct a capital stock. Both methods give the same result: Africa has not been saving enough to keep up with the requirements of capital widening. The Bosworth-Collins decomposition is shown in table 6 . We see that Africa is the only region to have experienced two consecutive decades of declining output per worker. According to Bosworth and Collins, Africa's shortfall is the result of both a declining capital-worker ratio and an outright decline in total factor productivity (which could reflect, for example, the effects of environmental degradation, not measured in the capital stock, on crop yields). ${ }^{26}$

The implementation of the AK model for the period 1980-2001 is shown in table 7 . There we assume that $A=1 / 3$, or an incremental capitaloutput ratio of 3 , which is a typical estimate in the development literature. ${ }^{27}$ According to the AK model, and ignoring growth in total factor productivity, we should expect the growth rate to equal $s A-(n+d)$. With

26. Bosworth and Collins (2003).

27. Note that $A$ is the ratio of $Y$ to $K$, so that $1 / A$ is the ratio of $K$ to $Y$. Kuznets (1966), for example, assumes $K / Y=3$ in his discussion of saving, investment, and growth. The unweighted average value of $K / Y$ in the Bosworth-Collins data for African countries in 2000 is around 2.5 . 
Figure 6. Growth in Gross National Income by Developing Region, Actual and Predicted, 1980-2001

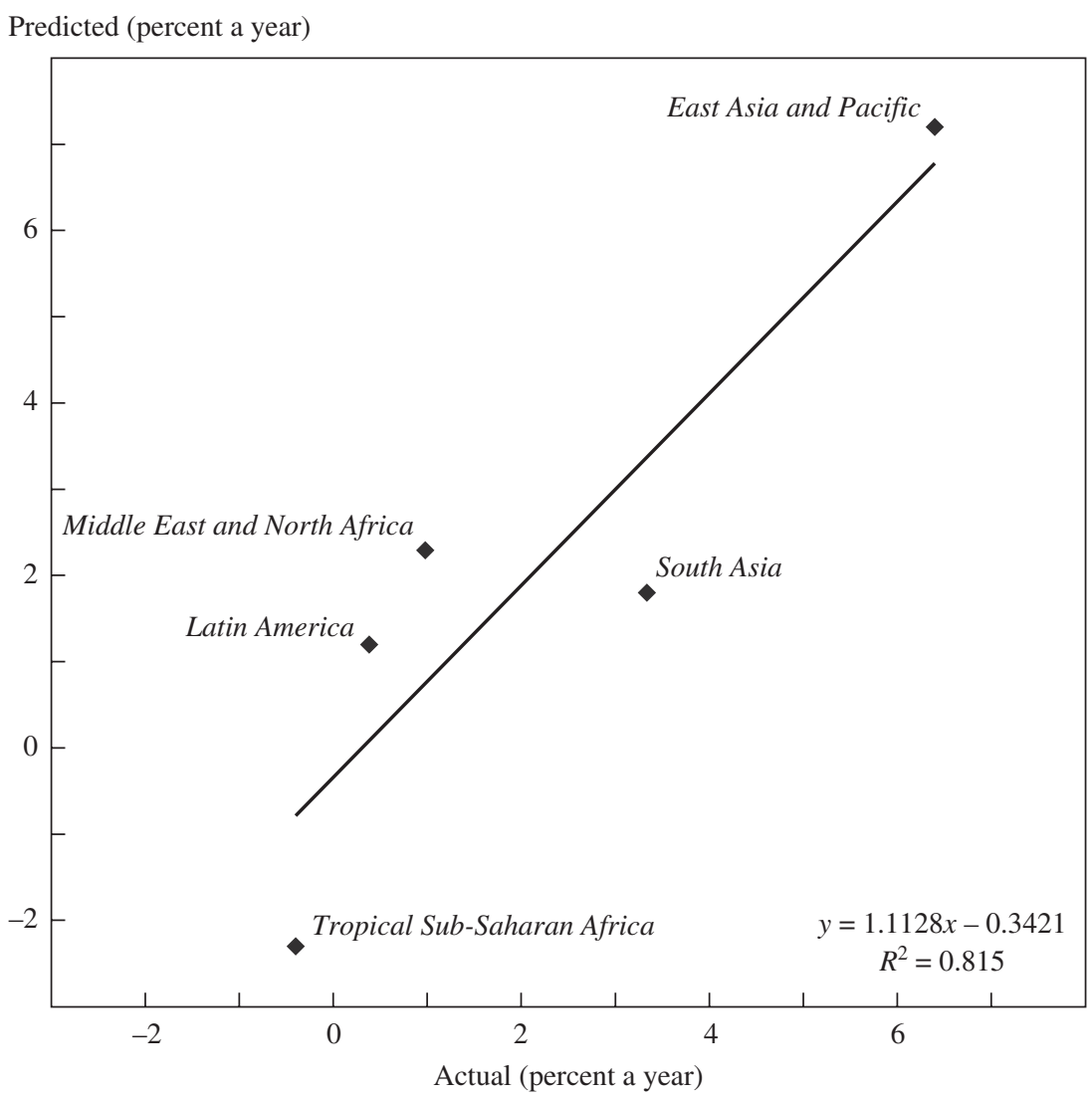

Source: World Bank (2003a) and authors' calculations using model described in the text.

$A=1 / 3, s$ equal to the national saving rate, $n$ equal to the population growth rate, and $d$ equal to capital consumption as a percentage of GNP divided by 3 (to give an estimate of capital consumption as a share of the capital stock), we see that Africa is indeed predicted by the simple AK model to have a negative growth rate. The combination of Africa's low domestic saving rate and high population growth rate is just as we expected. In fact, the AK model does remarkably well in accounting for the variation across the five regions in growth in income per capita, as shown by figure 6 . 
The situation is even worse than it looks, however, because the national income accounts data almost surely, and substantially, overestimate Africa's true saving rate. To a significant extent, Africa is living off of its natural capital but counting the resource depletion as income. Africa has been cutting down its rainforests to make room for new farmland and to provide fuel wood and timber, but the deforestation is not counted as a loss of natural capital. Farmers have been depleting the soils of nutrients by growing crops without fertilizers, but the loss of soil nutrients is not counted as a loss of capital. Countries depleting their mineral reserves (for example, Zambia's copper) are counted as earning income rather than converting one form of capital, mineral deposits, to another, financial assets. Sooner or later these forms of resource depletion will have to come to an end, and African real consumption will fall, perhaps significantly. Put differently, Africa's productive capital stock per person is falling even faster than was suspected once we take into account, even imperfectly, the decline of a number of forms of natural capital.

There is no readily accepted practical methodology for correcting measured national saving rates for resource depletion effects. We therefore use the World Bank's valiant, but very preliminary, attempt, adding in one calculation of our own. ${ }^{28}$ In the World Bank's corrected saving measures, the saving rate taken from the national accounts is augmented by expenditure on education (which is counted as consumption in the national accounts but should be counted as investment in human capital), and then reduced according to estimates of the economic costs of deforestation, energy depletion, and mineral depletion. This corrected saving rate is shown in the right-hand column of table 8 . We then make one more correction for tropical sub-Saharan Africa, by measuring the estimated annual loss to Africa's soil of three macronutrients-nitrogen, phosphorus, and potassium-which are currently being depleted with each harvest. Sooner rather than later, this loss of soil nutrients will have to be made up by the addition of nutrients through chemical or biological means. If we assume that the soil nutrients are replaced through inputs of chemical fertilizers purchased at market value in Africa, the annual cost of replacing the soil nutrients is around 2 percent of Africa's gross national income (GNI). We accordingly lower the measured saving rate by that amount. In sum, whereas Africa's measured national saving rate is

28. Hamilton and Clemens (1999). 
Table 8. Gross National Saving Rates by Developing Region, 1980-2001

Percent of gross national income

\begin{tabular}{lcc}
\hline Region & Unadjusted & $\begin{array}{c}\text { Adjusted for human } \\
\text { capital investment and } \\
\text { resource depletion }^{\mathrm{a}}\end{array}$ \\
\hline Tropical sub-Saharan Africa $^{\mathrm{b}}$ & 11.1 & $3.0(1.0)^{\mathrm{c}}$ \\
South Asia & 20.0 & 18.7 \\
Latin America & 18.7 & 15.7 \\
East Asia and the Pacific & 35.1 & 29.3 \\
Middle East and North Africa & 23.5 & 9.1 \\
\hline
\end{tabular}

Sources: World Bank (2003a) and authors' calculations using data from Henao and Baanante (1999) and African Agricultural Market Information Network data base, accessed at www.afamin.net/regionalenglish/reg_mis_en.asp on March 8, 2004.

a. Gross national saving plus education expenditure, minus energy, mineral, and net forest depletion.

b. Thirty-three-country sample listed in table 2 . Averages are weighted by population.

c. When soil nutrient depletion is calculated with the 1999 sub-Saharan Africa nutrient balance midpoint of 60-100 kilograms of nutrients (nitrogen, phosphorus, potassium) per hectare, the result is the first figure shown. When nutrient depletion indicators and fertilizer prices are used to calculate soil depletion (around 2 percent of GDP), adjusted gross saving is reduced to 1.5 percent of gross national income, and adjusted net saving is the figure in parentheses.

around 11.1 percent of GNI, the actual saving rate net of resource depletion might be only around 1.0 percent of GNI. Whatever the precise number, the conclusion is that Africa is failing to maintain its capital-labor ratio.

\section{A Big Push to End Africa's Poverty Trap}

If Africa is caught below $k^{T}$, and therefore is stuck in chronic low or negative growth, the main policy implication is to raise $k$ above $k^{T}$, which in turn would unleash self-sustaining growth by raising $A$ and $s$ and lowering $n$. We propose to increase the capital stock in one step, as it were, through a large, well-targeted infusion of foreign assistance. In other words, we are arguing not for endless flows of increased aid, and not for aid as simple charity, but rather for increased aid as an exit strategy from the poverty trap. For those who fear that aid increases dependency, our response is that aid that is ambitious enough would actually end Africa's dependency. Moreover, we see no other likely successful strategy for ending Africa's poverty trap.

In the short run we think of aid as augmenting national saving by a flow of external saving, so that the growth equation becomes $(s+a) A-$ $(n+d)$, where $a$ is official development assistance as a share of national income of the recipient economy. In our proposal this flow of aid is targeted to a particular set of priority investments, and specifically public 
sector investments, so that the aid cannot be used for consumption. The recipient country would commit to use the aid not to replace but rather to augment existing spending in the targeted areas. We believe that, with some care in designing the donor-recipient process, such a commitment can be enforceable through improved monitoring of budget processes and expenditures, perhaps with the help of local nongovernmental organizations. The results of debt relief under the Heavily Indebted Poor Countries initiative, in which the fiscal resources made available by reduced debt servicing were similarly targeted at predetermined areas of public spending (especially social spending), have been highly encouraging. In fact, the fear that increased aid would simply allow the recipient country to decrease its own efforts is not a major concern in our view, because the rates of domestic public investment in the targeted areas are already so low that there is in fact little to substitute for. Of course, a reasonable level of governance in the recipient country is a necessary precondition for this process to work.

If aid is to end the poverty trap, it must be large enough and maintained long enough to raise $k$ above $k^{T}$. Small or short-lived flows of aid will accomplish little, since they, too, will be overwhelmed by rapid population growth, so that $(s+a) A-(n+d)$ will remain negative. This basic point is important and widely misunderstood. It is often said that past aid to Africa has little to show for it. In fact, there has been too little aid to make a difference. Moreover, the aid has been very poorly targeted mainly toward the donors' foreign policy clients (such as President Mobuto Sese Seko of Zaire) rather than development purposes.

To use a simple analogy, consider a large forest fire with a tendency to spread. Suppose that only one fireman is initially sent to fight the blaze, and he is overwhelmed. The critics might then say, "Why should we send more firemen? We've already seen that they are ineffective!" In dealing with the control of any epidemic process, a proper scale of intervention is needed. Similarly, aid has to be large enough to ensure that $(s+a) A$ is in fact raised above $n+d$. The effectiveness of aid has been demonstrated in several well-governed African countries. For example, Mozambique has effectively used comparatively generous aid receipts of roughly $\$ 50$ per capita to finance infrastructure investments, the provision of social services, and the demobilization of the armed forces. ${ }^{29}$ In Tanzania progress 
in improving human and physical capital stalled after donors reduced their high aid disbursements during the 1980s and early 1990s. ${ }^{30}$

Any aid strategy must confront many complexities, especially regarding the conditions under which aid is provided. Unconstrained aid flows would probably be consumed rather than invested. The strategy needs to be designed to ensure that the aid is properly invested, and there must be a credible mechanism for enforcing the strategy over a relatively long period. We first take up the design of the investment program and then, in the final section of the paper, consider the recipient-donor enforcement mechanisms.

Our specific recommendation is to use the Millennium Development Goals for 2015 as the intermediate targets for the investment program. In other words, we argue that aid flows should be designed to enable otherwise well-governed African countries to meet the MDGs. There are both pragmatic and substantive reasons for this choice. The pragmatic reason is that the world has already promised to do just this. The MDGs are the only international goals that can motivate a complicated international machinery of intergovernmental cooperation and resource transfers. But there are deeper reasons as well. The MDGs in fact constitute a very reasonable balance of concerns and are the product of a decade or more of international debate and deliberation on economic development. They reflect the fact, for example, that the escape from poverty requires investments in both human capital and physical capital, and that poverty itself is multidimensional, involving not only income but also lack of food security, health, education, gender equality, environmental management, and access to basic amenities. The MDGs are also flexible enough to support a well-constructed growth strategy. For example, they call for halving the rate of income poverty by 2015 , but they do not specify exactly how this is to be done. That leaves open the possibility for sound analysis of the underlying growth dynamics and allows investment targets to be introduced in several areas (such as family planning, energy systems, and rural roads) that the MDGs do not explicitly mention, but that are nonetheless key inputs to a sound public investment strategy to end the poverty trap.

One final preliminary thought is important. The MDGs are an intermediate target, not a final goal. After all, even if met, they will still leave in place an enormous amount of extreme poverty. Indeed, it is quite likely that, whatever is achieved in terms of the MDGs, many African coun-

30. Foster and Keith (2003). 
tries will continue to require large-scale aid flows for another decade or more beyond 2015, since they will not have reached the threshold for selfsustaining growth. We are not arguing that the MDGs are sufficient for escaping poverty. We are arguing that they are a sensible, internationally agreed way station on the road to eliminating extreme poverty and ending Africa's poverty trap.

\section{Designing a Strategy to Meet the MDGs}

Ending the poverty trap in Africa and meeting the MDGs will require a comprehensive strategy for public investment in conjunction with improved governance. This section lays out such an investment strategy focusing on specific interventions - defined broadly as the provision of goods, services, and infrastructure-which we have grouped into seven areas in appendix A. A detailed background paper of the UN Millennium Project offers more information on both the general strategy and the various sets of interventions. ${ }^{31}$

Most of the interventions are expected to have effects on several goals. For example, improved education leads to many benefits, including reductions in income poverty, hunger, and child mortality. Conversely, meeting each goal (poverty, hunger, education, health, and the others) requires multiple interventions. This point is stressed in appendix B, which summarizes how each goal is affected by multiple sets of interventions. The combination of appendixes A and B approximates an "MDG production function," describing the set of inputs needed to achieve the desired set of outputs. Of course, this is a purely qualitative depiction at this stage; we provide a quantification of the inputs in the later analysis.

In designing the recommended package, we have given careful consideration to the issue of gender equity, that is, to an improved economic and social status for Africa's women. To a great extent, women are the farmers, caregivers, and child raisers of Africa. They perform an incredible amount of physical labor every day merely to keep their households alive. Fetching fuel wood and water, caring for the farm animals, plowing the fields, and caring for the sick and dying in the AIDS pandemic are all backbreaking tasks disproportionately borne by Africa's women. Many

31. UN Millennium Project (2004). 
Table 9. Poverty, Agricultural Employment, and Urbanization in Tropical Sub-Saharan Africa

Percent

\begin{tabular}{|c|c|c|c|c|c|c|}
\hline \multirow[b]{2}{*}{ Country } & \multicolumn{3}{|c|}{ Poverty rate $^{\mathrm{a}}$} & \multirow{2}{*}{$\begin{array}{c}\text { Share of } \\
\text { poor } \\
\text { living } \\
\text { in rural } \\
\text { areas }^{\mathrm{a}, \mathrm{b}}\end{array}$} & \multirow{2}{*}{$\begin{array}{l}\text { Share of } \\
\text { total } \\
\text { employ- } \\
\text { ment in } \\
\text { agriculture, } \\
1990\end{array}$} & \multirow{2}{*}{$\begin{array}{c}\text { Share of } \\
\text { population } \\
\text { in urban } \\
\text { areas } \\
1990\end{array}$} \\
\hline & National & Rural & Urban & & & \\
\hline Angola & n.a. & n.a. & n.a. & n.a. & 74.5 & 33.5 \\
\hline Benin & 33.0 & n.a. & n.a. & n.a. & 63.5 & 41.5 \\
\hline Burkina Faso & 45.3 & 51.0 & 16.5 & 94.3 & 92.4 & 16.2 \\
\hline Burundi & 36.2 & n.a. & n.a. & n.a. & n.a. & 8.6 \\
\hline Cameroon & n.a. & n.a. & n.a. & n.a. & 69.7 & 48.0 \\
\hline $\begin{array}{l}\text { Central } \\
\quad \text { African Rep. }\end{array}$ & n.a. & n.a. & n.a. & n.a. & 80.2 & 40.8 \\
\hline Chad & 64.0 & 67.0 & 63.0 & 80.1 & 83.2 & 23.5 \\
\hline $\begin{array}{l}\text { Congo, Dem. } \\
\text { Rep. of }\end{array}$ & n.a. & n.a. & n.a. & n.a. & 67.8 & n.a. \\
\hline Congo, Rep. of & n.a. & n.a. & n.a. & n.a. & 48.7 & 64.5 \\
\hline Côte d'Ivoire & 36.8 & n.a. & n.a. & n.a. & 60.0 & 43.2 \\
\hline Eritrea & 53.0 & n.a. & n.a. & n.a. & 80.5 & 18.4 \\
\hline Ethiopia & 44.2 & 45.0 & 37.0 & 86.3 & n.a. & 15.2 \\
\hline Ghana & 31.4 & 34.3 & 26.7 & 70.1 & n.a. & 35.8 \\
\hline Guinea & 40.0 & n.a. & n.a. & n.a. & 87.2 & 27.1 \\
\hline Kenya & 42.0 & 46.4 & 29.3 & 74.8 & 19.1 & 32.3 \\
\hline Liberia & n.a. & n.a. & n.a. & n.a. & 72.3 & 44.3 \\
\hline Madagascar & 71.3 & 76.7 & 52.1 & 76.5 & 78.2 & 28.8 \\
\hline Malawi & 65.3 & 66.5 & 54.9 & 87.2 & n.a. & 14.4 \\
\hline Mali & n.a. & n.a. & n.a. & n.a. & 85.8 & 29.5 \\
\hline Mauritania & 46.3 & 61.2 & 25.4 & 57.7 & 55.2 & 56.3 \\
\hline Mozambique & 69.4 & 71.3 & 62.0 & 71.1 & 82.7 & 30.8 \\
\hline Niger & 63.0 & 66.0 & 52.0 & 83.7 & 7.8 & 20.1 \\
\hline Nigeria & 34.1 & 36.4 & 30.4 & 60.7 & n.a. & 43.1 \\
\hline Rwanda & 51.2 & n.a. & n.a. & n.a. & 91.7 & 6.1 \\
\hline Senegal & 33.4 & 40.4 & n.a. & 64.6 & 76.7 & 46.7 \\
\hline Sierra Leone & n.a. & n.a. & n.a. & n.a. & 67.4 & 35.9 \\
\hline Somalia & n.a. & n.a. & n.a. & n.a. & 75.3 & 27.1 \\
\hline Sudan & n.a. & n.a. & n.a. & n.a. & 69.5 & 35.1 \\
\hline Tanzania & 41.6 & 49.7 & 24.4 & 82.3 & n.a. & 31.1 \\
\hline Togo & n.a. & n.a. & n.a. & n.a. & 65.5 & 32.8 \\
\hline Uganda & 55.0 & n.a. & n.a. & n.a. & n.a. & 13.8 \\
\hline Zambia & 72.9 & 83.1 & 56.0 & 68.9 & 74.7 & 39.5 \\
\hline Zimbabwe & 34.9 & 48.0 & 7.9 & 90.0 & 24.3 & 34.6 \\
\hline $\begin{array}{l}\text { All tropical } \\
\text { sub-Saharan } \\
\text { Africa }\end{array}$ & 48.4 & 56.2 & 38.4 & 76.6 & 67.5 & 31.8 \\
\hline
\end{tabular}

Source: World Bank (2003a) and authors' calculations.

a. Data are for the most recent year between 1990 and 2001 for which data are available.

b. Calculated as rural poverty rate $\times(100-$ urbanization rate $) /$ national poverty rate. 
of the recommended investments, such as improved access to water supply, modern cooking fuels, enhanced transport services, and improved soil nutrients, will have a special benefit for women.

The first area of interventions focuses on raising rural productivity, because three-quarters of Africa's poor live in rural areas, and an overwhelming percentage are employed in agriculture, as shown in table 9. In particular, the investments in farm productivity will increase rural incomes and reduce chronic hunger, which in Africa is predominantly caused by insufficient agricultural productivity. Additional interventions for roads, power, improved cooking fuels and stoves, and water and sanitation will provide a basis for higher productive efficiency.

The second area addresses Africa's extraordinary disease burden, widespread micronutrient deficiencies, and extremely high fertility rates by focusing on health, nutrition, and family planning. This package of interventions includes the medical interventions needed to improve child and maternal health; prevent the transmission of and provide treatment for HIV/AIDS, tuberculosis, and malaria; improve nutrition; and provide family planning services. We include an entire package of family planning and reproductive health services, aimed at enabling a significant reduction in Africa's very high total fertility rates. We believe that access to family planning, contraceptive services, girls' education, women's empowerment, and off-farm employment opportunities for young women can lead to a dramatic reduction in the total fertility rate in just a few years.

The third area of interventions aims for universal completion of primary education. In designing this package of interventions, particular attention needs to be paid to increasing girls' completion rates through additional demand-side interventions such as incentive payments to poor households to encourage them to keep their daughters in school. We also argue that secondary school enrollment needs to be increased, because the returns to education now and especially in the future will increasingly depend on secondary education. Moreover, large numbers of secondary school graduates will be required to help deliver the other MDG intervention packages; for example, secondary school graduates will be needed as community health workers and agricultural extension workers. Targeted adult literacy programs that are designed to raise educational attainment among the adult population will complete the investments in human capital.

The fourth area of interventions addresses challenges specific to urban areas. Throughout sub-Saharan Africa the large cities have not yet gener- 
ated internationally competitive manufacturing or service-based industries. In conjunction with abject rural poverty, which fuels rural-urban migration, the lack of urban jobs has led to extremely high levels of urban poverty, which are rising across much of the continent. An MDG-based urban strategy focuses on urban infrastructure and services (electricity, transport, water and sanitation, waste disposal, and so forth) and slum upgrading. Successful urban development and the creation of viable export industries across Africa are contingent on improving access to rich countries' markets, particularly for apparel and light manufacturing, and the flexibility to use targeted industrial policies as needed.

The fifth area of interventions focuses on the mobilization of science and technology. Currently, tropical sub-Saharan Africa produces roughly twenty times fewer patents per capita than the average for the rest of the developing world, and the region has only 18 scientists and engineers per million population, compared with 69 in South Asia, 76 in the Middle East, 273 in Latin America, and 903 in East Asia. We stress the need for increased investment in science advising, higher education, and research and development targeted at Africa's specific ecological challenges in food production, disease, nutrition, construction, energy, and other areas.

The sixth area focuses specifically on interventions for achieving gender equity that are not included as part of the other intervention areas. This includes ensuring full reproductive health rights and access to services, as well as the guarantee of equal property rights and access to work, backed up by affirmative action to increase political representation. Of particular concern in many parts of sub-Saharan Africa are persistently high levels of violence against women and girls; this violence needs to be confronted with legislative and administrative changes.

The seventh area of interventions focuses on regional integration as a sine qua non for economic growth. The fifteen of the forty-nine countries in sub-Saharan Africa that are landlocked have little chance to develop unless they have ready access to the coast with efficient, low-cost infrastructure. Moreover, from a global perspective, the African countries taken individually are very small markets. Regional integration will raise the interest of potential foreign investors by increasing the scope of the market that accompanies an operating presence in Africa. Regional integration is also important in achieving scale economies in infrastructure networks, such as power grids, large-scale electricity generation, road transport, rails, and 
telecommunications, and in eliciting increased $R \& D$ on problems that are specific to Africa's ecology but that extend beyond any single country, such as public health, energy systems, and agronomy.

As an overarching matter affecting each of these seven categories of interventions, we note that Africa will require large numbers of teachers, nurses, doctors, agricultural extension officers, infrastructure specialists, scientists, and so forth-experts who are in very short supply across the continent. Hence each of the seven investment areas relies on a substantial scaling up of specialized human resources. In addition to expanding formal higher education, therefore, African countries need to focus on vocational training and short-term training courses. Already several countries have demonstrated that community health workers or agricultural extension officers who have undergone one-year training courses can produce substantial improvements in the communities where they work. For example, Ethiopia is currently training several thousand community health workers who will be able to carry out malaria control, offer simple treatment, and help improve households' hygiene. If extended to other areas, this "barefoot doctor" approach could rapidly improve rural life at moderate cost. An additional advantage from the countries' perspective is that these vocationally trained experts are less likely to migrate abroad than their more highly trained colleagues.

\section{Specific Interventions to Achieve the MDGs}

A full discussion of these proposed interventions is far beyond the scope of this paper but is available from the UN Millennium Project. ${ }^{32}$ For purposes of illustration we describe here only two categories of interventions: investments in rural productivity and in reducing child mortality. Our aim is to show that specific investments exist that could make enormous changes in productivity at rather low cost.

INCREASING RURAL PRODUCTIVITY. As already mentioned, sub-Saharan Africa is the world's only major region where food output per capita has been stagnant since $1980 .{ }^{33}$ Reversing this trend lies at the heart of any strategy to achieve the MDGs in Africa. One key factor in this stagnation is the declining availability of arable land per capita, which has shrunk

32. UN Millennium Project (2004).

33. World Bank (2003a). 
Table 10. Land under Cultivation in Selected Sub-Saharan African Countries, 1960-99a

Hectares per capita

\begin{tabular}{lcccc}
\hline Country & $1960-69$ & $1970-79$ & $1980-89$ & $1990-99$ \\
\hline Ethiopia & 0.508 & 0.450 & 0.363 & 0.252 \\
Kenya & 0.459 & 0.350 & 0.280 & 0.229 \\
Mozambique & 0.389 & 0.367 & 0.298 & 0.249 \\
Rwanda & 0.215 & 0.211 & 0.197 & 0.161 \\
Zambia & 1.367 & 1.073 & 0.896 & 0.779 \\
Zimbabwe & 0.726 & 0.664 & 0.583 & 0.525 \\
\hline
\end{tabular}

Source: Jayne and others (2001).

a. Data are period averages.

dramatically from 0.38 to 0.25 hectare over the past twenty years, ${ }^{34}$ mainly because of population growth. Table 10 shows the tremendous decreases in land under crop cultivation relative to population in agriculture in several African countries since $1960 .^{35}$

Overcoming the fall in average farm size and availability per capita of arable land requires increased food productivity coupled with a reduction in the growth rate of the rural population. In general, five sets of constraints must be addressed to increase African food productivity. First, soil fertility in Africa is low and has been declining. This is due to several factors: lack of available soil nutrients (such as nitrogen, phosphorus, sulfur, magnesium, and zinc), insufficient soil organic matter, poor physical structure of the soil, poor water-holding capacity, high risk of erosion, limited rooting depth, and lack of biodiversity. ${ }^{36}$ Second, smallholder farmers in Africa lack access to improved seeds that are suited to their soils. Third, limited water availability and increasingly variable precipitation patterns pose major challenges for smallholder water management and irrigation. ${ }^{37}$ Fourth, knowledge concerning new technologies that can increase crop yields is extremely limited. Fifth, women typically conduct the majority of African farm work, but they frequently have limited access to farm prop-

34. Centro Internacional de Agricultura Tropical, Tropical Soil Biology and Fertility, and International Center for Research in Agroforestry (2002).

35. Jayne and others (2001).

36. Donovan and Casey (1998).

37. According to data from the Food and Agriculture Organisation (FAO), sub-Saharan Africa includes eleven of the sixteen nations of the world that receive less than 1,000 cubic meters of water per hectare-a situation described as "absolute water scarcity" (FAO, 1995a). 
erty rights, face barriers to generating and controlling their own incomes, and have limited access to improved agricultural technologies.

These constraints on raising rural productivity can be overcome through a series of well-targeted interventions. Soil nutrient deficiencies can be addressed through chemical fertilizers that help to increase crop yields and through agroforestry techniques that use nitrogen-fixing trees. ${ }^{38}$ One approach is to interplant such trees in young maize fields and allow them to grow as fallows during dry seasons, accumulating 100 to 200 kilograms of nitrogen per hectare in six months to two years. In the subhumid regions of eastern and southern Africa, this technology can double or more the yields of maize, a staple crop. ${ }^{39}$ It can be supplemented with investments in improved seeds adapted to African farming environments. Suitable seeds can raise yields, reduce the time to harvest, improve germination, reduce labor requirements, reduce vulnerability to diseases, and improve cooking, processing, and storage qualities.

To improve crop irrigation in the arid and subhumid regions where most Africans live, it is generally acknowledged that small-scale and technically simple water management systems are most appropriate because of their low cost and ease of operation and maintenance. Options include water harvesting through the use of embankments, check dams and small impoundment dams, shallow wells, drip irrigation, and treadle or diesel pumps. Experience in Burkina Faso, Kenya, and Sudan shows that rain harvested from one hectare for supplementary irrigation of another can triple or even quadruple production. ${ }^{40}$

These physical interventions need to be augmented by agricultural extension services that provide farmers with technical support and training. ${ }^{41}$ Although debate continues over the most appropriate model for extension services, there is consensus on the need for increased human resources and research programs, and particularly on the need to improve the technical qualifications of extension workers. ${ }^{42}$

38. Such trees include leguminous trees of the genera Sesbania, Tephrosia, Crotalaria, and Glyricidia.

39. Sanchez (2002).

40. FAO (1996).

41. Birkhaeuser, Evenson, and Feder (1991).

42. Sasakawa Africa Association (2000). The Green Revolution relied mainly on the training and visitation $(\mathrm{T} \& \mathrm{~V})$ model, whereby extension served as a transmission belt between research centers and farmers through cadres of field-based, professional trainers. However, this model had its limitations, including poor linkages of the research undertaken 
A central theme throughout the rural productivity strategy is the need for special attention to the critical role that women play in African agriculture. Africa's women contribute 60 to 80 percent of the labor used to produce food both for household consumption and for sale, yet they face enormous cultural and legal inequities. ${ }^{43}$ Special interventions are needed to reach them through extension services and to provide them with access to technologies and skills that they can use to reduce the time spent in the field and increase production. Christopher Udry, John Hoddinott, and Lawrence Haddad show that merely allocating factors of production evenly across plots controlled by women and men could increase plot output by 10 to 15 percent. ${ }^{44}$

Interventions outside the formal agricultural sector are also crucial for farm productivity. Not surprisingly, education is important. The International Food Policy Research Institute (IFPRI) estimates, for example, that an extra year of primary education provided to women farmers in Kenya would increase maize yields by 24 percent. ${ }^{45}$ Transport infrastructure and services are also critical, since well-maintained feeder, district, and national roads are crucial in order to bring products to markets and to lower the costs of agricultural inputs, such as fertilizer and improved seeds. In one indication of the severity of rural farmer isolation, John Hine and John Rutter estimate that, for 51 percent of villages in Ghana and 60 percent of villages in Malawi, the walking distance to the nearest pickup point for motorized transport services was more than 2 kilometers; it was over 10 kilometers for 10 percent of Ghanaian villages and 19 percent of Malawian villages. ${ }^{46}$ D. S. Spencer calculates that, for tropical Africa to reach a road density (measured in kilometers of roads per square kilometer of land) equivalent to that of India at the

with the needs of small farmers, inability to adapt to local conditions, and inadequate practical knowledge on the part of the trainers; all of these shortcomings were compounded by budgetary constraints and lack of long-term fiscal support. Increasingly, hybrid solutions have been proposed that combine the best of the T\&V model with principles of demanddriven and farmer-led knowledge creation and management systems. However, basic principles of increased investment in hiring and training extension workers (especially women workers to reach women farmers), close links to research, and continual and timely training remain critical.

43. FAO (1995b).

44. Udry, Hoddinott, and Haddad (1995).

45. IFPRI (2000).

46. Hine and Rutter (2000). 
onset of the Green Revolution in 1950, the length of the road network would have to be increased by a factor of six. ${ }^{47}$

Often forgotten in the rural productivity equation are modern energy services, and in particular safe thermal energy for cooking as well as electricity for illumination, water pumps, and refrigeration. In addition to providing health benefits through reduced indoor air pollution, improved cooking stoves and fuels help to preserve biomass and dung for use as fertilizer. Subsidized access to safe fuel sources such as liquid petroleum gas also allows women to spend less time collecting biomass fuel and cooking and more time tending to farm production and opportunities to generate private income.

REDUCING CHILD MORTALITY. Table 1 showed how child mortality rates in Africa are by far the worst in the world; a total of 4 million African children under five die each year. Remarkably, five conditions account for approximately 95 percent of these fatalities: one quarter result from neonatal disorders (infections, birth asphyxia and injuries, and complications of prematurity) that occur in the first twenty-eight days of life; 22 percent from malaria; 21 percent from pneumonia; 20 percent from diarrheal diseases; and 8 percent from HIV/AIDS. ${ }^{48}$ Although these estimates are imprecise because of the difficulty of attributing cause of death and the dubious quality of the underlying data, the basic message is that controlling a limited number of preventable and treatable conditions could bring about a dramatic reduction in child mortality.

Underlying these proximate causes of death are contributing factors that render children susceptible. Malnutrition, for example, is a contributing factor in at least half of all child deaths, ${ }^{49}$ because malnourished children cannot resist common infections as readily as adequately nourished children and, when infected, have a much higher risk of complications and death. Even mildly underweight children are estimated to have a twofold higher risk of death than those that are adequately nourished. ${ }^{50}$ Meanwhile, poor indoor air quality and lack of access to drinking water and sanitation predispose children to pneumonia and diarrhea.

Because the causes of child death are both direct and indirect, interventions focused on saving children's lives need to both treat children

47. Spencer (1994).

48. Black, Morris, and Bryce (2003).

49. Black, Morris, and Bryce (2003).

50. Black, Morris, and Bryce (2003). 
who are sick and prevent children from becoming sick. Treatment interventions typically fall within the realm of the formal health sector, but preventive interventions necessarily span other sectors as well. Prominent among health sector interventions to improve child health outcomes is an integrated neonatal package that includes clean delivery, newborn resuscitation, prevention of hypothermia, antibiotics for infection, tetanus toxoid, breastfeeding education, and community hygiene education. ${ }^{51}$ Such a package may reduce neonatal mortality by up to 60 percent..$^{52}$ Immunizations are another simple intervention with well-documented benefits in the early stages of life: vaccinations against major diseases such as polio, diphtheria, pertussis, tetanus, measles, hepatitis B, and yellow fever have all been shown to reduce child mortality. Immunizing all children against measles alone could save 2.3 million children in Africa within the current decade..$^{53}$

For children beyond infancy, a broad set of interventions has been established under the UNICEF-WHO protocol known as the Integrated Management of Childhood Illness (IMCI). This includes a series of preventive and curative interventions that enable health workers to treat symptoms that could have multiple underlying causes. Specific IMCI interventions include insecticide-treated nets (ITNs) to prevent malaria; complementary feeding ${ }^{54}$ vaccinations; micronutrient supplementation; case management of acute respiratory infections, diarrhea, measles, malaria, and malnutrition; treatment with iron; and antihelminthic treatment. ${ }^{55}$ This protocol has been applied successfully in dozens of developing countries. For example, early results from Tanzania show a significantly reduced hospital admission rate for children in IMCI districts. ${ }^{56}$

Interventions to prevent and treat malaria are part of IMCI but deserve special elaboration in the African context. On the prevention side, ITNs provide both a physical and a chemical barrier to the mosquitoes that transmit malaria, with benefits extending beyond the individual user as

51. Marsh and others (2002).

52. Bang and others (1999).

53. World Health Organization, United Nations Children's Fund, and Global Alliance for Vaccines and Immunizations (2003).

54. Complementary feeding involves adding solid foods to the diet of breastfed infants over six months of age to prevent nutritional deficiencies.

55. The IMCI protocol is available at World Health Organization (2001).

56. Armstrong Schellenberg and others (2004). 
the chemical halo emitted by the net repels and shortens the lives of mosquitoes in the vicinity. The impact of comprehensive ITN programs can be substantial. A review evaluating twenty-two trials concluded that approximately 6 lives could be saved for every 1,000 children protected with ITNs. ${ }^{57}$ In Tanzania, C. A. Maxwell and colleagues found that ITNs were linked to 55 to 75 percent reductions in malarial morbidity for children aged six months to two years. ${ }^{58}$ On the treatment side, the recent rise in malarial resistance to chloroquine and sulfadoxine-pyrimethamine in Africa has accelerated the need to make the transition to more effective therapies such as artemisinin-based combination treatment. ${ }^{59}$ This treatment can enhance clinical efficacy and delay the development of resistance. ${ }^{60}$

Of course, interventions outside of the formal health sector are also crucial for reducing child mortality, as described in appendix B. Targeted nutritional interventions can help enormously. For example, a UN study demonstrated that vitamin A supplementation resulted in a 23 percent average reduction in mortality rates among infants and children between six months and five years old. ${ }^{61}$ Substituting clean cooking fuels for domestic biomass fuels has been estimated to reduce acute respiratory infections in several developing countries by approximately 30 percent. ${ }^{62}$ D. Leipziger and colleagues, in a study of forty-three developing countries, estimated that improved access to water explains 37 percent of the difference in child mortality between the poorest and richest quintiles within countries. ${ }^{63}$ Simple hand washing with soap and water reduces shigella and diarrheal disease transmission by 35 percent. ${ }^{64}$

Maternal education similarly contributes to child health. Each additional year of a mother's education corresponds to an estimated 7 to 9 percent decline in her under-five child's mortality risk, although the precise

57. Lengeler (2004).

58. Maxwell and others (2002).

59. World Health Organization and United Nations Children's Fund (2003).

60. World Health Organization (2001).

61. Beaton and others (1993).

62. Reductions in the range of 21 to 44 percent were found for acute lower respiratory infections and 24 to 64 percent for all acute respiratory infections (Ezzati and Kammen, 2002).

63. Leipziger and others (2003).

64. Kotloff and others (1999); Khan (1982). 
mechanisms of this relationship are not yet entirely clear. ${ }^{65}$ Access to contraception can also have a strong impact on child mortality rates.

These interventions must be provided in an integrated manner, but one must be careful not to think of their effects as purely additive. A critical lesson from past experience with development programs in the health sector is that successful scale-up and utilization of a broad range of diseasespecific health interventions requires a functioning health system, including an adequate complement of health workers; good management capacity for supervision and oversight; ongoing monitoring, evaluation, and quality assurance; and sustained outreach and education for communities, among other features.

In a prominent recent study, G. Jones and colleagues evaluated the impact of a broad set of health sector and non-health sector interventions on child survival and concluded that 63 percent of annual child deaths could be prevented by providing universal (defined as 99 percent) access to an integrated set of interventions. ${ }^{66}$ Although these authors did not evaluate the role of a full health management system, they did include preventive medical interventions (such as immunization, micronutrient supplementation, and clean delivery), curative interventions (such as oral rehydration therapy through salt tablets, antibiotics for pneumonia and sepsis, and antimalarial medications), promotion of breastfeeding, ITNs, complementary feeding, and improved access to water, sanitation, and hygiene education. ${ }^{67}$

\section{MDG Needs Assessments for Ghana, Tanzania, and Uganda}

To be aligned with the MDGs, the full intervention package outlined in appendix A must be converted into a country-level investment plan, one that works backward from the outcome targets to identify needed input targets and then identifies infrastructure, human, and financial resource requirements to meet the targets. We dub this a "needs assessment"

65. Cleland and Van Ginneken (1988).

66. Jones and others (2003).

67. Importantly, Jones and others (2003) point out that their estimate of lives saved through known interventions may be conservative, since they evaluate only those interventions for which good cause-and-effect evidence exists and that are "feasible" for developing countries to implement (for example, they exclude emergency obstetric care). They do not assess other underlying factors, such as maternal education, that have a strong although indirect impact on child survival. 
approach to the MDGs.$^{68}$ Here we estimate the costs of interventions for three countries: Ghana, Tanzania, and Uganda. We chose these countries because all have high rates of extreme poverty, are making insufficient progress toward achieving the MDGs, and are well governed for their level of income per capita, as indicated by their "good" and "average" governance ratings in table 2 . These are countries where governance is not the binding constraint.

To highlight the extent of poverty in Ghana, Tanzania, and Uganda, table 11 summarizes available data for some key MDG indicators. Although the underlying data are often imprecise and incomplete (a reflection of the extreme poverty in these countries), they highlight each country's uneven progress across the MDGs. Persistently high rates of hunger and child mortality are particularly notable. Indeed, the fact that Ghana's child mortality rate of 100 per 1,000 live births in 2001 is the lowest in the group reflects how extreme poverty is in these countries. Human capital accumulation meanwhile remains slow in Ghana and Tanzania in particular, as reflected in their low primary enrollment rates, and more than a third of the population in all three countries was living on less than $\$ 1$ a day in the latest available surveys.

To meet the MDGs systematically in each of these countries, we assume that the interventions are scaled up linearly through 2015. As much as possible, the intervention package is also adjusted according to the age and gender structure of the population and to the rural-urban divide. To account for population growth and other changes in a country's demographic profile, the UN Population Division's 2002 revision of medium population forecasts is used. ${ }^{69}$ Where more recent population data are available at the country level, we use those.

For each intervention, such as the provision of ITNs or the hiring of new teachers, we specify quantitative input targets that are consistent with the MDGs. We then translate the interventions into budget lines, estimating financial costs per year. We use local unit costs wherever possible and regional proxies where these are not available. In some cases, unit costs are assumed to increase as coverage rates increase. For example, teachers'

68. The UN Millennium Project needs assessment (UN Millennium Project, 2004) draws on several works including Bruns, Mingat, and Rakotomalala (2003), World Bank (2002), Delamonica, Mehrotra, and Vandermoortele (2001), FAO (2002), Commission on Macroeconomics and Health (2001), and Global Water Partnership (2000).

69. United Nations (2003). 


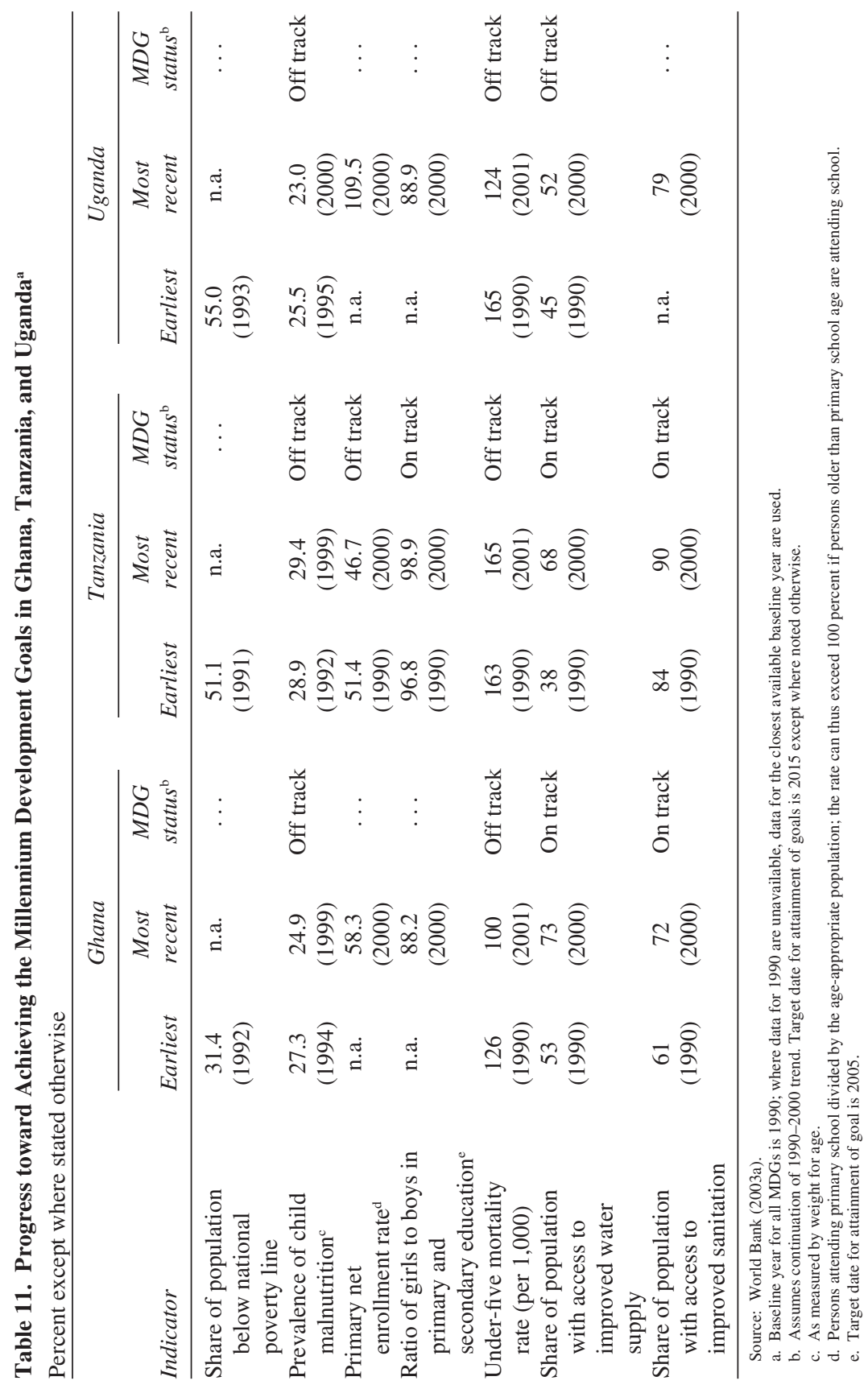


salaries are increased to improve retention rates. Importantly, we estimate capital as well as operating costs, and total costs instead of incremental costs. This implicitly assumes that all investments and service deliveries follow best practice, regardless of current efficacy of delivery, yielding a downward bias in our cost estimates. Since the marginal costs of a major scale-up are unknown - they could be increasing or decreasing when making investments in rural communities-we use average unit costs.

Next we identify key interventions that, upon implementation, would reduce resource requirements for other interventions. The resulting cost savings can occur through reductions in the population in need or reductions in unit costs for other interventions. Quantifying these links is often difficult, especially for the interventions that have numerous indirect effects, such as girls' education. And even where clear data exist, the magnitude of the impact may not be known for different settings or for different delivery mechanisms. Nonetheless, our estimates include the effect of several synergies that are likely to result in particularly large cost savings. These are a reduction in diarrhea morbidity through expanded access to improved water supply and sanitation, including improved hygiene behavior; a reduction in acute respiratory infections through increased use of improved cooking fuels; a reduction in HIV/AIDS incidence through increased condom use; and a reduction in malaria incidence through increased use of ITNs.

As a last step in the needs assessment, we develop a basic financing strategy for each country, distinguishing among domestic government resources, out-of-pocket household expenditure, and ODA. We assume that domestically financed government spending on MDG-related interventions will rise by 4 percentage points of GDP between 2005 and 2015, in addition to the increase in domestic resource availability resulting from GDP growth alone. We also assume that, as a result of this package of interventions, GDP per capita rises between 2.2 and 3.3 percent a year on average during 2005-15, which is approximately the growth rate needed to reduce income poverty by half at an average elasticity of headcount poverty with respect to income per capita of $-1.4 .^{70}$

70. Several studies have estimated these elasticities for low-income countries. Bruno, Ravallion, and Squire (1998) estimate a global average of -2 , whereas Besley and Burgess (2003) cite a low value of -0.49 for sub-Saharan Africa. In the case of Uganda, the Economic Policy Research Center estimates a value of -1.39 (Okidi, Okwi, and Ddumba, 2000); Tanzania's elasticity for basic needs poverty has been estimated at -1.45 (TAKWIMU, 2000). 
Household contributions are estimated based on the incentive effects of user fees and overall ability to pay. Since user fees can play a critical role in preventing poor people from accessing basic services, we assume no user fees for primary school education, adult literacy programs, improving gender equality, basic health care, nutritional interventions, and roads. ${ }^{71}$ In some cases, however, user fees may be necessary to avoid wasting scarce resources after basic minimum needs have been ensured. "Lifeline tariffs," which ensure the free provision of water (or other basic needs) up to the minimum daily requirement for personal hygiene and cooking, but then charge for consumption above the minimum, have been used successfully in many parts of the world to avoid wastage while improving access to clean drinking water. We assume that households bear some of the cost of agricultural interventions, secondary school education, energy provision, water supply, and sanitation. To calculate households' ability to pay, we divide the population of each country into three segments using income shares derived from national household budget surveys as reported by the World Bank..$^{72}$ It is assumed that the poorest segment of the population, that living below the national poverty line, will not contribute to the cost of meeting the MDGs. The middle segment and the top segment (with income above twice the poverty line) are assumed to contribute larger shares of operating and capital costs. ${ }^{73}$

A core result of our needs assessment is that the investment program required to meet the MDGs is beyond the financing means of the poorest countries, even when one assumes that governments will devote an additional 4 percent of GNP to meeting the MDGs alongside roughly 3 percent annual growth in income per capita and that households contribute to the increased investments. We estimate an "MDG financing gap" as the total cost of the package of interventions minus the contributions by the

71. "Experience has taught repeatedly that user fees end up excluding the poor from essential health services, while at the same time recovering only a tiny fraction of costs" (Commission on Macroeconomics and Health, 2001, p. 61). Even modest user fees have been shown to have a strong impact on reducing effective access to these basic services, particularly for women, young girls, and other vulnerable groups. See World Education Forum (2000). The Education for All Dakar Goal 2 reads as follows: "Ensuring that by 2015 all children, particularly girls, children in difficult circumstances, and those belonging to ethnic minorities, have access to and complete free and compulsory primary education of good quality" (available at www.unesco.org/education/efa/ed_for_all/dakfram_eng.shtml).

72. World Bank (2003a).

73. Details are outlined in UN Millennium Project (2004). 
domestic government and households. This is the amount that donors would have to bear in order to finance the MDG intervention package. Table 12 presents the total estimated resource requirements for the three countries, based on an eleven-year scale-up period from 2005 through 2015. The results suggest that each of the three countries will be able to finance between 41 and 48 percent of the total investment needs through domestic sources. This translates into an average total need for external development assistance equivalent to $\$ 47$ (for Uganda) to $\$ 60$ (for Tanzania) per capita per year. Points of interest for each country are drawn from the UN Millennium Project and summarized below: ${ }^{74}$

-Ghana's total investment needs for meeting the MDGs average $\$ 2.0$ billion a year, or $\$ 82.8$ annually per capita. Of this total, $\$ 1.2$ billion is estimated for required average annual external assistance. This need remains significantly above the $\$ 653$ million in net ODA that donors disbursed to Ghana in 2001 for MDG- and non-MDG-related activities.

-Of the three countries in our sample, Tanzania faces the biggest challenges in meeting the MDGs. We estimate that the country will require the highest per capita levels of average investment and external finance to meet the MDGs, at $\$ 100.4$ and $\$ 60.2$, respectively. These figures are equivalent to an aggregate investment of $\$ 4.2$ billion a year and imply external finance of $\$ 2.5$ billion a year. More than a third of these investments are required to achieve the health MDGs, because of the country's high prevalence of HIV/AIDS and malaria.

- Uganda is widely lauded for its progress in education and its HIV/ AIDS control program over the past decade. However, the country still remains off track in several areas, including hunger, health, and water. We project that the country will need to spend an average of $\$ 3.0$ billion a year to meet the MDGs, or $\$ 89.7$ per capita. More than half of these investments will need to be financed externally, requiring an average of $\$ 1.6$ billion, or $\$ 46.7$ per capita, annually. An important gap in our Uganda study is an estimate of the transport and communications infrastructure required to provide the landlocked country with improved access to world markets. The Northern Corridor highway to Mombasa, Kenya, is in critical need of upgrading, as is the rail infrastructure.

74. UN Millennium Project (2004). 
Table 12. Estimated Total Cost and Projected Sources of Funding to Meet Millennium Development Goals in Ghana, Tanzania, and Uganda, 2005-15 ${ }^{\text {a }}$

\begin{tabular}{|c|c|c|c|c|c|c|}
\hline \multirow[b]{2}{*}{$\begin{array}{l}\text { Cost (or funding } \\
\text { source) and } \\
\text { intervention area }\end{array}$} & \multicolumn{2}{|c|}{ Ghana } & \multicolumn{2}{|c|}{ Tanzania } & \multicolumn{2}{|c|}{ Uganda } \\
\hline & $\begin{array}{l}\text { Percent } \\
\text { of GDP }\end{array}$ & $\begin{array}{c}\text { Per } \\
\text { capita } \\
\text { (dollars) }\end{array}$ & $\begin{array}{l}\text { Percent } \\
\text { of GDP }\end{array}$ & $\begin{array}{c}\text { Per } \\
\text { capita } \\
\text { (dollars) }\end{array}$ & $\begin{array}{l}\text { Percent } \\
\text { of GDP }\end{array}$ & $\begin{array}{c}\text { Per } \\
\text { capita } \\
\text { (dollars) }\end{array}$ \\
\hline \multicolumn{7}{|l|}{ Total cost $t^{\mathrm{b}}$} \\
\hline Hunger & 1.9 & 5.9 & 3.2 & 11.5 & 1.7 & 5.9 \\
\hline Education & 5.6 & 17.7 & 3.3 & 12.1 & 4.1 & 13.9 \\
\hline Gender equality & 0.7 & 2.1 & 0.6 & 2.4 & 0.7 & 2.3 \\
\hline Health & 7.9 & 24.8 & 9.6 & 34.8 & 9.4 & 32.2 \\
\hline $\begin{array}{l}\text { Water supply } \\
\text { and sanitation }\end{array}$ & 2.8 & 8.8 & 1.6 & 5.9 & 1.1 & 3.9 \\
\hline Energy & 4.5 & 14.3 & 4.0 & 14.4 & 3.8 & 13.0 \\
\hline Roads & 2.9 & 9.2 & 5.3 & 19.4 & 5.4 & 18.4 \\
\hline Total & 26.3 & 82.8 & 27.7 & 100.4 & 26.3 & 89.7 \\
\hline \multicolumn{7}{|c|}{$\begin{array}{l}\text { Financing sources: } \\
\text { Household contribution }\end{array}$} \\
\hline Hunger & 0.3 & 0.9 & 0.5 & 1.8 & 0.4 & 1.2 \\
\hline Education & 0.3 & 0.9 & 0.2 & 0.7 & 0.6 & 1.9 \\
\hline Gender equality & 0.0 & 0.0 & 0.0 & 0.0 & 0.0 & 0.0 \\
\hline Health & 0.0 & 0.0 & 0.0 & 0.0 & 0.0 & 0.0 \\
\hline $\begin{array}{l}\text { Water supply } \\
\text { and sanitation }\end{array}$ & 1.2 & 3.9 & 0.7 & 2.7 & 0.5 & 1.7 \\
\hline Energy & 1.4 & 4.5 & 1.3 & 4.8 & 1.2 & 4.0 \\
\hline Roads & 0.0 & 0.0 & 0.0 & 0.0 & 0.0 & 0.0 \\
\hline Total & 3.3 & 10.2 & 2.8 & 10.0 & 2.6 & 8.9 \\
\hline \multicolumn{7}{|c|}{ Domestically financed government expenditure ${ }^{\mathrm{c}}$} \\
\hline Hunger & 0.5 & 1.7 & 1.0 & 3.5 & 0.7 & 2.3 \\
\hline Education & 1.6 & 5.0 & 1.0 & 3.6 & 1.5 & 5.3 \\
\hline Gender equality & 0.2 & 0.6 & 0.2 & 0.7 & 0.3 & 0.9 \\
\hline Health & 2.2 & 7.0 & 2.9 & 10.5 & 3.6 & 12.2 \\
\hline $\begin{array}{l}\text { Water supply } \\
\text { and sanitation }\end{array}$ & 0.8 & 2.5 & 0.5 & 1.8 & 0.4 & 1.5 \\
\hline Energy & 1.3 & 4.0 & 1.2 & 4.3 & 1.4 & 4.9 \\
\hline Roads & 0.8 & 2.6 & 1.6 & 5.8 & 2.1 & 7.0 \\
\hline Total & 7.5 & 23.5 & 8.3 & 30.2 & 10.0 & 34.1 \\
\hline \multicolumn{7}{|c|}{ Required total external budget support } \\
\hline Hunger & 1.1 & 3.3 & 1.7 & 6.2 & 0.7 & 2.4 \\
\hline Education & 3.7 & 11.8 & 2.1 & 7.8 & 2.0 & 6.7 \\
\hline Gender equality & 0.5 & 1.5 & 0.5 & 1.6 & 0.4 & 1.4 \\
\hline Health & 5.7 & 17.8 & 6.7 & 24.3 & 5.9 & 20.0 \\
\hline $\begin{array}{l}\text { Water supply } \\
\text { and sanitation }\end{array}$ & 0.8 & 2.4 & 0.4 & 1.5 & 0.2 & 0.7 \\
\hline Energy & 1.8 & 5.7 & 1.4 & 5.2 & 1.2 & 4.1 \\
\hline Roads & 2.1 & 6.6 & 3.7 & 13.6 & 3.4 & 11.4 \\
\hline Total & 15.6 & 49.1 & 16.6 & 60.2 & 13.7 & 46.7 \\
\hline
\end{tabular}

Source: UN Millennium Project (2004).

a. Data are averages per year. Costs for three intervention areas (environment, improving the lives of slum dwellers, and science and technology) are still to be determined. Data may not sum to totals because of rounding.

b. Sum of household contributions, domestically financed government expenditure, and required total external budget support.

c. Government expenditure on the MDGs financed solely through domestic revenue generation; on a pro forma basis, expenditures are allocated to budget line items based on their relative share of funding from all sources. 
In addition to estimating the costs of meeting the MDGs, the bottomup needs assessments yield detailed estimates of each country's human resource and infrastructure requirements. For example, our analysis suggests that Tanzania will need to increase the number of primary and secondary school teachers from approximately 134,000 in 2005 to 215,000 in 2015.

We emphasize that these results are preliminary and likely to underestimate the true costs of achieving the MDGs in each country, since they assume an optimal intervention package and exclude a number of expensive interventions, such as ports, railroads, infrastructure for water storage and transport, urban infrastructure and slum upgrading, expanding higher education, and information and communications technologies. ${ }^{75}$ The estimates nonetheless provide an important first approximation of the combination of resources and inputs required to achieve the MDGs.

\section{Implications for Development Assistance}

The external financing requirements presented in table 12 are not total ODA needs. Table 12 includes only MDG-oriented investments and excludes programs that are not directly linked to the MDGs but that might be indirectly important, such as support for the judicial system or other institutions that underpin democratic governance. To calculate the three countries' total ODA needs, one needs to add other important forms of ODA to directly MDG-focused ODA. One can then identify the total incremental ODA need for each country.

Table 13 presents estimated current ODA and incremental total ODA needs for Ghana, Tanzania, and Uganda. The first column shows aid levels per capita in 2001. The second indicates the estimated share of that ODA that is focused on MDG-related activities other than those addressing income poverty, using a decomposition accounting methodology developed by Brian Hammond of the OECD Development Assistance Committee (DAC). The actual results produced through that methodology were in the range of 33 to 59 percent, but because it is difficult to allocate aid flows precisely to each MDG, and because poor aid quality (for example, due to lack of donor coordination) often limits resource efficacy, we assume a figure toward the low side of that range, namely, 40 percent. The third column of the table reports the estimate of non-MDG aid per capita.

75. Appendix A lists all the interventions that have so far not been included in the needs assessment. 


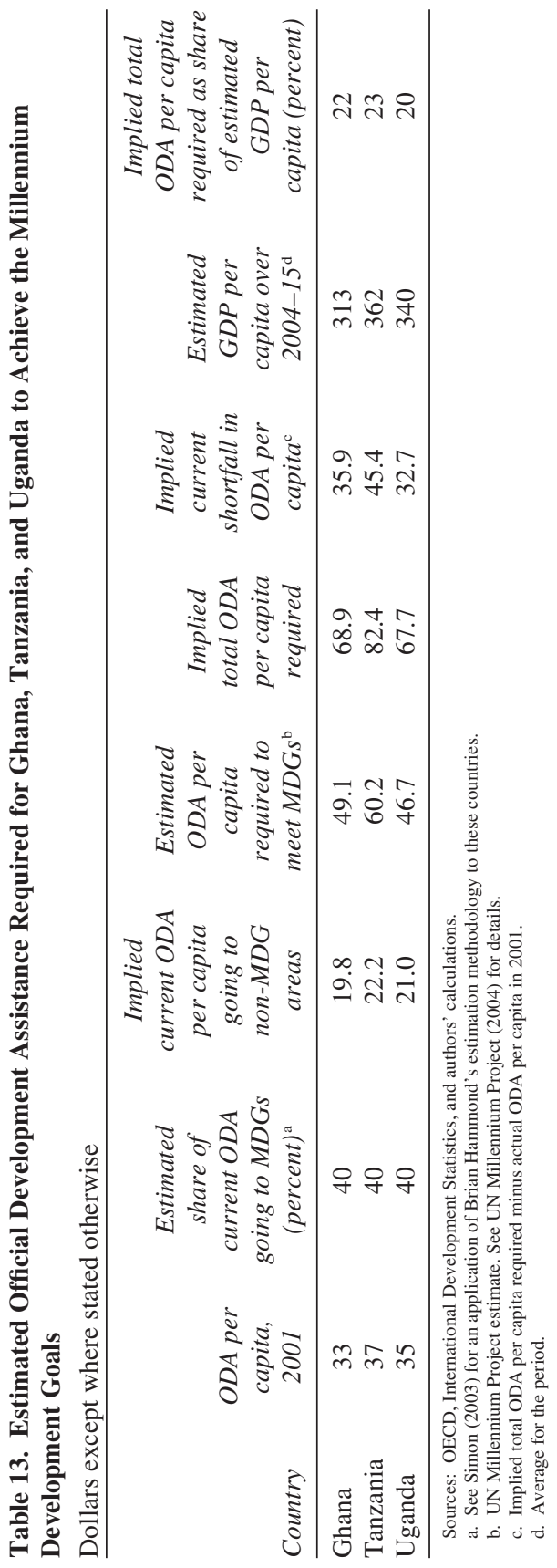


We assume perfect donor delivery mechanisms and so do not distinguish between currently efficient and inefficient aid dollars. This biases upward the estimate of current MDG-related aid and biases downward the implied aid gap. The fourth column of the table repeats from table 12 the estimated total external finance gaps per capita. The fifth column then assumes that current non-MDG aid spending will remain constant as MDG-based investments are scaled up, so that the total ODA need per capita is the sum of MDG-targeted ODA and complementary ODA. The sixth column presents the implied shortfall in ODA per capita, indicating that roughly a doubling of ODA is needed in each country.

The seventh column of table 13 then presents the average GDP per capita that is assumed by our financing model, which in turn is used to calculate the final column, total ODA required as a share of GDP in each country. The results, which range from 20 to 23 percent of GDP, present a lower bound for estimates of the aid required for these three countries to achieve the MDGs. These are lower bounds because the costing model excludes several "big ticket" items listed above and neglects the inherent overhead costs of managing aid delivery, which are likely in the neighborhood of 15 to 20 percent of total aid, or 3 to 4 percentage points of GDP. Overall, the results thus suggest that these countries will require average ODA equivalent to 20 to 30 percent of GDP through 2015.

\section{A New Framework for Donor-Recipient Country Relations}

The package of public investments proposed in this paper implies a significant increase in ODA transfers to Africa, perhaps a doubling or more. Many will read this as an excessively bold proposal, because skepticism is widespread among policymakers and voters regarding the efficiency and level of coordination in aid delivery. Although there is much evidence that aid works, it is true that, even in well-governed developing countries, a lack of coordination and goal orientation leave the current system far from adequate to the task. Nonetheless, the pieces of the solution are now coming together. For instance, there is broad conceptual agreement on the need to focus on poverty as an outcome rather than on macroeconomic stability alone. Likewise there is recognition of the need to provide development assistance through common financing arrangements that harmonize donor practices and allow recipient countries to 
define their own Poverty Reduction Strategies (PRSs). ${ }^{76}$ In what follows we sketch the kind of donor-recipient mechanisms that will be needed to translate large-scale aid flows into effective investments and poverty reduction under conditions of good governance, as well as some thoughts on situations where governance is inadequate to justify large-scale aid flows.

\section{Guidelines for Converting Goals into Plans}

in Well-Governed Countries

To meet the MDGs in cases where domestic governance is adequate (that is, at or above the norm for countries at the given income level), aid processes should be guided by four core principles. First, policies should be aligned with the 2015 time horizon, with that MDG target date serving as the planning horizon for both recipient countries and donors. Given a decade-long horizon, developing countries can address key questions of absorptive capacity by investing in human resources and infrastructure. The international adoption of a 2015-based planning horizon would amount to an enormous shift in development policy, because today's primary vehicles for development assistance in Africa, the Poverty Reduction Strategy Papers (PRSPs) and Medium-Term Expenditure Frameworks, adopt a much shorter horizon, usually three years. Within such a short-term view, today's absorptive capacity constraints are seen as fundamental impediments rather than as targets of opportunity for public investment, especially in human resources and managerial capacity.

Second, the public investment program needs to be guided by bottomup assessments of needs rather than ex ante budget constraints set by the donor countries. In development policy as practiced today, the first point of discussion is to identify the external resources available to a country and then to decide how those resources can best be deployed. Crucially, we recommend that this process be turned on its head. The first step would be to undertake a real needs assessment methodology along the lines of that presented in this paper. The second would be to mobilize the necessary external resources. This differs from current practice in that the PRSPs are the core development assistance framework for Africa, yet the World Bank's own assessment shows that these documents are not consistently

76. This was reaffirmed in the 2002 Monterrey Consensus and subsequently in the Rome Declaration on Harmonization. 
aligned with the MDGs. ${ }^{77}$ This happens because, in the typical case where existing development assistance flows are insufficient to achieve the MDGs, developing country governments are encouraged not to be too ambitious in aspiring to the MDGs but instead to be "realistic" in their targets. They are encouraged to "accelerate progress toward the MDGs" rather than to achieve the MDGs. ${ }^{78}$

A related and perhaps deeper problem within the current approach to goal setting is that targets in many PRSPs have been based solely on loose aspirations rather than on a rigorous assessment of the real investment needed to achieve the targets. According to the World Bank's own PRSP sourcebook, "[PRSP] targets tend to be too optimistic, and the cost of reaching them tends to be underestimated." ${ }^{\prime \prime 9}$ A rigorous MDG-oriented process must therefore include not just outcome goals, but also specific paths that will lead to those goals, with clear and monitorable input targets, including adequate financing.

Third, donor assistance needs to be harmonized and coordinated around budget support, particularly in countries like Ghana, Uganda, and Tanzania where governance structures are not the binding constraint on accelerating progress toward achieving the MDGs. Uncoordinated and supply-driven development assistance from the twenty-three bilateral donors that are members of the DAC places unnecessary transactions cost burdens on recipient country governments. The tendency for bilateral donors to go their own way in providing project support is known as "planting the flag," because the donor country gets political credit and a good photo opportunity for its aid. We strongly urge a less photogenic but more meaningful approach, in which donors combine their resources into a common pool of budgetary support. A convenient way to do this would be to increase substantially the funding provided by the World Bank through its concessional lending arm, the International Development Association. Current IDA flows are on the order of $\$ 8$ billion a year, and

77. The data in Harrison, Klugman, and Swanson (2003) show the lack of PRSP alignment with the MDGs. Their table 5, for example, indicates that seven of twelve recent PRSPs do not even include targets that can be compared with the hunger MDG. Similarly, seven of twelve do not have targets relevant to the education MDG.

78. The language of "accelerating progress toward the MDGs" rather than "achieving the MDGs" is used, for instance, in the recent World Bank staff paper for the Bank's Development Committee (World Bank, 2003c).

79. See, for instance, the critique of "too optimistic" PRSP targets in Christiansen, Scott, and Wodon (2002). 
Table 14. Estimated Budget Support to All of Sub-Saharan Africa, 2002 ${ }^{\text {a }}$

Millions of dollars

\begin{tabular}{lrrr}
\hline & $\begin{array}{c}\text { From } \\
\text { bilateral } \\
\text { sources }\end{array}$ & $\begin{array}{c}\text { From } \\
\text { multilateral } \\
\text { sources }\end{array}$ & Total \\
\hline Grants & 9,735 & 2,831 & 12,566 \\
Gross loans & 732 & 5,032 & 5,764 \\
\cline { 2 - 4 }$\quad$ Gross ODA disbursements & 10,467 & 7,863 & 18,330 \\
Minus: & & & \\
Technical cooperation & 2,412 & 419 & 2,831 \\
Development food aid & 336 & 104 & 439 \\
Emergency aid & 1,023 & 620 & 1,643 \\
Debt forgiveness grants & 2,911 & 279 & 3,191 \\
Support through nongovernmental & 378 & 0 & 378 \\
$\quad$ organizations & 7,061 & 1,422 & 8,483 \\
Equals: Gross ODA paid into & & & \\
$\quad$ government budgets & 3,406 & 6,441 & 9,848 \\
Minus: & & & \\
Principal repayments actually made & 454 & 1,480 & 1,934 \\
Interest payments & 87 & 449 & 536 \\
Equals: Estimated net budget support & 2,865 & 4,513 & 7,377 \\
$\quad$ As share of total support (percent) & 27 & 57 & 40 \\
\hline
\end{tabular}

Source: Estimates by Yasmin Ahmad, Brian Hammond, and Rudolphe Petras, Development Assistance Committee (DAC) Secretariat, Organization for Economic Cooperation and Development, personal correspondence with the authors, May 2004.

a. Numbers may not sum to totals because of rounding.

b. Based on DAC estimates.

these could be tripled or more in coming years to be consistent with the scale of need that we have identified. A somewhat more complicated alternative would be for the bilateral donors to pool their money at the country level into budget support for particular sectors, in what is known as the sector-wide approach (SWAp).

As presented in table 14, which draws on OECD statistics, only about 27 percent of the net transfer of bilateral ODA to sub-Saharan Africa in 2002 took the form of budget support. For both bilateral and multilateral aid flows, the table calculates budget support by subtracting from gross ODA (loans and grants) those forms of ODA that do not go toward supporting the recipient government's budget (these include technical cooperation, development food aid, emergency aid, debt forgiveness, support through nongovernmental organizations, and repayments of loan principal and interest). Note that a significant portion of this budget support still 
takes the form of loans that need to be repaid, although on concessional terms. As hinted by the "technical cooperation" line of the table, tied aid (the practice of linking development assistance to the purchase of donor country goods or services) also remains a significant issue for many developing countries.

Fourth, reforming donor financing requires new notions of sustainability. The first point is that recipient countries will need large-scale support for many years to come - at least a decade and possibly more. Therefore it is completely unsound to expect development projects or programs to become self-sustaining financially in a few years, as many donors now assume. It is also necessary, for the poorest countries, to finance these programs through grants rather than loans. We have seen that countries will require perhaps 20 to 30 percent of their GDP in annual development assistance for a decade or more. If much of this comes in the form of loans, those countries will be bankrupt once again by the end of the decade. Grant financing is the only way to pay for the investments and leave the recipient countries with viable public finances at the end of the process. For the same reason, the outstanding debts of the poorest countries should also be cancelled in their entirety as part of the MDG process. After all, what is the meaning of "debt sustainability" for a country that also requires annual aid of more than 20 percent of GDP just to achieve basic poverty reduction targets? Debt cancellation will need to be deepened accordingly. ${ }^{80}$

\section{National Planning Processes}

We recommend that African governments implement these guiding principles through a three-stage process. First, each country should convene a planning team comprising its own representatives and those of key stakeholders and technical advisers-the bilateral and multilateral donors, UN specialized agencies, and civil society leaders - to conduct an MDG needs assessment. In the second step, the needs assessment should feed into a ten-year public investment and human resource strategy. The third step would be to construct the medium-term budget framework (covering, for example, three years, as with the PRSPs), which would finance the first three years of the ten-year investment strategy.

Developing multisector ten-year scale-up plans will require a great deal of technical work. In the poorest countries, UN agencies already pro-

80. Sachs (2002). 
vide vital support in almost every sector and can thus play a crucial role in assisting national governments as they develop their MDG plans. The challenge will be to coordinate this work around the specific MDGs. In most low-income countries, the resident representatives of all agencies now meet regularly as UN Country Teams (UNCTs), which report to the UN Development Group that was established by the secretary-general in 1997 as the overall coordination mechanism among developmentoriented UN agencies. The UNCTs, including representatives of the International Monetary Fund (IMF) and the World Bank, can provide vital assistance to countries in formulating the ten-year strategy and three-year budget framework.

As an explicit MDG-based planning framework is developed, increases in ODA inflows will raise a number of structural macroeconomic issues. Countries must maintain their efforts to mobilize domestic revenue and foster domestic saving and investment in order to support long-term economic growth. We have assumed, for example, that governments will raise domestic resources committed to the MDGs by 4 percent of GNP. Of course, governments should not spend what they do not have, especially if the funds are obtained through domestic credit expansion. The increased MDG investment program must be financed through reliable increases in ODA grants.

With significant increases in ODA inflows, issues of Dutch disease will arise and need to be managed carefully. However, the implications should not be too quantitatively significant, as Alessandro Prati and his colleagues have argued..$^{81}$ The reason is that there is a substantial tradable goods component to scaling up, both in capital investments and in the high proportion of skilled labor that is globally mobile. The ODA will also be directed toward raising supply-side productivity through investments in agriculture and human capital rather than toward a consumption boom of the kind typically linked to a squeeze in the tradable goods sector. More important than the size of the ODA inflows is their predictability, as the IMF's own analysis has shown. ${ }^{82}$

Underlying this discussion of macroeconomic programming is the consideration of what to do if donor funds are not readily forthcoming to meet the needs of the MDG-based PRSP. In that case, of course, the

81. Prati, Sahay, and Tressel (2003).

82. IMF Fiscal Affairs Department, personal correspondence with the authors, April 2004. 
MDGs are unlikely to be met. The IMF, however, should not then simply urge the country to live within its means. It should also present the technical case that the country could achieve the MDGs if given additional support, and it should urge donor countries to expand available support to a level that would enable any well-governed African country making the effort to achieve the MDGs.

\section{National Implementation Processes}

Government-led coordination will be crucial not just for crafting these plans but also for implementing them. As their part of the bargain, recipient governments will need to put in place a clear and transparent system for monitoring and evaluating the implementation of the plans, building in regular milestones and checkpoints through which the plans can be finetuned or adjusted as necessary. Public evaluation of plans will need to take place within the context of the African Peer Review Mechanism (APRM) of the New Partnership for Africa's Development (NEPAD). The APRM, which is beginning its first evaluations in 2004, entails African countries publicly reviewing each other's performance in four categories: democracy and political governance, economic governance and management, corporate governance, and socioeconomic development.

To ensure that ODA resources are being used effectively, monitoring and evaluation mechanisms will need to be included in the MDG-based PRSs, including PRSPs when appropriate. These systems will need to evolve as scale-up proceeds, but they will need to be consistently guided by key principles of fiscal accountability, institutional strengthening, substantive goal orientation, and benchmarking of progress. ${ }^{83}$ Importantly, progress will need to be measured with respect to both financial management and MDG-based development outcomes. Too often, development evaluations focus on assessing the procedural outcomes of projects and processes rather than the development outcomes of programs. More important, intermediate input targets and milestones will be required en route to reaching the long-term outcome goals. For instance, bed net use needs to be measured as an input en route to reducing the incidence of malaria. Before implementation of the PRS begins, such intermediate and outcome

83. As described in UN Millennium Project Task Force on Poverty and Economic Development (2004). 
benchmarks need to be developed and proposed by the recipient governments and then agreed upon by the donors.

Domestically, successful implementation will require African governments to work closely with civil society organizations to ensure that public trust is maintained in the accountability of public expenditure managers, to identify best mechanisms for service scale-up, and to help with service delivery where appropriate. Procedures for public accountability include the opportunity for consultation in policy planning processes, the release of budgets for public review, and the release of independent audit reports on public expenditure. In larger countries where it is difficult to transmit information to remote rural areas, distributive mechanisms of budget disbursement and community-based oversight can be most appropriate both for maintaining accountability and for identifying the best means of service delivery. For instance, targeted block grants can be given to rural communities, allowing them to decide how those resources should best be spent. There is considerable evidence to suggest that women's community organizations should be given key oversight roles, since their members make household investment decisions that yield greater community benefits than those made by men. ${ }^{84}$ Actual delivery of services will no doubt involve a mix of public sector institutions, nongovernmental organizations that operate on a national scale, and community-based organizations that receive transfers from the public sector.

\section{Donor Assistance When Governance is Weak}

Although the bulk of this paper focuses on poor African countries with good governance, a few observations can be made about what to do in poorly governed countries. In those instances the preceding framework will not apply, mainly because development aid allocated to poorly functioning governments can easily be squandered or even used to reinforce bad practices. The key is to understand the nature of the poor governance and to take actions that make sense in that context. Here we offer some basic thoughts on this difficult topic.

In some cases what is called "poor governance" is in fact an issue of lack of financial resources to carry out reasonable public functions. The political and social will may be present, but the government may simply lack the means to maintain an effective police force, judiciary, and other

84. Quisumbing and Maluccio (2000). 
instruments of governance. In such cases an increased flow of ODA can make a significant difference, not only by financing key public investments but also by financing key instruments of governance.

In other cases the problems of governance run deeper than simple lack of finances. They may involve violent conflict, authoritarian rule, or corrupt and predatory practices by the state. When the problem is violent conflict, the role of aid needs to be focused in the first instance on peacemaking, peacekeeping, and humanitarian assistance. Early funding of postconflict situations may help to sustain the peace, for example by providing funds for disarmament and resettlement of combatants. Aid may also be vital for refugees and the sustenance and relocation of displaced populations. The current aid system operates haphazardly in these circumstances, although the case of Liberia provided an impressive recent example of a rapid UN system response in designing a postconflict aid agenda. Of course, in this and related cases a key question is whether pledged donor support will actually arrive in a timely fashion.

When the problem is entrenched despotic rule, large-scale aid transfers to the government are ill advised. Even tight conditionality will not be very successful in ensuring that such aid is well used. Governments that do not intend to carry out needed reforms can find too many ways to circumvent the conditions. Therefore our basic answer for this scenario is that the scale of aid to such governments should be limited, and aid should be substantially allocated through nongovernmental organizations and international agencies rather than through the central government. This approach will generally not be sufficient to achieve the MDGs, but it will at least help to ensure progress (or lack of retrogression).

Some guidelines on providing aid in this "third-best" situation might include the following. First, donors should focus on direct delivery of humanitarian assistance and on cases where aid is provided in kind and delivery is monitorable (immunizations or emergency food programs, for example). These programs have proved successful even in situations of disastrously poor governance. "Immunization days," for example, have been successfully implemented in the middle of civil wars. Second, donors should seek out nongovernmental organizations that can effectively deliver longer-term services, such as health care and education, recognizing that the scale of services provided by such organizations will rarely substitute for effective public sector delivery. Third, donors should encourage small-scale demonstration projects by civil society, as precursors 
to large-scale programs should governance conditions someday change. Fourth, cutoffs in aid should not be used punitively in an attempt to finetune the quality of governance (for example, in protest of a single government decision that the donor finds undesirable). Micromanagement of local governance is a disaster and a self-fulfilling trap. When aid is cut, governance itself is put in jeopardy. Cutting aid over small matters can easily trigger a downward spiral of political instability.

Finally, we have serious reservations about punitive sanctions, such as trade embargoes, on poorly governed countries. Although such countries cannot be entrusted with large-scale aid inflows, it is a mistake to punish them with trade embargoes (other than an arms embargo). Trade sanctions rarely bring down a government, because they weaken civil society at least as much as they weaken government power. Therefore they tend to create intense economic hardship without tilting the balance of power between a despotic government and its opposition. Of course, in a few widely noted cases (such as the end of apartheid in South Africa), trade sanctions seem to have played a role in accelerating the transition to good governance, but an even larger number of cases can be cited (Cuba, Haiti, and Myanmar, for example) where trade sanctions made little difference to governance, but instead contributed to country-wide impoverishment.

\section{The Role of Trade Reform}

Most of this paper has focused on the quantity and direction of ODA needed for African countries to make the public investments necessary to break out of a poverty trap. The implied aid flows are large, equivalent to 20 to 30 percent of recipient countries' GDP over the course of a decade or more. An important related issue is how these costs compare with the benefits of increased international trade. Could improved trade conditions substitute for the required aid? Have the advocates of "trade, not aid" discovered a less expensive solution? These questions are particularly relevant in the context of the current Doha round of negotiations under the auspices of the World Trade Organization, which are meant to focus in large part on developing country needs, although the talks have produced few results as yet. The long-term ambition for African economies with respect to trade needs to be to diversify away from dependence on commodity exports and the related long-term decline in terms of trade, but 
several other trade policy issues are of immediate importance ${ }^{85}$ Market access remains crucial for African exporters, as is an intellectual property regime that permits reliable access to key pharmaceutical products and a trade regime that allows enough flexibility for countries to implement industrial promotion policies. Yet even though trade reform is welcome and important, it is certainly not sufficient to achieve the MDGs. Trade will not directly provide the targeted public investment strategies outlined above, and the gains from trade are simply insufficient to finance the necessary investments. Even the much-heralded Africa Growth and Opportunity Act of the United States has had only marginal effects on most African countries' exports. ${ }^{86}$

Within the African trade agenda, the most immediate political priority is progress in agricultural trade liberalization. ${ }^{87}$ Yet progress will mean different things in different countries. The countries that are net agricultural exporters will naturally seek greater access to protected markets in industrial countries for their exports. Those that are net agricultural importers, particularly food importers, are at risk of immediate adverse welfare shocks if, for instance, industrial countries' export subsidies are quickly removed, resulting in major price increases for core foodstuffs ${ }^{88}$ Many countries in Africa are net food importers but net exporters of nonfood agricultural products, so that welfare outcomes from trade liberalization will be mixed. Given these countervailing forces and existing data limitations, it is difficult to estimate the country-specific effects of trade liberalization packages. That challenge is further compounded by our proposal to double or triple agricultural productivity through a package of rural investments, since most trade modeling exercises are limited to comparative statics and hold agricultural productivity constant when examining changes in trade regimes.

85. One World Bank estimate indicates that the cumulative loss to non-oil-exporting countries from the decline in their terms of trade from 1970 to 1997 was equivalent to 119 percent of their combined GDP. See World Bank (2000).

86. Brenton and Ikezuki (2004).

87. Agricultural trade reform is of course a less pressing concern for fuel-exporting countries such as Angola, the Republic of the Congo, Equatorial Guinea, Gabon, and Nigeria.

88. Hoekman, Ng, and Olarreaga (2002) have usefully outlined the country-specific effects of export subsidies and tariffs. 
Nonetheless, one can begin to evaluate the differing effects of agricultural trade liberalization measures by distinguishing between the impact of liberalization of food commodities and that of liberalization of nonfood commodities. Among the latter, cotton is likely the most prominent. It is estimated that the United States spends nearly $\$ 4$ billion a year on cotton subsidies, or more than twice the entire annual U.S. bilateral development assistance budget for Africa, to maintain annual production by its roughly 25,000 cotton growers at about $\$ 4$ billion a year. ${ }^{89}$ China exports much less cotton than the United States but supports its domestic cotton production with $\$ 1.2$ billion in annual subsidies; the European Union directs roughly $\$ 0.8$ billion a year to support cotton producers in Greece and Spain.

Although the precise global impact of cotton subsidies is not easily calculated, they clearly have a deleterious effect on several West African economies, especially Benin, Burkina Faso, Chad, Mali, and Togo, where cotton production amounts to a significant portion of GDP and a large share of agricultural export earnings. In Mali, for instance, cotton production was 9 percent of GDP and 38 percent of merchandise exports in 2000-01. In Benin it was 5.3 percent of GDP in the same period and fully two-thirds of merchandise exports. ${ }^{90}$ John Baffes estimates that global cotton liberalization would raise the world price by approximately 13 percent over what it would be without reforms. ${ }^{91}$ This would present a clear benefit to West African cotton producers, whose exports under liberalization would also increase by an estimated 13 percent annually. ${ }^{92}$ In welfare terms the West African cotton-exporting countries could enjoy as much as a 1 or 2 percent increase in GDP from cotton trade liberalization. In comparison, their ODA needs are above 20 percent of GNP.

The liberalization story is much more complicated for food commodities, among which sugar and groundnuts are two of the most important products for Africa. These two foodstuffs are subject to very different global trade dynamics. As is well known, sugar is one of the world's most protected industries. In the European Union, long-standing domestic subsidies and quotas have maintained prices for producers at roughly double the world price, resulting in overproduction and limited market access for

89. Figures cited in this paragraph are from Baffes (2004).

90. UNCTAD (2003a).

91. Baffes (2004).

92. Baffes (2004) 
low-cost producers such as Australia and Brazil. High levels of price support are also in effect in the United States and Japan. However, many African countries benefit from the EU Sugar Protocol, a series of bilateral sugar trading agreements that give some developing countries preferential access to sell sugar at the vastly inflated European prices. Beneficiaries include the Republic of Congo, Côte d'Ivoire, Kenya, Madagascar, Malawi, Mauritius, Swaziland, Tanzania, Uganda, Zambia, and Zimbabwe. ${ }^{93}$ The Sugar Protocol arrangement is extremely lucrative to the most successful African exporters, Mauritius and Swaziland, but these are both middle-income countries, and so its benefits are distributed somewhat regressively. ${ }^{94}$ Among low-income countries, the Sugar Protocol yields benefits of roughly $\$ 10$ million a year to Malawi, or a minuscule 90 cents per capita. ${ }^{95}$ The United States also has a quota system in place, but it tends to prefer Latin American sugar producers and so is of less significance for African countries.

Although sugar is one of the few products exempted from the EU Everything But Arms initiative, the European Union is scheduled to start reducing sugar tariffs in July 2006, with full phase-out complete by July 2009. While the precise path of future European sugar market reform is uncertain, it is estimated that full liberalization of industrial country sugar markets would yield a 40 percent increase in the world price. Yet that new price would still be less than the current price available through preferential access, and thus many African sugar producers would not necessarily gain from the world price change. ${ }^{96}$ Moreover, a removal of import quotas in Europe, Japan, and the United States would benefit the low-cost sugar producers such as Australia and Brazil much more than the African producers. All told, the net liberalization effect for African sugar producers is unclear and, if positive, likely to be extremely small. ${ }^{97}$

Groundnut products, meanwhile, follow very different patterns of production and protection. China and India together produce nearly twothirds of the world's groundnuts. Those countries' high levels of domestic consumption and market protection result in very thin international mar-

93. Huan-Niemi and Niemi (2003).

94. Borrell and Pearce (1999).

95. Borrell and Pearce (1999).

96. Mitchell (2004).

97. Borrell and Pearce (1999). 
kets, equivalent to only 5 percent of global production. Among exporters, the major traders are China (32 percent share of total exports), the United States (19 percent), and Argentina (11 percent). Collectively, the groundnut exporters of sub-Saharan Africa-The Gambia, Malawi, Nigeria, Senegal, South Africa, and Sudan - account for only 5 percent of the traded market. ${ }^{98}$ Since the groundnut markets of Argentina, China, India, and the United States are all protected, one might think that full liberalization would create a major opportunity for African producers. However, the results again differ by country. Ndiame Diop, John Beghin, and Mirvat Sewadeh estimate that the African winners would be Senegal, which is slated to gain \$21 million a year, or \$2 per capita (in 1995 dollars), and Nigeria, which would gain $\$ 13$ million a year, or roughly 10 cents per capita. ${ }^{99}$ The Gambia is estimated to gain less than half a million dollars a year, or 35 cents per capita, and Malawi would lose roughly $\$ 1$ million a year, or 9 cents per capita.

Although we discuss only three commodities here, product-by-product assessments are instructive for pinpointing who wins and who loses from specific components of trade policy. The evidence is also important for highlighting that the benefits from liberalization in particular commodities are not necessarily enormous, if indeed they are positive at all. A key question thus hinges on how the benefits of trade liberalization aggregate across products. Elena Ianchovichina, Aaditya Mattoo, and Marcelo Olarreaga focus on the benefits of full access to the "Quad" markets of Canada, the European Union, Japan, and the United States; they estimate that such access would yield a $\$ 2.5$ billion, or 14 percent, increase in nonoil exports and a $\$ 1.8$ billion, or 1.2 percent, welfare enhancement for thirty-seven sub-Saharan African countries (all except Angola, Botswana, Lesotho, Malawi, Mauritius, Mozambique, Namibia, South Africa, Swaziland, Tanzania, Zambia, and Zimbabwe). ${ }^{100}$ Most of these benefits would accrue through improved access to EU markets. Ianchovichina and colleagues also estimate that if, in addition to full Quad access, nonpreferential tariffs were cut by 25 percent across all countries, this would remove more than $\$ 500$ million of the same African countries' benefits. Thus full rich-country access and significant global tariff liberalization

98. Diop, Beghin, and Sewadeh (2004).

99. Diop, Beghin, and Sewadeh (2004, p. 30).

100. Ianchovichina, Mattoo, and Olarreaga (2001). 
would result in less than a 1 percent net welfare increase for most of Africa.

Other researchers have used different modeling assumptions to estimate trade liberalization benefits of a similar order of magnitude. Anderson and others calculate that the countries of the Southern African Customs Union (SACU; Botswana, Lesotho, Namibia, South Africa, and Swaziland) would gain nearly $\$ 1.4$ billion a year from full global trade liberalization, and that the rest of sub-Saharan Africa would gain $\$ 3.2$ billion (both figures in 1995 dollars). ${ }^{101}$ The United Nations Conference on Trade and Development (UNCTAD) meanwhile estimates that comprehensive, across-the-board cuts in agricultural and manufacturing tariffs by 50 percent would entail a terms-of-trade loss to sub-Saharan Africa that would balance the market access benefits, to yield an outcome that is effectively welfare neutral. ${ }^{102}$ Stephen Tokarick estimates the net effects of global agricultural liberalization for SACU members at $\$ 1.8$ billion a year, or 1.3 percent of GDP. ${ }^{103}$ For the rest of sub-Saharan Africa, he estimates the total benefits at $\$ 1.0$ billion, or roughly 0.5 percent of GDP.

This range of estimates underscores a key point. Even if the Doha trade negotiations yielded African countries the most optimistic of estimated outcomes, these countries' benefits would likely not exceed 1 or 2 percent of GDP a year. Although these benefits would be nontrivial in scale and important for long-term economic development, they would be an order of magnitude less than the level of resources required to achieve the MDGs in the poorest countries. They are not a substitute for the sustained increases in ODA needed to fund the public investments described in this paper.

The diversity of commodity-specific, and thereby country-specific, trade scenarios underscores a second crucial point for macroeconomic planning. Just as a local needs assessment approach is necessary to identify the public investments that a country should undertake, so, too, a similar approach must be taken to identify how a country's macroeconomic framework will evolve in step with changes to the global trade system. Some net exporters

101. Anderson and others (2001).

102. UNCTAD (2003b, p. 48). Importantly, UNCTAD distinguishes between the benefits to sub-Saharan Africa of a global reduction in agricultural tariffs, estimated at $\$ 226$ million, and the high costs of a removal of industrial countries' agricultural export subsidies, estimated at $\$ 355$ million (both figures in 1997 dollars).

103. Tokarick (2003). 
might emerge as major winners, while their net food-importing neighbors suffer tremendously. The MDG-based PRS process will need to be developed and constantly updated, within a larger process that systematically anticipates how the poorest countries will be affected by changes in international trade policy. Those countries slated to suffer losses from trade liberalization will need to have their external assistance adjusted upward accordingly.

\section{Regional Integration and Cross-Country Infrastructure}

The small populations of most African countries and the large number of landlocked countries reinforce the need for deepening regional integration and investments in cross-country transport, energy, and communications infrastructure, as promoted by NEPAD. ${ }^{104}$ Not only does sub-Saharan Africa have extremely low per capita densities of rail and road infrastructure, but indeed existing transport systems were largely designed under colonial rule to transport natural resources from the interior to the nearest port. As a result, cross-country transport connections within Africa tend to be extremely poor and are in urgent need of extension, to reduce intraregional transport costs and promote cross-border trade.

Regional cooperation is also needed to develop and consolidate energy supplies. Countries across sub-Saharan Africa need to invest in petroleum refining, storage, and distribution infrastructure, including pipelines to lower transport costs and ensure the continuous availability of fuel throughout the region. Cross-country infrastructure for the transmission of electricity also needs to be improved. ${ }^{105}$ Similarly, a regional backbone of information and communications infrastructure is required.

Regional organizations like NEPAD and the African Union will be critical for the management of the regional "hardware" listed above and for the key "software" of international economic integration that is fostered by harmonizing cross-border policies and procedures, including customs policies, macroeconomic policies, and the joint management of major ecosystems such as international watersheds. In light of their importance for ending the poverty trap in Africa, these supranational organizations

104. New Partnership for Africa's Development (2004).

105. U.S. Department of Energy, Energy Information Administration (1999). 
will need increased direct funding from donors in addition to the support required for individual countries.

\section{Investing in Global Public Goods}

In addition to aid and trade, many of Africa's challenges in agriculture, health, the environment, and access to energy services will require breakthroughs in science and technology. Examples of promising technologies that could help Africa achieve the MDGs include new vaccines or treatments for malaria and HIV/AIDS, improved agricultural varieties and cropping systems for rain-fed and drought-prone agriculture, low-cost information and communications technologies, and low-cost water treatment and purification technologies. Private markets in industrial countries are able to produce development-stage and, to a lesser extent, researchstage science, but those in poor countries cannot. Even though these market failures have been understood for some time, the international system has so far not responded adequately. Appropriate solutions could consist of global coordinating mechanisms based on one of the following models: precommitment purchase agreements, ${ }^{106}$ prizes, ${ }^{107}$ public-private partnerships based on contractual terms that would ensure free access to intellectual properties generated through publicly funded research, ${ }^{108}$ and direct financing of research.

Despite several efforts, global research into areas critical to African development remains woefully underfunded. For example, the annual operating budget of $\$ 400$ million for the worldwide network of sixteen tropical agricultural research centers known as the Consultative Group on International Agricultural Research (CGIAR) is minuscule compared with the research and development (R\&D) budgets of the world's six largest agrobiotech companies, estimated at roughly $\$ 3$ billion a year. ${ }^{109}$ The budget of the CGIAR system as well as of the national agricultural research centers remains low despite considerable evidence of the high social rates of return from $R \& D$ in tropical food production.

106. Kremer (2002).

107. Masters (forthcoming).

108. Several of these partnerships have been developed by private foundations, such as the Rockefeller and Gates Foundations.

109. Robert Evenson, Department of Economics, Yale University, personal communication with the authors, 2004. 
Similarly, R\&D into tropical diseases amounts to only 10 percent of global health-related R\&D spending, even though such diseases account for 90 percent of the global disease burden. ${ }^{110}$ As a result, the World Health Organization's Commission on Macroeconomics and Health (CMH) recommends that annual funding for R\&D into global public goods in health (for malaria, AIDS, tuberculosis, and nutrition, among other priorities) be increased by $\$ 3$ billion by 2007 and $\$ 4$ billion by $2015 .{ }^{111}$ The situation is similar in other areas that are critical to the needs of poor people. Low-cost sanitation technologies that are adapted to local cultural preferences, ability to pay, and environmental constraints are notoriously underresearched across the developing world.

Global science is also vitally needed to address the regional consequences and risks for Africa of long-term climate change caused mainly by rich countries' emissions of greenhouse gases. Climate change is likely to lead to a reduction in potential crop yields in most tropical and sub-tropical regions of Africa, worsening food security and raising Africa's total need for assistance. ${ }^{112}$ A concerted global effort is required to improve countries' ability to mitigate and adapt to climate change through additional investments in critical global public goods, such as improved climate modeling and forecasting tools. These can help predict changes in precipitation patterns so as to improve the management of reservoirs and help African farmers adapt their cropping and irrigation techniques accordingly.

Because African science remains severely underdeveloped, the global science community-led by national research laboratories, universities, and national academies of science-needs to play a critical role in developing the public goods required to overcome these constraints. In addition to supporting R\&D institutions within African countries, international donors and foundations need to increase funding to focus existing global science institutions on the unique challenges of Africa. A very rough back-of-the-envelope estimate of the total global cost of these public goods is likely to reach at least $\$ 6.5$ billion a year. Of this, perhaps $\$ 4$ billion would be directed toward public health; ${ }^{113}$ another $\$ 1$ billion to agriculture, through a tripling of the current budget of the CGIAR;

110. Global Forum for Health Research (2002).

111. CMH (2001).

112. Intergovernmental Panel on Climate Change (2001).

113. CMH (2001). 
roughly another $\$ 1$ billion toward research into energy technologies for Africa (such as geothermal energy in East Africa and off-grid electricity sources for rural Africa); and perhaps $\$ 500$ million for improved understanding of year-to-year, seasonal, and long-term climate change in Africa.

\section{Implications for Global Development Assistance}

Planning, investing, and coordinating efforts to achieve the MDGs in African countries stuck in poverty traps amounts to an undoubtedly ambitious agenda. Yet we have argued that only an effort of such scale can enable countries in tropical sub-Saharan Africa to escape the poverty trap, and we have outlined that such an effort is feasible. The set of known and effective interventions that can be successfully deployed at the necessary scale suggests that, in most areas, technology is not the limiting factor. Instead, shortsighted and poorly coordinated institutional mandates of the world's development agencies are currently a limiting factor, but these can be realigned and better coordinated fairly quickly through more-focused policies and increased multilateral financing.

The current level of ODA is surely a limiting factor for achieving the MDGs in the well-governed African countries. It is not only necessary but also possible to remove this constraint. We have found that well-governed African countries need an additional $\$ 40$ or so per capita per year in development assistance. If we supposed that 620 million Africans were to receive that amount, it would add about $\$ 25$ billion a year to the roughly $\$ 18$ billion a year provided in 2002, or more than a doubling of aid flows to the continent. That total amounts to less than 0.2 percent of the rich countries' combined GNP. Of course, if the increment were limited only to well-governed countries, the overall increase would be significantly less, perhaps a bit more than half of the $\$ 25$ billion a year, depending on where the donors draw the line.

Calculating the global increase in ODA needed for all countries to meet the MDGs is of course even trickier, and we have not tried to do that, either for this paper or for the UN Millennium Project to date. Still, we can make a few observations. Perhaps 30 percent of the world's poorest people live in Africa. If one estimates that Africa requires around 50 percent of the world's incremental donor needs, the $\$ 25$ billion or so increase 
in assistance for Africa might signify an increase of perhaps $\$ 50$ billion globally for the MDGs, which in turn would signify roughly a doubling of worldwide development assistance, from around $\$ 60$ billion a year at current rates to perhaps $\$ 110$ billion a year. Again, these dollar figures are likely to be underestimates because of the big-ticket items not costed, dollar depreciation, the assumption of optimal intervention packages, and the ongoing need for aid not directly geared toward the MDGs. Moreover, we would add investments in a variety of global public goods, including increased funding for specialized international agencies, such as the World Health Organization, that have had their core budgets frozen for a decade or more, and for increased spending on science and technology needed for the poorest countries. The total global need might be an additional $\$ 75$ billion in ODA each year.

The order of magnitude for these indicative estimates conforms well with those reported by other recent studies. The UN High-Level Panel on Financing for Development, chaired by former president of Mexico Ernesto Zedillo, similarly estimated that at least $\$ 50$ billion in extra annual ODA would be required to achieve the MDGs. The U.K. government has also recently called for "doubling aid to halve poverty." Our rough estimates suggest that a somewhat larger amount might be needed, but still within the same general range.

The bottom line, however, is how small even these "large" numbers really are. Adding to the many promises of the rich world before and since, the 2002 Monterrey Consensus includes a commitment of the world's industrial countries "to make concrete efforts towards the target of 0.7 per cent of gross national product (GNP) as ODA to developing countries. ..." (pp. 9-10). With a combined GNP of around \$27 trillion, the donor countries of the OECD have in effect committed to donor flows on the order of $\$ 190$ billion, compared with actual flows of roughly $\$ 60$ billion, or around 0.2 percent of GNP. Even an additional $\$ 75$ billion a year would put the donor countries' assistance at around $\$ 135$ billion a year, or 0.5 percent of their current GNP, far below their own commitment. If one includes additional ODA for development assistance above and beyond the increment needed for the MDGs, for instance to middle-income countries, total global ODA needs are still likely to be less than or equal to 0.7 percent of donor GNP.

To close where we began, however, large-scale aid is not sufficient for ending the poverty trap, nor is it even warranted where domestic gover- 
nance is poor. We are advocating large-scale help only for those countries that can help themselves. We do not seek to pick ODA numbers out of the air, but instead argue for true needs assessments on a country-bycountry basis. We believe that the situation in much of Africa is sufficiently desperate, and that the potential benefits of increased donor-financed investment are sufficiently high, that the world community should start immediately in partnership with well-governed African countries to help them to escape their poverty trap once and for all.

APPENDIX A

\section{Recommended Intervention Packages and Their Components*}

\section{Area 1: Agricultural Productivity and Rural Infrastructure}

\section{Farm Production}

INCREASING AGRICULTURAL PRODUCTIVITY

Investments in soil health: Application of chemical fertilizers, agroforestry (use of trees to replenish soil nutrients), green manure, and/or cover crops in combination, as appropriate, depending on soil characteristics

Improved inputs*: Application of improved seeds, livestock feed, and implements (such as plows)

Small-scale water management: Application of water management techniques and structures, pumps, drip irrigation, wells, etc., as appropriate

Extension services and agricultural research: Provision of comprehensive extension services, combining technical support, farmer participation, and investment in agricultural research

Special interventions to reach women farmers: Recruitment and training of women extension workers, provision of inputs (seeds, fertilizers, implements) targeted to reach women on an equitable basis with men

LINKING FARMERS TO MARKETS

Storage, marketing, and agroprocessing facilities*: Construction of warehouses to reduce postharvest losses; construction of market spaces; provision of training and equipment to encourage small-scale agroprocessing industries in rural areas

*From UN Millennium Project (2004). Interventions marked by asterisks are not yet quantified in the needs assessment. 
Access to credit*: Extension of the formal banking system and/or provision of microcredit services to enable farmers to access credit

\section{Rural Transport Infrastructure}

ROADS

District roads: Upgrading, construction, and maintenance of paved secondary or district roads

Feeder and community roads: Upgrading, construction, and maintenance of small paved roads connecting villages and farmers to the nearest district road

Footpaths*: Extension and improvement of footpaths connecting individual rural farmers to feeder roads

\section{Rural Energy Services}

THERMAL ENERGY SYSTEMS

Improved stoves: Distribution and maintenance or replacement of appropriate cooking stoves (ceramic stoves, liquid petroleum gas [LPG] stoves, ethanol stoves, charcoal, etc.)

Improved fuel inputs: Production and distribution system for appropriate improved fuels (LPG, ethanol, dimethylsulfoxide [DMSO], kerosene, etc.) including safe containers, depending on specific fuel mix available in the country

\section{ELECTRICITY}

Electric power generation capacity: Extension, upgrading, and maintenance of capacity (thermal energy plants, hydropower, or geothermal power, as appropriate) to supply electricity grids

Electric power grid: Extension of grid through high-voltage lines, medium- to low-voltage lines (including end-user connections), and other related infrastructure (such as transformer stations)

Off-grid electric power systems: Provision of diesel generators, hybrid systems, or solar home systems together with necessary wiring to remote rural communities

\section{Access to Water and Sanitation and Water Management Infrastructure}

WATER

Water supply infrastructure: Provision and operation of infrastructure for water supply (such as standpipes, boreholes, dug wells, and rainwater harvesting) 
Sachs, McArthur, Schmidt-Traub, Kruk, Bahadur, Faye, and McCord 189

Water storage and other infrastructure for water management*: Construction and operation of water storage infrastructure for drinking water supply, agricultural water use, and hydropower; extension of large-scale water harvesting

Integrated water resources management $*$ : Protection and allocation of water resources to agricultural, domestic, and industrial uses, as well as environmental needs ("green water") based on comprehensive assessment of renewable and nonrenewable water resources

Hydrological monitoring *: Operation and extension of hydrological monitoring systems

\section{SANITATION}

Sanitation infrastructure: Construction and operation of toilets (simple pit latrines, ventilated improved pit latrines, septic tanks, flush toilets, etc.), including emptying of pits and safe disposal of sullage

Awareness building: Targeted awareness building measures accompanying the provision of new sanitation infrastructure to ensure the choice of the adequate technology option and proper use by all household members

Hygiene

Hygiene education: Awareness campaigns (in primary schools, through community-based organizations, media, etc.) to promote hygienic behavior, with particular focus on hand washing and personal hygiene, as well as appropriate use of sanitation facilities and safe water storage.

\section{Environmental Sustainability}

NATURAL Resource MANAGEMENT

Prevention of desertification*: For example, improving land husbandry through soil erosion control and soil fertility improvement

Forest management*: For example, implementation of sustainedyield forest management techniques; forest plantation to satisfy demand for forestry products; tree seedlings and other measures to support afforestation

Watershed management*: For example, promotion of afforestation to protect selected water catchment areas

Management of coastal ecosystems and fisheries*: To be specified in each country

Other protected areas*: To be specified in each country

Environmental monitoring systems*: To be specified in each country 


\section{Area 2: Health, Nutrition, and Family Planning}

\section{Child health}

Neonatal integrated package: Clean delivery, newborn resuscitation, prevention of hypothermia, kangaroo care (skin-to-skin contact), antibiotics for infection, maternal tetanus toxoid, breastfeeding education, hygiene education

Immunization: Vaccines for polio, diphtheria, pertussis, tetanus, measles, hepatitis B, Haemophilus influenzae type b, and yellow fever

Integrated management of childhood illness (IMCI): Integrated approach to child health that focuses on the well-being of the whole child to reduce mortality, illness, and disability and to promote improved growth and development among children under five years of age; includes both preventive and curative elements to address leading causes of child mortality such as diarrheal disease, acute respiratory infection, measles, malaria, and malnutrition

\section{MATERnAL HEALTH}

Antenatal care: Routine care during pregnancy, including preventive and curative interventions such as blood pressure and weight monitoring, treatment of infections, nutrition and smoking counseling, intermittent preventive treatment for malaria, and antiretrovirals for HIV-positive women

Skilled attendance and clean delivery: Presence of trained and registered midwives, nurses, nurse-midwives, or doctors at birth with ability to diagnose and refer emergent complications

Emergency obstetric care: Rapidly accessible treatment for delivery complications such as eclampsia, hemorrhage, obstructed labor, and sepsis

Safe abortion: Access to abortion counseling, safe abortion services, and postabortion care

\section{HIV/AIDS: PREVENTION}

Behavior change programs: Programs to encourage safer sexual behavior including condom social marketing, peer-based education, mass media campaigns, and school-based AIDS education

Control of sexually transmitted diseases: Routine screening and effective treatment of sexually transmitted diseases (such as syphilis, gonorrhea, and chlamydia)

Voluntary counseling and testing: Pre- and posttest counseling and HIV testing 
Harm reduction for injecting drug users: Actions to prevent transmission of HIV and other infections that occur through sharing of nonsterile injection equipment and drug preparations; specific programs include provision of sterile syringes and needles and drug substitution treatment

Prevention of mother-to-child transmission: Prevention of transmission of HIV from infected women to their infants during pregnancy, labor, and delivery as well as during breastfeeding; includes short-term antiretroviral prophylactic treatment, infant feeding counseling and support, and use of safer infant feeding methods

Blood safety interventions: Measures to reduce risk of receiving infected blood through a transfusion, including HIV antibody screening, protocols to avoid unnecessary blood transfusions, ${ }^{*}$ and policies to exclude high-risk donors*

HIV/AIDS: CARE AND TREATMENT

Antiretroviral therapy: Combination drug therapy to treat HIV infection

Treatment of opportunistic infections: Treatment of any infection caused by a microorganism that would not normally cause disease in the individual but occurs in persons with abnormally functioning immune systems (such as AIDS patients)

Orphan support: Provision of support to orphans to minimize the impact of AIDS on their lives; includes school fee support, provision of orphanages, and community support

\section{TUBERCULOSIS}

$B C G$ vaccine: Vaccine using Calmette-Guérin bacillus for tuberculosis

Directly Observed Treatment-Short-Course: Internationally recommended tuberculosis control strategy combining five elements: political commitment, microscopy services, drug supplies, surveillance and monitoring systems, and use of highly efficacious regimes with direct observation of treatment

\section{Malaria}

Insecticide-treated nets and curtains: Mosquito nets that are treated with insecticide, providing a physical and chemical barrier to mosquitoes and shortening the mosquito's life span

Artemisinin combination treatment: Combination of drugs used to treat first-line-drug-resistant falciparum malaria, which is now widespread in Africa 


\section{Nutrition and Emergency Food Assistance}

\section{NUTRITION}

Nutrition for infants: Complementary feeding (food additional to breast milk) for infants aged seven to twenty-four months

Nutrition for children attending school: Provision of school meals with locally produced foods

Nutrition for women in reproductive age group: Introduction of community-based programs to provide micronutrient supplementation for adolescent girls and women of childbearing age

Food fortification: Introduction of fortification for the entire population (adding micronutrients to foods, for example by using iodized salt)

EMERGENCY FOOD ASSISTANCE

Direct assistance in food-scarce areas: Food-for-work programs and/ or direct food aid

\section{FAMILY PLANNING}

Counseling on contraception and family spacing: Information and education on benefits and methods of family planning

Provision of modern contraceptive methods: Program to ensure universal access to modern contraceptive methods including sterilization (male or female), intrauterine devices, long-acting hormonal methods (injectable and implant), birth control pills, condoms, vaginal barrier methods, and spermicides

\section{Area 3: Education}

\section{PRIMARY EDUCATION}

School infrastructure: Provision of schools, including classrooms, toilets (especially girls' toilets), furniture, and transportation facilities

Teachers: Recruitment of teachers, especially female teachers, with provision of incentives (such as housing in rural areas where applicable and adequate salaries) and ensuring preservice and regular in-service training

Learning materials: Provision of textbooks and other learning materials such as stationery

Curriculum reform: Implementation of curriculum reform, where necessary, to improve education content*

Demand-side incentives: Provision of uniforms, school meals (and/or take-home food rations where needed), special targeted subsidies to girls 
and other vulnerable populations (such as certain ethnic groups), and conditional cash transfers to parents (if appropriate) to reduce the opportunity cost of children attending school and increase attendance

\title{
SECONDARY EDUCATION
}

School infrastructure: Provision of schools, including classrooms, toilets (especially girls' toilets), furniture, transportation facilities, and other facilities such as libraries, laboratories, and sports facilities

Teachers: Recruitment of teachers, especially female teachers, with provision of incentives (such as housing in rural areas where applicable and adequate salaries) and ensuring adequate preservice and in-service training

Learning materials: Provision of adequate textbooks and other learning materials such as stationery

Curriculum reform*: Implementation of curriculum reform, where necessary, to improve education content, with a focus on vocational and nonformal training as necessary to prepare students for transition to work

Demand-side incentives: Provision of uniforms, school meals (and/or take-home food rations where needed), special targeted subsidies to girls and other vulnerable populations (such as certain ethnic groups), and conditional cash transfers to parents (if appropriate) to reduce the opportunity cost of children attending school and increase attendance

\section{Adult Literacy}

Adult literacy programs: Implementation of adult literacy programs through trainers and volunteers and accompanied by mass media campaigns to increase awareness of the importance of literacy

\section{HARD-TO-REACH CHILDREN}

Special packages for hard-to-reach populations*: Examples include introduction of distance education and emergency schooling in conflict areas

\section{Area 4: Slum Upgrading and Urban Management}

\section{Urban Infrastructure and Slum Upgrading}

\author{
SLUM UPGRADING
}

Shelter*: Upgrading and construction of houses 
Urban infrastructure*: Upgrading and extension of roads and sidewalks, street lighting, storm drainage, and communications infrastructure within slums

TENuRE

Security of tenure*: Improving the security of tenure through noneviction legislation, legitimized occupancy, or formal title

Enforcement of improved land tenure legislation*: Legal protection and enforcement of slum dwellers' rights

Citywide URBAN PLANNING AND MANAGEMENT

Urban infrastructure*: Planning of urban infrastructure (roads, footpaths, sidewalks, street lighting, stormwater drainage, bus lanes, and other transport infrastructure)

Basic services*: Provision of basic services (such as refuse collection and solid waste disposal, policing and security, and fire protection)

Pollution control*: Controlling pollution of air and water

Transport system*: Operation of bus, rail, and other mass transport systems

\section{Urban Transport Infrastructure}

ROADS

Urban roads: Upgrading, construction, and maintenance of urban roads Infrastructure for mass transport systems*: For example, bus lanes

Footpaths*: Extension and improvement of footpaths within cities

\section{Urban Energy Services}

THERMAL ENERGY SYSTEMS

Improved stoves: Distribution and maintenance or replacement of appropriate cooking stoves (ceramic stoves, LPG stoves, ethanol stoves, charcoal, etc.)

Improved fuel inputs: Production and distribution system for appropriate improved fuels (LPG, ethanol, DMSO, kerosene, etc.), including safe containers, depending on specific fuel mix available in the country

\section{ELECTRICITY}

Electric power generation capacity: Extension, upgrading, and maintenance of electric power generation capacity (thermal energy plants, hydropower, or geothermal power, as appropriate) to supply electric power grids 
Sachs, McArthur, Schmidt-Traub, Kruk, Bahadur, Faye, and McCord 195

Electric power grid: Extension of grid through high-voltage lines, medium- to low-voltage lines (including end-user connections), and other related infrastructure (such as transformer stations)

\section{Urban Water Supply and Sanitation}

WATER

Water supply infrastructure: Provision and operation of infrastructure for water supply (for example, household connections, standpipes, boreholes, and rainwater harvesting)

Hydrological monitoring*: Operation and extension of hydrological monitoring systems

\section{SANitation}

Sanitation infrastructure: Construction and operation of toilets (simple pit latrines, ventilated improved pit latrines, septic tanks, flush toilets, etc.) and sewers, including emptying of pits and safe disposal of sullage

Sewage treatment: Construction and operation of simple sewage and other wastewater treatment facilities (such as waste stabilization ponds or other forms of primary treatment) where needed in dense urban settlements or because of specific environmental concerns (such as eutrophication of freshwater lakes)

Awareness building: Targeted awareness building measures accompanying the provision of new sanitation infrastructure to ensure the choice of the adequate technology option and proper use by all household members

\section{HyGIENE}

Hygiene education: Awareness campaigns (in primary schools, through community-based organization, media, etc.) to promote hygienic behavior, with particular focus on hand washing and personal hygiene, as well as appropriate use of sanitation facilities and safe water storage

\section{Urban Environmental Management}

POLLUTION CONTROL

Air pollution control*: To be specified in each country

Water pollution control*: For example, industrial wastewater treatment to complement sewage treatment, as necessary

Solid waste and soil pollution control*: Construction and maintenance of technically sound landfills 


\section{Urban Industrial Development}

PRIVATE SECTOR DEVELOPMENT

Export processing zones ${ }^{*}$ : Provision of export processing zones, industrial parks, and other designated areas for private sector development

Industrial promotion activities*: Supportive policies, including tax concessions and grants, as well as provision of additional infrastructure for development of manufacturing and service industries

\section{Area 5: Science, Technology, and Innovation}

\section{SCIENCE AND TECHNOLOGY INSTITUTIONS}

Science and technology advice*: Creation of independent body charged with providing scientific advice and technology forecasting to policymakers

Higher education*: Extension and maintenance of higher education system, with a particular focus on science and engineering education

Science and technology research*: Extension and maintenance of centers of excellence for scientific research, including the financing of research at universities and the establishment of science parks

INFORMATION AND COMMUNICATIONS TECHNOLOGIES

Telecommunications infrastructure*: Provision of telecommunications infrastructure, including international and trunk fiber infrastructure; provision of connectivity to hospitals and schools

\section{Area 6: Gender Equality}

\section{REPRODUCTIVE HEALTH RIGHTS AND SERVICES}

Awareness of and access to reproductive health rights and services: Legislation and awareness campaigns to decriminalize and enable safe access to abortions, to protect the rights of women to plan their families, to enable access to safe contraceptives, and to discourage female genital mutilation and other harmful practices

ACCESS TO PROPERTY RIGHTS AND WORK

Equal access to and treatment in work: Provision and enforcement of equal opportunity legislation,* legislation promoting gender-sensitive policies such as provision of maternity and dependent care leave and training, ${ }^{*}$ and support programs for women entrepreneurs and young girls training to transition to work 
Equal access to property rights*: Legislation and administrative support to provide and protect women's equal rights to property and other inherited and acquired assets

\section{SECURITY}

Security for girls and women from violence: Legislation and administrative actions to protect women against violence, promotion of awareness of women's right to seek redress, protection from perpetrators of violence (through access to shelters, services, etc.), and mechanisms to dispense justice to perpetrators

\section{PARTICIPATION AND INSTITUTIONAL REFORM}

Political representation*: Mechanisms (such as quotas and reservations) to allow for adequate representation at all levels of government along with adequate training

Involvement of women's groups at the village level*: Recognition of and support to women's groups organized at the village level to encourage women to be partners in the design and delivery of public services

National women's machineries (NWMs)*: Legislative and financial support to NWMs (defined by the United Nations as "a single body or complex organized system of bodies, often under different authorities, but recognized by the government as the institution dealing with the promotion of the status of women")

DATA COLLECTION AND MONITORING

Gender-disaggregated data*: Collection of gender-disaggregated statistics on health, education outcomes, access to assets and infrastructure, conditions of work and employment, political representation, and genderspecific violence

\section{Area 7: Cross-National Infrastructure, Trade Integration, and Government Cooperation}

\section{Transport Infrastructure}

RoADS

National highways and international transport corridors: Upgrading, construction, and maintenance of paved highways for bulk transport

RAILROADS

Railroad infrastructure*: Extension, upgrading, and maintenance of railroads, including rolling stock 
PorTs

Port infrastructure* : Construction and modernization of container port facilities; dredging and other maintenance of ports

Integration of transport systems*: Construction and maintenance of railroad and truck terminals for containerized freight

\section{Energy Infrastructure}

THERMAL ENERGY SYSTEMS

Petroleum refining and storage*: As appropriate, rehabilitation and extension of petroleum refining, pipeline, and storage systems

Gas and oil pipelines*: Construction and maintenance of regional pipelines to improve supply of fossil fuels (examples include the West African Gas Pipeline and the Kenya-Uganda oil pipeline)

\section{ELECTRICITY}

Geothermal electric power plants*: Construction of geothermal electric power plants in East Africa and parts of southern Africa

Regional electricity pool*: Extension of international electric power grid through international high-voltage lines and pooling of electricity grids to reduce peak generating capacity need

\section{Trade Integration and Government Cooperation}

TRADE

Trade liberalization and harmonization*: Opening of markets for trade and finance, harmonization of standards, and facilitation of customs procedures

\section{GOVERNMENT COOPERATION}

Supranational institutions for regional public goods*: Establishment of regional institutions and strengthening of regional cooperation on migration, finance, monetary policies, watershed management, energy policy, and other areas 
Sachs, McArthur, Schmidt-Traub, Kruk, Bahadur, Faye, and McCord 199

APPENDIX B

Critical Intervention Areas for MDG Targets and Their Effects*

\section{Income Poverty (MDG 1, target 1)}

Agriculture

-Increasing agricultural productivity directly raises the incomes of the rural poor.

\section{Nutrition}

- Better nutrition contributes to human capital accumulation and improved labor productivity.

\section{Education}

-Education increases human capital.

-Education is linked to lower fertility rates, which in turn are linked to increases in economic growth per capita.

\section{Gender Equality}

- Awareness of and access to reproductive health rights and services enable and empower women to plan their families, leading to lower fertility rates and reduced poverty.

-Empowerment through access to work, property rights, political representation, and safety from violence leads to increased participation of women in economic activity.

\section{Health}

-Improved health has pervasive direct and indirect effects on raising both the level and the growth rate of income.

\section{Environment}

- Many poor people depend on natural resources for their livelihoods. Improving natural resource management can sustain or even raise their incomes. 


\section{Water and Sanitation}

- Improved water supply for productive activities can raise economic growth through agriculture and the urban manufacturing and service sectors.

\section{Slum Upgrading and Urban Planning}

-Providing security of tenure can improve labor market participation and access to credit markets.

-Urban infrastructure, including transport systems, is necessary for establishing manufacturing and service industries.

Science and Technology

- Science and technology institutions improve technological learning in society and improve the adoption of technology by the private sector.

-Higher education can open new employment opportunities.

\section{Energy}

-Access to electric power and improved thermal energy systems is necessary for manufacturing, service, or cottage industries.

\section{Transport}

- Roads, railroads, and ports lower transport costs and thereby increase the real incomes of the poor.

-In urban areas improved transport infrastructure supports manufacturing and service industries, contributing to employment.

\section{Hunger (MDG 1, target 2)}

\section{Agriculture}

-Increasing agricultural productivity through investments in soil health, water management, extension services, and improving food storage infrastructure increases food availability for subsistence farmers.

\section{Nutrition}

-Nutrition interventions are needed for vulnerable populations and to address micronutrient deficiencies.

-Direct food assistance in food-scarce areas alleviates short-term hunger. 


\section{Education}

- Literacy contributes to better management of nutritional needs and farm production.

\section{Gender Equality}

- Land rights allow women to increase agricultural production.

-Increased access to work and higher incomes enable women to purchase adequate food for themselves and their families.

-Equal access to productive inputs increases plot yields.

\section{Health}

—Reducing parasitic and infectious disease burden improves nutrition.

\section{Environment}

-Improved water resource management and protection of water catchment areas can raise crop yields.

-Biodiversity protection sustains pollination and seed dispersal mechanisms necessary for agricultural production.

\section{Water and Sanitation}

- Safe drinking water reduces the incidence of water-borne diseases, which cause malnourishment.

-Drinking water supplied through wells and boreholes can help irrigate fields during unforeseen droughts.

-Access to sanitation reduces the incidence of diarrheal disease and thereby increases nutrient uptake.

- Integrated water resources management sustains adequate water supply for agriculture.

-Water storage and water management infrastructure improve water management for agriculture.

\section{Slum Upgrading and Urban Planning}

- Slum upgrading and accompanying interventions help raise incomes and reduce urban hunger.

-Improved transport infrastructure lowers the cost of food products, further reducing hunger. 
Science and Technology

- Increased agricultural research is critical for improving seed varieties, cropping systems, pest control, and water management, to increase agricultural productivity, thus reducing hunger.

-Increased access to higher education can help increase the number of agricultural extension workers.

-ICT improves farmers' market information, raising agricultural production.

\section{Energy}

- Improved access to electricity and liquid fuels can power diesel pumps for irrigation, facilitate mechanization, and power agroprocessing machinery, thus increasing agricultural output and reducing hunger.

-Improved energy services lower transportation and marketing costs, which reduces food prices.

-Access to improved cooking fuels is necessary to ensure safe cooking of food.

\section{Transport}

- Footpaths and feeder, district, and national roads lower the cost of agricultural inputs, increase farmgate prices, and facilitate marketing, which can increase agricultural production.

-Improved transport infrastructure reduces postharvest losses through accelerated transport of products to markets.

\section{Primary Education (MDG 2, target 3)}

\section{Education Interventions}

- Increase access to improved primary and secondary schools as well as adult literacy programs through provision of infrastructure; hiring, improved remuneration, and training of teachers; provision of learning materials; curriculum reform; and demand-side interventions to retain children in school.

\section{Agriculture}

-Agricultural interventions to improve soils, seeds, and water management raise rural incomes and reduce the time young children spend in the field, freeing them to attend school. 
Sachs, McArthur, Schmidt-Traub, Kruk, Bahadur, Faye, and McCord 203

\section{Nutrition}

- Nutrition interventions for infants improve cognitive development and improve learning outcomes in the future.

\section{Gender Equality}

- Maternal education contributes strongly to higher primary enrollment.

\section{Health}

- Improved health enhances educational outcomes by improving cognitive abilities and attendance rates.

-AIDS prevention and treatment reduce the disease's impact on teacher attendance and attrition.

-AIDS prevention and treatment reduce the number of orphans, who are less likely to complete primary education.

\section{Environment}

- Improved natural resource management can free up children's time and increase school attendance.

\section{Water and Sanitation}

- Improved access to water frees up children's time, thus allowing them to attend school.

-Improved health through sanitation and hygiene reduces school absenteeism.

- Girls' toilets in schools can increase their enrollment and completion rates.

\section{Slum Upgrading and Urban Planning}

- Security of land tenure and a fixed address are often necessary for children to be allowed to attend school.

\section{Science and Technology}

- Higher education is essential to training secondary school teachers and provides additional incentives to complete primary and secondary school.

- ICT infrastructure can improve the quality of education. 
Energy

-Access to electric power and improved cooking fuels lowers time spent by children (especially girls) collecting fuel wood, thus facilitating school attendance.

-Improved access to liquid fuels is necessary to render mechanized school transport more affordable.

-Electrification permits children to read and study longer, thus improving school outcomes.

\section{Transport}

-Improved transport infrastructure and services increase incentives for teachers to work in rural areas.

-Feeder roads and footpaths reduce the time it takes for children to reach school and allow them to travel farther, raising enrollment rates.

- Improved roads and footpaths reduce the time required for households to fetch fuel and water and to carry out other tasks, lowering the opportunity cost of children attending school.

\section{Gender Equality (MDG 3, target 4)}

\section{Direct Interventions}

- Programs to reduce violence against women, improve their property and other rights, ensure full access to reproductive health services and contraception, and improve women's participation in decisionmaking processes.

\section{Agriculture}

-Improved soils, seeds, and water provision can reduce the time girls spend in the field, freeing them to attend school.

-Increased agricultural production increases the incomes of women farmers.

\section{Nutrition}

-Nutrition interventions for girls (infants and children) lead to better health and education outcomes.

\section{Education}

-Education contributes to increased employment opportunities, improved decisionmaking, and empowerment of women more broadly. 
Sachs, McArthur, Schmidt-Traub, Kruk, Bahadur, Faye, and McCord 205

\section{Health}

-Family planning services appear to improve employment opportunities for women, strengthen partner relationships, and provide a greater sense of well-being.

\section{Environment}

-Women benefit disproportionately from improved management of natural resources, including through time savings and reduced transport burden.

\section{Water and Sanitation}

- Improved access to water generates time savings for women and girls.

- Improved access to water reduces the need to carry heavy loads over long distances, thus improving women's health.

-Increasing access to toilets reduces women's exposure to harassment and improves personal hygiene and well-being.

\section{Slum Upgrading and Urban Planning}

-Women benefit disproportionately from slum upgrading, since it reduces their transport burden and time poverty, improves their health, and provides them with additional income generating opportunities.

\section{Energy}

- Improved access to electricity and fuels reduces the time poverty of women and lowers their daily transport burden.

-Improved access to energy creates additional employment opportunities for women.

\section{Transport}

-Improved transport infrastructure reduces women's time poverty and transport burden.

- Roads improve communication and lower transactions costs, thus increasing employment opportunities for women. 


\section{Child Mortality (MDG 4, target 5)}

\section{Health Interventions}

-Provide the neonatal integrated package of interventions, immunization, the integrated management of childhood illness (IMCI), and the range of preventive approaches to public health (such as mass distribution of insecticide-treated bednets).

Agriculture

-Increased rural incomes and food availability lead to improved health outcomes.

\section{Nutrition}

- Nutrition interventions for pregnant women lead to higher birth weight, an important determinant of child survival.

-Micronutrient supplementation and complementary feeding reduce child mortality.

\section{Education}

- Secondary education increases the age of marriage, lowers fertility rates, and increases care seeking for child illnesses.

-Adult literacy programs increase awareness of the causes and prevention of child mortality.

\section{Gender Equality}

-Women's empowerment leads in multiple ways to greater awareness of child health issues.

\section{Environment}

— Reducing pollution of water and air can lower child morbidity and mortality.

\section{Water and Sanitation}

-Access to sanitation and improved hygiene reduce the incidence of waterborne disease.

\section{Slum Upgrading and Urban Planning}

- Slum upgrading, improved urban infrastructure, and access to basic services (including solid waste disposal) can reduce exposure to pollutants and thereby reduce child mortality rates. 
Sachs, McArthur, Schmidt-Traub, Kruk, Bahadur, Faye, and McCord 207

— Road curbing and street lighting can reduce traffic deaths.

Science and Technology

- ICT improves diffusion of hygiene education and thereby lowers child mortality.

-Access to higher education increases the supply of health workers.

\section{Energy}

-Reducing indoor air pollution through improved cooking fuels and stoves decreases respiratory infections.

- Improved access to energy allows households to boil water, thus reducing the incidence of waterborne diseases.

\section{Transport}

-Improved transport infrastructure increases access to health care clinics and services and reduces costs for health care workers serving in rural areas.

\section{Maternal Mortality (MDG 5, target 6)}

\section{Health Interventions}

-Ensure access to emergency obstetrical care, antenatal care, skilled attendance, and clean delivery, as well as safe abortion.

\section{Agriculture}

-Increased rural incomes and food intake lead to improved health outcomes.

\section{Nutrition}

-Nutrition interventions such as iron supplementation for women of reproductive age reduce risk during pregnancy and childbirth.

\section{Education}

- Secondary education increases the age of marriage, contraception use, and access to prenatal care and safe delivery, all of which reduce maternal mortality.

-Adult literacy programs increase awareness of the causes and prevention of maternal mortality. 
Gender Equality

-Women's empowerment leads to greater effective demand for prenatal care and safe delivery.

\section{Water and Sanitation}

- Running water and sanitation facilities are essential for provision of prenatal care and emergency obstetric care.

-Access to sanitation and hygienic behavior improve women's health.

Slum Upgrading and Urban Planning

- Slum upgrading and security of land tenure improve women's access to health systems and emergency obstetric care.

Science and Technology

- ICT is critical for providing adequate access to emergency obstetric care.

-Access to higher education increases the supply of health workers.

\section{Energy}

- Improved access to energy services improves communication and transport, which are critical for emergency obstetric care.

- Modern energy services reduce the costs for health care workers serving in rural areas.

\section{Transport}

-Feeder roads are critical for providing timely access to emergency obstetric care.

- Improved transport infrastructure reduces the costs for health care workers serving in rural areas.

\section{HIV/AIDS (MDG 6, target 7)}

\section{Health Interventions}

-Provide comprehensive HIV/AIDS prevention programs, orphan support, voluntary counseling and testing, harm reduction for drug users, prevention of mother-to-child transmission, antiretroviral treatment, and treatment of opportunistic infections. 
Sachs, McArthur, Schmidt-Traub, Kruk, Bahadur, Faye, and McCord 209

Agriculture

- Increased agricultural incomes improve access to prevention services.

\section{Nutrition}

- Adequate nutrition interventions can improve survival and quality of life of patients with HIV/AIDS.

\section{Education}

-Education and literacy programs increase awareness of ways to prevent and treat HIV/AIDS.

\section{Gender Equality}

-Women's empowerment leads to greater effective demand for HIV/ AIDS prevention and treatment, including the ability to negotiate safe sexual practices.

\section{Water and Sanitation}

- Improving access to clean water and sanitation improves the nutritional status of HIV/AIDS patients.

\section{Slum Upgrading and Urban Planning}

- Slum upgrading and security of land tenure improve access to HIV/ AIDS treatment and prevention.

\section{Science and Technology}

- Scientific research can improve the diagnosis and treatment of HIV/AIDS.

- ICT is critical for media-based HIV/AIDS prevention.

-Access to higher education increases the supply of health workers.

\section{Energy}

-Electricity and modern energy services support functioning health clinics and hospitals.

-Modern energy services increase incentives for health workers to work in rural areas. 


\section{Transport}

-Improved transport infrastructure facilitates treatment and prevention of HIV/AIDS.

-Improved transport infrastructure reduces costs for health workers serving in rural areas.

\section{Malaria and Other Major Diseases (MDG 6, target 8)}

\section{Health Interventions}

- Combine comprehensive use of insecticide-treated bednets, indoorresidual spraying where appropriate, effective malaria treatment (using artemisinin combination therapies where appropriate), and epidemic control measures.

- Contain tuberculosis through promotion of vaccines, Directly Observed Treatment Short-Course (DOTS) protocol, and DOTS-Plus for multi-drug-resistant tuberculosis.

\section{Agriculture}

-An increase in agricultural incomes improves access to and information about ways of preventing and treating malaria.

\section{Education}

-Education and literacy programs increase awareness of ways to prevent and treat malaria and tuberculosis.

\section{Gender Equality}

-Women's empowerment leads to greater effective demand for insecticide-treated nets and malaria and tuberculosis treatment.

\section{Environment}

- In some instances environmental control can contribute to containing malaria.

\section{Water and Sanitation}

- In some instances improved water management in urban areas can contribute toward containing mosquito breeding sites and transmission. 
Sachs, McArthur, Schmidt-Traub, Kruk, Bahadur, Faye, and McCord 211

\section{Slum Upgrading and Urban Planning}

- Improving housing and urban water management infrastructure can reduce the incidence of malaria and especially tuberculosis (which is transmitted in overcrowded slum conditions).

- Slum upgrading improves access to appropriate malaria and tuberculosis treatment.

Science and Technology

- Research is necessary to develop new drugs and diagnostics for malaria and tuberculosis.

-Access to higher education increases the supply of health workers.

\section{Energy}

-Electricity and modern energy services improve health care.

-Modern energy services reduce costs for health care workers serving in rural areas.

\section{Transport}

- Improved transport infrastructure reduces the cost of distributing bednets.

-Improved transport infrastructure increases incentives for health care workers to work in rural areas.

\section{Access to Essential Medicines (MDG 8, target 17)}

\section{Health Interventions}

-Improve supply and distribution systems for essential medicines together with strengthened quality control and quality assurance and programs to promote rational use.

\section{Agriculture}

-An increase in agricultural incomes makes essential medicines more affordable.

\section{Education}

-Education and literacy programs increase access to and appropriate use of essential medicines. 
Gender Equality

-Women's empowerment leads to greater effective demand for essential medicines of good quality.

Science and Technology

- Research increases the total stock and effectiveness of essential medicines.

Transport

- Improved transport infrastructure lowers the cost of essential medicines and improves access.

\section{Reverse Loss of Environmental Resources (MDG 7, target 9)}

\section{Environmental Interventions}

-Improve management of natural resources through market mechanisms, strengthened regulation and enforcement, and investments in the management of critical ecosystems.

\section{Agriculture}

- Investments in soil health replenish soils and prevent further land degradation.

-Intensive agricultural production is an alternative to slash-and-burn and to the deforestation that results.

- Small-scale water management can restore water tables and prevent runoff.

\section{Gender Equality}

-Equal access to property rights allows women, as primary users, to manage natural resources in a sustainable manner.

\section{Health}

-Family planning reduces total fertility rates, thus mitigating population pressures on the environment.

\section{Water and Sanitation}

-Improved sanitation and sewage treatment can reduce environmental pollution. 
Sachs, McArthur, Schmidt-Traub, Kruk, Bahadur, Faye, and McCord 213

-Integrated water resources management can ensure sufficient "green water" necessary for ecosystem functioning.

-Hydrological monitoring systems can help protect aquifers and freshwater ecosystems from excessive withdrawals.

\section{Slum Upgrading and Urban Planning}

- Slum upgrading and improved urban water and waste management infrastructure reduce environmental pollution.

Science and Technology

- Research can improve natural resource management (including management of freshwater ecosystems and wetlands, biodiversity conservation).

\section{Energy}

- Access to modern cooking fuels reduces demand for biomass cooking fuels, thus reducing pressure on marginal lands and forests.

- Improved energy services reduce outdoor air pollution.

- Improved energy services can reduce carbon emissions.

\section{Water and Sanitation (MDG 7, target 10)}

\section{Water and Sanitation Interventions}

-Provide, operate, and maintain water and sanitation infrastructure and services in conjunction with behavior change programs to improve household hygiene.

\section{Agriculture}

- Small-scale water management increases water availability for rural farmers.

\section{Education}

—Education and literacy programs improve hygiene.

\section{Gender Equality}

-Political representation allows women to ensure that access to water is a priority in local decisionmaking. 


\section{Environment}

-Improved management of wetlands, water catchment areas, and freshwater ecosystems is critical for ensuring access to drinking water.

-Control of industrial pollution improves drinking water quality.

\section{Slum Upgrading and Urban Planning}

-Slum upgrading reduces water pollution and improves drinking water quality.

-Improved urban infrastructure ensures the separation of sewage from drinking water supplies.

\section{Science and Technology}

- Research can help improve sanitation and water management techniques.

-Access to higher education increases the supply of trained workers to design and manage water supply and sewer infrastructure.

\section{Energy}

-Electricity and improved access to modern fuels are necessary to power water supply infrastructure and water treatment systems.

\section{Transport}

-Improved transport infrastructure facilitates provision, operation, and maintenance of water supply and sanitation systems.

-Improved transport systems reduce the costs of providing hygiene education through community workers.

\section{Improve Lives of Slum Dwellers (MDG 7, target 11)}

\section{Direct Interventions}

- Scale up slum upgrading programs with the support of improved urban planning and investments in core urban infrastructure as well as basic services.

\section{Agriculture}

-Investing in urban agriculture increases agricultural productivity and the incomes of slum dwellers. 
Sachs, McArthur, Schmidt-Traub, Kruk, Bahadur, Faye, and McCord 215

\section{Nutrition} lations.

-Nutrition interventions improve the health outcomes of urban popu-

\section{Education}

-Education and literacy programs improve the employment prospects of slum dwellers.

\section{Gender Equality}

-Equal access to property rights, political representation, and security for girls and women allows women living in slums to improve their lives and the lives of their families.

\section{Health}

-Access to health services reduces the burden of ill health for slum dwellers.

\section{Environment}

- Improving solid waste disposal and water treatment can improve health outcomes.

\section{Water and Sanitation}

-Improved access to water supply and sanitation services can reduce household expenditure on water.

- Sewage treatment can further improve health outcomes in urban areas.

- Storm water drainage systems are improved through sanitation infrastructure, thus minimizing the risk of flooding.

Science and Technology

- Higher education provides new employment opportunities for the urban poor.

-ICT reduces the cost of income-generating activities.

\section{Energy}

- Improving access to electricity and modern fuels lowers indoor air pollution. 
-Access to electricity and modern fuels can lower household expenditure on energy services, thus raising incomes.

- Improved energy services lower the cost of urban transport.

\section{Transport}

-Improved rural transport infrastructure reduces the cost of food in urban areas, thus increasing real incomes.

-Improved urban transport infrastructure is critical to enhancing income-generating opportunities as well as access to social services.

- Proper sidewalks and curbing are critical to reduce traffic deaths.

\section{Information and Communications Technology (MDG 8, target 18)}

\section{Direct Interventions}

- Strengthen science advisory mechanisms, invest in higher education and research, promote private sector development, and improve access to communications technologies.

\section{Agriculture}

-Increased agricultural incomes improve access to ICT.

\section{Education}

- Secondary education prepares students to provide, use, and manage ICT.

\section{Energy}

-Electricity is necessary to power ICT applications and to operate research institutions. 


\section{Comments and Discussion}

Michael Kremer: This is an interesting and indeed provocative paper, arguing for a large increase in foreign aid to Africa to help the continent escape from a poverty trap. I agree that aid should be increased, but I will take issue with a few of the building blocks in the authors' analysis and will suggest an alternative case for aid. In particular, I will argue that the limited empirical evidence seems just as consistent with conventional growth models, in which government quality and policies determine steady-state income, as with the idea that Africa is caught in a poverty trap. This should not be taken as an argument against aid, however, because there is little evidence for the "new Washington consensus" that aid cannot work in areas with weak governments and that conditionality is a failure. In fact, the case for aid may be greater where governments are doing a poor job. I will conclude by arguing that planning development expenditure around the Millennium Development Goals (MDGs) risks generating distortions.

Poverty trap models suggest that if countries can get over a certain income threshold, they will take off economically. These models therefore suggest that aid can have a powerful effect by raising countries over this threshold. The basic microeconomic case for poverty traps typically involves nonconvexities. However, even if nonconvexities exist at the microeconomic level (for example, lumpy capital investments), it is not clear that they exist at the macroeconomic level. If a certain level of transport and communications infrastructure is needed for development, for example, one could imagine a country starting out by building this level of infrastructure in a single port or capital city and then expanding outward. This might eliminate nonconvexities at the macroeconomic level. 
Setting aside the theoretical issue, the question arises of how one would empirically distinguish a poverty trap model from a conventional model in which government policy determines steady-state income. In this model, countries converge to steady-state income from above or from below, depending on initial income. One can consider both microeconomic and macroeconomic approaches.

There are certainly some people in Africa with money to invest, and in some poverty trap models those people should be able to set up very prosperous enterprises, hire more and more labor, and expand their enterprises rapidly. However, we do not see that happening. In fact, many people with money in Africa move it to Europe or elsewhere rather than take advantage of the potentially huge returns available under poverty trap models to people who can reach a certain scale of investment.

At the macroeconomic level, poverty trap models suggest that African countries that attain a threshold income level should then take off. Again, this does not appear to be the case. In 1998 Gabon's GNP per capita was $\$ 3,870$, but by 2002 its GNP per capita had fallen to $\$ 3,060 .{ }^{1}$ In 1980 Nigeria's GNP per capita was almost $\$ 1,000$, but in 2002 it was only $\$ 300$. Many argue that governments tend to waste oil revenue, but, in a pure poverty trap model, cases such as Nigeria are difficult to explain. Nor is the problem limited to countries with oil: consider the case of Zambia, where GNP per capita was $\$ 680$ in 1981 but $\$ 340$ in 2002. Nor is it limited to minerals in general: Côte d'Ivoire had for a while a relatively high income per capita for Africa, but then the economy collapsed. Zimbabwe had a GDP per capita of over $\$ 1,100$ in 1982 , but it had fallen to $\$ 480$ by 2002 and is presumably below that now. South Africa's income per capita is certainly above the level associated with poverty traps in this paper, but it has not taken off economically. ${ }^{2}$ One relatively well off African country with good economic performance is Botswana, but with strong economic policies, democracy, and ethnic homogeneity, its experience is just as consistent with the story that good government is central as with the poverty trap story.

Under a conventional model, countries experiencing a large negative shock should grow quickly once conditions change for the better, whereas in poverty trap models they will stagnate. In fact, the fastest-growing countries in Africa in recent years have been Uganda and Mozambique,

1. All data cited here are from World Bank (2004a).

2. See, for example, World Bank (2004b). 
both of which suffered major shocks due to war, followed by the establishment of a government with good economic policies. (It is worth noting that aid has played a major role in each case.)

The authors argue that indicators of government quality in Africa are no worse than expected given income levels. The authors perform a service here by challenging stereotypes that many people have about Africa. For example, many seem to feel that Africa is uniquely mired in tribal violence. Yet when one compares the body count in Africa with that of Europe during the twentieth century, it is hard to make the case that Africans are more subject to ethnic strife than Europeans.

However, I do not think that one can argue from the authors' regression results that government policy is not fairly fundamental to Africa's problems. First, it is not clear that traditional measures are well suited to measuring the problems of government in Africa. For example, these measures are not designed to pick up the absence of government. Somalia does not have a central government, and even stable countries like Uganda or Kenya have areas where the government provides little security. Another issue is that respondents in corruption surveys may be giving judgments relative to expectations, and they may have low expectations for Africa.

More fundamentally, even if African countries do not have worse governments than would be expected given their income level, this does not imply that government quality does not determine income. In a model in which government quality determines income, African governments should be no worse than expected, given their income. If other factors (for example, geography) also contribute to African poverty, one would expect that African governments would look good relative to their income. Thus the authors' regression results are consistent with a model in which government quality and economic policies are the primary determinants of income, with other factors, such as the geographic factors that Sachs has discussed in previous work, also playing a role.

Although I find it quite plausible that Africa's poverty is due as much to poor economic policy and bad government as to a poverty trap, I support the paper's call for large increases in aid. I do so largely because I reject the current consensus in the development policy community that aid will only be effective if it is given to good governments and that conditionality has failed. The empirical evidence for both these propositions is weak. 
Theoretically, one could imagine that aid directed at countries with "bad" governments would be much more effective. Consider, for example, a government that is neither vaccinating children nor adequately financing primary education, but rather is spending all of its resources on palaces. The fact that kids are not being vaccinated or sent to primary school implies that high-value investments are available in the country for potential donors. There are certainly incentive issues in giving large amounts of aid to bad governments, but aid need not be given to governments. Donors could provide aid to whatever institutions in the country are educating children, whether they be private schools or nonprofit organizations. Such an arrangement may well strengthen alternative power bases and even help promote reform.

It is also unclear to me why we have given up on conditionality. The classic poster child for the failures of conditionality was supposed to be Kenya. Many observers, including the Economist, have retold the story of how President Daniel arap Moi took advantage of soft-hearted or weak willed donors at the IMF and the World Bank: Moi promises to reform, donors give him money, Moi reneges on his promises; Moi later makes another set of promises, gets more money from the donors, and reneges again, in cycle after cycle.

Arguably, this story has things exactly backward. Conditionality did induce Moi to make both economic and political changes, including freeing the exchange rate, expanding scope for freedom of speech and creation of political parties, and instituting term limits. As a direct result of these changes, term limits in particular, Moi is out of office now, and Kenya is a reasonably well functioning democracy. The idea that conditionality is never effective and that governments always manipulate donors is hard to reconcile with the idea that conditionality can actually force a leader like Moi out of office. Nor is such an outcome at all unique to Kenya. There has been political reform across Africa, in large part as a reaction to pressure from donors.

At the same time, we should admit that we do not know very much about what will produce growth in Africa or when that will happen. In my view, although the case that economic policy—and, ultimately, government quality-influence income is supported by somewhat more evidence than the poverty trap view, we know very little about what does produce economic growth, and even less about how aid can play a major role in stimulating economy-wide growth. 
At the microeconomic level, however, I think much more is known. The case for aid should be based not on the view that small amounts of aid delivered the right way will somehow magically deliver rapid, economywide growth, but rather on the extremely pressing human needs in the region and the fact that amounts of aid that are extremely small by developed country standards can have a huge impact on whether families have clean water, whether children get vaccinated, whether people have roads to get their products to market, and so forth.

Donors should fund interventions that work. The paper lists a number of these. In the areas where we are not sure what works, donors should try multiple approaches, rigorously evaluate them using randomized trials, and then fund those that are demonstrated to work.

I agree with the authors' point that there are plenty of useful interventions that foreign aid can support. Opponents of increasing aid often refer to capacity constraints in the recipient countries, but, in my view, these constraints are artificial and are created by the expectation that aid must be "sustainable." Many in the aid community hold the view that donors have to fund "sustainable" projects. This means that new projects and programs have to be dreamed up every few years, and that donors are reluctant to finance recurrent costs, such as teachers' salaries. Abandoning that view and admitting there are some things donors should fund for at least the next fifteen to twenty years would substantially loosen these so-called capacity constraints. It is important for children to be vaccinated, and donors should be willing to pay for that for the next twenty years; it is important for children to go to school, and donors should be willing to pay for that as well. At some point, African countries will presumably take off economically, just as many other countries have that were once considered basket cases, but it may not be for a while, and it may not be because of anything donors do.

The authors suggest that aid and development planning should focus on achieving the MDGs. ${ }^{3}$ A potential upside of the MDGs is that they help in fundraising. But a potential downside of focusing aid and development planning on the MDGs is that it may distort how funds are spent. I fear that the upside is not materializing, and indeed the authors point out that donors have not provided the resources needed to achieve the MDGs.

3. My discussion of aid and the MDGs has been shaped by conversations with Lant Pritchett of the World Bank. 
Given the overwhelming importance attached to the MDGs within the world's aid agencies, I worry that the MDGs may distort development spending, particularly aid spending. Poor countries have many needs, not all of which fit neatly within the MDGs. It is not clear why aid should be given to meet the MDGs rather than other important objectives. For example, the MDGs talk about reducing poverty and seem to rely on a headcount measure of poverty. One would presumably value improvements in income almost as much for someone just above an arbitrarily drawn international poverty line as for someone just below this poverty line. The MDGs do not seem to take this into account.

To take another example, the MDGs assign no value to benefits that will occur sometime after the deadlines have passed. Why is this important? Arguably, one of the most important things that can be done to improve health in Africa is to invest in research on vaccines against diseases such as malaria and AIDS. However, developing such vaccines might take long enough that the benefits would be realized after the deadlines. If development planning is single-mindedly focused on meeting the MDGs, funds for this research might be cut.

Basing national development plans around the MDGs is a risky strategy. As the authors point out, meeting the MDGs in Africa would require a great deal of external money. If that money does not materialize, countries will be left with a laundry list of everything from building refineries to vaccinations. I worry that countries may well wind up with a halffinished refinery and without the vaccinations.

Finally, in an age when development practitioners emphasize the importance of local participation, it seems odd to establish a set of goals through a UN process, the very unanimity of which suggests a lack of local participation, and then to ask people at the local level to come up with participatory ways to implement this agenda. Needs vary from country to country.

The jury seems to be out on whether the fundraising benefits of the MDGs will outweigh the potential distortions to development planning. I would suggest a much more modest, microeconomically based approach to aid. Instead of setting macroeconomic goals, such as escaping from a poverty trap or achieving the MDGs, and then planning aid around them, it would be better to make decisions based on microeconomic evidence on the impact of particular programs and policies. 
Stephen A. O'Connell: It is a privilege to discuss this important essay in persuasion by Jeffrey Sachs and his coauthors. The paper makes three bold claims. The first is that modern economic growth will begin in tropical Africa only when profound geographical disadvantages have been overcome. The second is that this will require a massive, temporary public investment program that can readily be organized around the Millennium Development Goals (MDGs) as intermediate targets. The third is that external finance represents in many cases the binding constraint on implementing this program, and therefore on getting growth started in Africa.

Africa has received a lot of foreign assistance for a long time. ${ }^{1}$ Much of the aid has been misdirected, but much has been geared to precisely the types of intervention endorsed by the authors. One should therefore ask two questions of the current paper. First, is the authors' diagnosis of "needs" significantly better than previous or competing diagnoses? Second, can a sharper take on needs, plus an overhaul of donor practices, improve the effectiveness of aid by anything like the magnitude suggested? My own view is that there is considerable scope for boldness in certain well-defined areas and particular countries. I believe nonetheless that the authors have underplayed both the uncertainties in their prescription and the constraints on an effective scaling up of aid.

The scope of the paper is extraordinary, and I will begin by quickly reviewing its contributions. Drawing on Sachs' pathbreaking research (with various coauthors) on the "human ecology" of tropical Africa, the authors document Africa's acute and in some cases widening disadvantage in agricultural productivity, transport costs, disease burden, and demographic structure. They interpret this persistent stagnation by appealing to a class of poverty trap models with geographically based increasing returns. These models provide a clear rationale for a massive, temporary infusion of external finance. To this end the authors develop a program that, at the scale proposed, amounts to a new development strategy for tropical Africa-one in which near-term efforts would focus, not on growth per se, but on establishing the preconditions for growth.

At the level of specific needs and interventions, the authors lay out an impressively concrete program. They appeal to an interdisciplinary set of

1. O'Connell and Soludo (2001). 
literatures to identify effective interventions in agriculture, health, and education. They cost these out on a country-specific basis for Ghana, Tanzania, and Uganda. In an exercise familiar to all aid practitioners but exemplary in important respects-including its treatment of recurrent costs and the incentive effects of user fees-they calculate a financing gap. The bottom line is daunting but perhaps doable: the MDGs for income poverty, health, and education can be met in these countries through a (first sharply, then gradually) scaled-up commitment that would roughly double real aid levels for a decade. In a final section the authors lay out a program for addressing donor shortcomings that might hamper success.

Perhaps the most striking bit of persuasion in the paper is its ex post motivation of the MDGs as take-off thresholds in a big-push development strategy. It is important that this argument not obscure two features of the MDGs that have already proved critical in rallying global support for increased aid to Africa. The first is their intrinsic appeal as merit goods. Here Sachs' work on economic geography continues to be instrumental in deepening our understanding of the particular deficits faced by African populations. The second is the political genius of the MDGs, as a set of well-defined targets squarely centered on poverty reduction and human development. As the authors point out, this is an agenda that cannot easily be rejected by any party to the aid relationship. As such it may provide a framework for overcoming the conflicts of interest that have undermined this relationship in the past.

Let me now turn to the substance of the paper, starting with the development strategy it proposes. This strategy has noble (even Nobel) lineage. In 1953 future laureate W. Arthur Lewis advised the government of the Gold Coast (soon to become Ghana) as follows. "The main obstacle to development," he wrote, "is the fact that agricultural productivity per man is stagnant. Very many years will have elapsed before it becomes economical for the government to transfer any large part of its resources towards industrialization and away from the more urgent priorities of agricultural productivity and public services." ${ }^{2}$ This is precisely the sequencing argument of the present paper. Nor is the geographical scope of the current argument much different, because in 1953 Ghana had an unambiguous head start in human development relative to most of tropi-

2. Lewis (1953, paragraph 255; reprinted in Kay, 1972, p. 88). 
cal Africa. Lewis would have extended the same advice to most of the continent.

Ghana's early development plans decisively rejected Lewis's advice. Like many African leaders, Kwame Nkrumah viewed agriculture as inert and industrialization as the way forward. That view was consistent, ironically, with Lewis's famous 1954 paper, in which agriculture provides a surplus that can be leveraged into capital accumulation and growth in the industrial sector. ${ }^{3}$ But it ignored Lewis's deeper advice that the preconditions were not yet there in Ghana: agricultural productivity was too low to generate a surplus.

Mauritius had something closer to a Korean-style head start in the 1950s, and here Lewis's shadow fell more heavily, although not to better effect. In Mauritius future Nobel laureate James Meade dispensed advice that was vintage Lewis $1954 .{ }^{4}$ This meant a disastrous ten-year detour into import-substituting industrialization. It was only in the late 1960s that this small island economy began to leverage its favorable preconditions (and the rents from sugar preferences) into an outward-oriented strategy based on labor-intensive textile exports.

The strategy advanced here therefore resonates with what at least one deep observer of the African situation saw as early as the 1950s. Moreover, although the authors do not really answer the "what next" question, Mauritius must be the model they have in mind. This would be consistent with the 1998 Brookings Paper by Sachs and David Bloom, which notes the hostile environment for African agriculture and (gingerly) endorses a move into labor-intensive manufacturing and services. ${ }^{5}$ Relative to Bloom and Sachs 1998, the current paper says that a platform must be built first, in the rural economy and in human development. Relative to Lewis 1953, the difference is one of urgency and scale: the platform should be constructed over the next decade, in a big push.

The contrast with Lewis 1953 highlights the central challenge this paper throws down to donors: are they being anywhere near bold enough? I think there is tremendous scope for scaling up donor activity in the broad area of science-intensive regional public goods, including basic research in health and agriculture. Here successful models are available,

3. Lewis (1954).

4. Meade and others (1961).

5. Bloom and Sachs (1998). 
including the eradication of polio and the development of high-yielding seed varieties in the Green Revolution in Asia; and donors have an unambiguous comparative advantage in the direct provision or local supervision of this effort. I also believe that donors should be much bolder in providing debt relief, which is a matter of housecleaning rather than net resource transfers; here Jubilee 2000 had it right, and the Heavily Indebted Poor Countries initiative has it wrong. But where the current paper innovates is in advocating a massive and externally funded scaling up of in-country public service delivery. This is vintage capital fundamentalism, and here the challenge reverses itself. The central thrust of the literature on African development has been to dismiss capital fundamentalism as a viable interpretation of Africa's way forward: are the authors being too bold?

To answer this I will start with the gap calculation itself. Such calculations are structurally optimistic, because they are designed to spur the ambitions of donors. But their empirical failings in traditional growthtargeting applications are sobering. ${ }^{6}$ Similar weaknesses confront a gapfinancing approach to the MDGs, and particularly one of the scale proposed here. For Tanzania (the results for Ghana and Uganda are similar), the authors call for a 78 percent increase in real domestic MDGbased spending in the first year of the program, followed by a decade of further real increases at nearly 7 percent a year. ${ }^{7}$ The initial increases in MDG spending and aid are each on the order of 10 percent of GDP. The latter is a lower bound, moreover; some big-ticket items are left out, and constant, state-of-the-art efficiency is assumed. Nor is there any genuine sense in which the program proposed here can look any different in 2016 than it does in 2015, as the authors acknowledge.

It is clear, then, that if absorptive capacity constraints are at all relevant in African countries, the scale of this program will bring them to the fore. The question is not whether the "needs" identified here are genuine; they are. But the African development literature locates ongoing needs-or capital shortages - in dysfunctional policy environments, and dysfunctional policy environments in weak institutions. The authors acknowledge this by limiting their proposal to countries in which policies and institutions are reasonably good, after controlling for income. This is an impor-

6. Easterly (1999).

7. Calculated from detailed spreadsheets generously provided by the authors. 
tant concession to reality, but the proviso is a non sequitur. The question is not whether governance is good relative to income, but whether it is good enough in absolute terms to avoid sharply diminishing returns or even outright institutional deterioration when managing a massive scaling up of public services.

The point that "absorptive capacity matters" is my central one, and I will briefly develop it in three arenas. First, Sachs has written eloquently elsewhere about the curse of natural resources. If financial resources were the binding constraint, African countries that have enjoyed persistent commodity booms should have leveraged those into an exit from the trap. They have systematically failed to do so. One reason may be that commodity rents have tended to become a focal point for distributional struggles that have undermined policy and institutional performance. Aid may be better in this respect; unlike commodity rents, it is encumbered by donors, who pay at least some attention to the activities being financed. Paul Collier and Anke Hoeffler have shown empirically, for example, that whereas natural resource abundance tends to increase armed conflict, higher levels of aid do not. ${ }^{8}$ But the limited and even adverse development impacts of commodity rents nonetheless pose serious questions about state capability in Africa, and about the idea that resources are the key constraint. If some form of accountability has indeed been critical in forging a constructive link between aid and conflict, the question is whether this accountability can be scaled up to support a doubling and more of public service delivery by weak government institutions.

The natural resource curse may also manifest itself via the Dutch disease, and in my own view the authors are on shaky ground in dismissing this. It is impossible for monetary policy to peg the real exchange rate over anything more than a temporary period. A large and persistent aid inflow that is geared toward domestic spending on nontraded goods and services is therefore very likely to create a serious competitiveness problem in the near term. In effect, the authors are placing another large bet on their sequencing argument: the implicit view here is that there is no point to having a competitive real exchange rate if a country lacks the human capital to go with it. This argument may be correct, but in the interim

8. Collier and Hoeffler (2002a, 2002b). The natural resource effect is nonlinear, but the risk of conflict peaks when the ratio of natural resource exports to GDP is quite high (30 percent). 
export diversification will clearly have to wait; and the empirical evidence strongly suggests that trade is more important for growth in Africa than it is elsewhere. ${ }^{9}$

Second, the authors assume "perfect delivery" of public services. Again the scale of the operation gives rise to concern. Improving public service delivery is currently at the frontier of public sector reform in Africa. But if institutions are currently weak, does it make sense to expand their financing and their mandate very rapidly? This might even exacerbate existing weaknesses. In a recent paper, Jean-Paul Azam, Shantayanan Devarajan, and I develop a trap model that is formally similar to the ones developed in this paper. ${ }^{10}$ But ours is a dependency trap, in which donor activities tend to drive out the institutional learning-by-doing that is critical to improved governance. If donors ignore this link between aid and institutional development, they can trap themselves and the recipient in a high-aid, low-institutional-capacity equilibrium. The possibility is not one we are allowed to dismiss after forty years of high aid and low growth.

As a third point, there has been substantial recent progress in building greater accountability into aid design, through the use of outcomes-based assessments. But how far can such assessments take us in ensuring high productivity of public service delivery? As Lant Pritchett and Michael Woolcock point out in a recent paper, many of the MDG services are both transactions-intensive and discretionary. ${ }^{11}$ Unlike macroeconomic reforms, the delivery of many health and education services requires the collaboration of multiple individuals who make highly discretionary choices in an environment where many key actions are unobservable. Such services cannot be delivered by a few politically protected technocrats, or even by a ministry stamping out a well-defined protocol in disparate locations. They are intrinsically subject to deep incentive problems. Consistent with this reality, the empirical link from spending on health and education to outcomes is notoriously weak-a point emphasized by the World Bank's 2004 World Development Report. ${ }^{12}$

The final section of the paper lays out a program to address a set of donor shortcomings-short horizons, inadequate ambition, and poor

9. Collier and Gunning (1999); Block (2001).

10. Azam, Devarajan, and O'Connell (2002).

11. Pritchett and Woolcock (2002).

12. World Bank (2003d). 
coordination - to which the authors attribute past failures in aid effectiveness. These shortcomings are serious, and the poverty reduction strategy process has begun to produce important improvements. Some donor shortcomings may be intrinsic, however, to a transaction that is ultimately a component of bilateral foreign policy. It is not clear, for example, that donors can adopt a credible ten-year horizon for aid to a high-performing African country whose current leadership might be replaced in short order by one with, well, short horizons, inadequate ambition, and poor coordination. Too many times, individual African countries or country pairs of similar geography have switched places in terms of growth performance. Examples include Uganda before and after 1986, Tanzania and Kenya in East Africa, and Côte d'Ivoire and Ghana in West Africa. Changes in the policy environment in these countries have swung growth differentials by 3 or 4 percentage points or more on a decadal basis. As we speak, landlocked Zimbabwe and Zambia are switching places in southern Africa. Aid cannot have a horizon that is longer than the uncertainties inherent in a fundamentally weak institutional environment. It may be possible to push horizons to something like five years; for programs insulated from political uncertainties (like the science-intensive regional public goods I mentioned earlier), the horizon can be much longer. But such insulation is implausible for in-country service delivery on a large scale.

Most fundamentally, improving the effectiveness of aid requires coming to grips with the deep inverse correlation of poverty with institutional capability. This will require scaling ambitions not only to need but also to absorptive capacity. A final example may convey the complexity of this issue, even within the group of countries with comparatively strong governance. Consider health interventions in Uganda and Ghana. In 1995 Ghana adopted its own structure for coordinating donors, setting up a sector-wide program in the health ministry to which donors were compelled to conform. This was precisely what Botswana had done from the outset with its own highly effective aid program-owning the process and coordinating donors around its own agenda. Ghana is now plausibly in a position to scale up aggressively in the health sector.

Uganda emerged from civil war in the mid-1980s and experienced a remarkable recovery over the next fifteen years or so. ${ }^{13}$ This was accomplished by creating tremendous coherence at the highest levels of the bud-

13. Reinikka and Collier (2001). 
get and policy process - in the president's office, the Ministry of Planning and Finance, and the central bank. The spending ministries, in contrast, have remained a mixture of well-functioning and nonfunctioning entities, with the health ministry in the latter category. The scaling up advocated here might therefore face a Ugandan response of the following form: "We have a functioning budget process and have set our spending priorities consistent with our needs and the delivery capacity of our ministries. It is not appropriate, at this time, to move an additional 4 percent of GDP through our health ministry. Nor do we wish you to set up a competing health service delivery structure." To insist in such a context that "it can and must be done" would at best be a risky strategy for donors.

I close by saying that this is a challenging paper in the deepest and most constructive sense. I have argued for a more moderate scale of intervention, but there is much that can and must be done in precisely the areas identified here. The authors have made a concrete and powerful case for a retargeting of aid efforts in tropical Africa and a significant increase in overall assistance.

General discussion: Richard Cooper disagreed sharply with the authors' proposals for greatly expanding aid to sub-Saharan Africa at this time, unless one could ensure that the aid could be used effectively. He argued that the aid would be wasted in many countries in the region because they lacked the elementary functions of law and order that would be needed to deliver aid effectively. Cooper also questioned some of the paper's analysis of Africa's economic plight. While granting that the region was desperately poor compared with many nations in other parts of the world, he pointed to Africa's own history as evidence that Africa is not in a subsistence-level poverty trap. Over the past fifty years, average income per capita has grown by 60 percent, longevity has increased before adjusting for the impact of AIDS, infant mortality has fallen, and population growth has been rapid. Nor was Cooper persuaded that geography makes Africa a special case: other countries, such as Switzerland, are landlocked and have even fewer resources than Africa. He observed that the British, the French, and the Portuguese had built important railroads in Africa, which had fallen into disuse through negligence and the ravages of civil war. Cooper suggested that drastic measures may be needed in some African countries, such as a twenty-first-century version of the British colonial office (for example, a UN trusteeship, with forces to backstop it), to pro- 
vide minimal law and order so that economies could begin meaningful development and make use of expanded aid.

Edward Glaeser, by contrast, was convinced by the authors' arguments on the importance of geography and reasoned that, were it not for strict immigration laws in the developed countries, no one would be living in sub-Saharan Africa today. However, given the region's geography, he was skeptical about developing agriculture in the region, noting that, with transportation costs so low, only countries with comparative advantage should be in the staple crop business.

Robert Gordon found a parallel between the post-World War I reparations imposed on Germany and current plans to greatly expand aid transfers to Africa. In his classic essay "The Economic Consequences of the Peace," John Maynard Keynes argued that, through the positions they took at Versailles, Britain and France had undermined their own export industries because the reparations they demanded would force a real devaluation on Germany. Gordon worried that Africa could be similarly hurt if massive aid transfers led to a real appreciation of currencies there. 


\section{References}

Anderson, Kym, and others. 2001. "The Burdens of Rich Country Protection to Developing Countries." Journal of African Economies 10, no. 3: 227-57.

Armstrong Schellenberg, Johanna, and others. 2004. "The Effect of Integrated Management of Childhood Illness on Observed Quality of Care of UnderFives in Rural Tanzania." Health Policy and Planning 19, no. 1: 1-10.

Azam, Jean-Paul, Shantayanan Devarajan, and Stephen A. O'Connell. 2002. "Equilibrium Aid Dependence." University of Toulouse, World Bank, and Swarthmore University (November).

Baffes, John. 2004. "Cotton: Market Setting, Trade Policies, and Issues.” Policy Research Working Paper 3218. Washington: World Bank (February).

Baland, Jean Marie, and Jean-Philippe Platteau. 1996. Halting Degradation of Natural Resources: Is There a Role for Rural Communities? New York: FAO.

Bang, A. T., and others. 1999. "Maternal Morbidity during Labour and the Puerperium in Rural Homes and the Need for Medical Attention: A Prospective Observational Study in Gadchiroli, India." Lancet 354: 1955-61.

Barro, Robert, and Xavier Sala-i-Martin. 1998. Economic Growth. MIT Press.

Beaton, George H., and others. 1993. "Effectiveness of Vitamin A Supplementation in the Control of Young Child Morbidity and Mortality in Developing Countries." Nutrition Policy Discussion Paper 13. New York: UN Administrative Committee on Coordination, Sub-committee on Nutrition.

Ben-David, Dan. 1998. "Convergence Clubs and Subsistence Economies.” Journal of Development Economics 55, no. 1: 155-71.

Besley, Timothy, and Robin Burgess. 2003. "Halving Global Poverty." Journal of Economic Perspectives 17, no. 3: 3-22.

Birkhaeuser, Dean, Robert E. Evenson, and Gershon Feder. 1991. "The Economic Impact of Agricultural Extension: A Review." Economic Development and Cultural Change 39, no. 3: 607-50.

Black, Robert E., Saul S. Morris, and Jennifer Bryce. 2003. "Where and Why Are 10 Million Children Dying Every Year?” Lancet 361: 2226-34.

Block, Steven A. 2001. "Does Africa Grow Differently?" Journal of Development Economics 65, no. 2: 443-67.

Bloom, David E., and Jeffrey D. Sachs. 1998. "Geography, Demography, and Economic Growth in Africa." BPEA, no. 2: 207-73.

Bloom, David, David Canning, and Jaypee Sevilla. 2003. "Geography and Poverty Traps." Journal of Economic Growth 8, no. 4: 355-78.

Borrell, Brent, and David Pearce. 1999. "Sugar: The Taste Test of Trade Liberalisation." Canberra: Centre for International Economics.

Boserup, Ester. 1965. The Conditions of Agricultural Growth: The Economics of Agrarian Change under Population Pressure. Chicago: Aldine.

- 1981. Population and Technical Change: A Study of Long-Term Trends. University of Chicago Press. 
Bosworth, Barry P., and Susan M. Collins. 2003. "The Empirics of Growth: An Update." BPEA, no. 2: 113-79.

Brenton, Paul, and Takako Ikezuki. 2004. "The Initial and Potential Impact of Preferential Access to the U.S. Market under the African Growth and Opportunity Act.” Policy Research Working Paper 3262. Washington: World Bank.

Bruno, Michael, Martin Ravallion, and Lyn Squire. 1998. "Equity and Growth in Developing Countries: Old and New Perspectives on the Policy Issues." Policy Research Working Paper 1563. Washington: World Bank.

Bruns, Barbara, Alain Mingat, and Ramahatra Rakotomalala, eds. 2003. Achieving Universal Primary Education by 2015: A Chance for Every Child. Washington: World Bank.

Center for International Earth Science Information Network (CIESIN), Columbia University. 2002. National Aggregates of Geospatial Data: Population, Landscape and Climate Estimates (PLACE). Palisades, N.Y. Available at sedac. ciesin.columbia.edu/plue/nagd/place.

Centro Internacional de Agricultura Tropical (CIAT) and others. 2002. "Soil Fertility Degradation in Sub Saharan Africa: Leveraging Lasting Solutions to a Long Term Problem." Conclusions from a Workshop held at the Rockefeller Foundation Bellagio Study and Conference Center, Bellagio, Italy, March 4-8.

Christiansen, Luc, Christopher Scott, and Quentin Wodon. 2002. "Development Targets and Costs." In A Sourcebook for Poverty Reduction Strategies ( 2 vols.), edited by Jeni Klugman. Washington: World Bank.

Cleland, J. G., and J. K. Van Ginneken. 1988. "Maternal Education and Child Survival in Developing Countries: The Search for Pathways of Influence." Social Science Medicine 27, no. 12: 1357-68.

Collier, Paul, and Jan-Willem Gunning. 1999. "Explaining African Economic Growth.” Journal of Economic Literature 37, no. 1: 64-111.

Collier, Paul, and Anke Hoeffler. 2002a. "Aid, Policy, and Peace." Defence and Peace Economics 13, no. 6: 435-50.

. 2002b. "Greed and Grievance in Civil War." Working Paper Series 2002-1. Oxford, United Kingdom: Centre for Study of African Economies (March).

Commission on Macroeconomics and Health (CMH). 2001. Macroeconomics and Health: Investing in Health for Economic Development. Geneva: World Health Organization.

Delamonica, Enrique, Santosh Mehrotra, and Jan Vandermoortele. 2001. "Is EFA Affordable? Estimating the Global Minimum Cost of 'Education for All."' Innocenti Working Paper 87. Florence, Italy: UNICEF Innocenti Research Center.

Diop, Ndiame, John Beghin, and Mirvat Sewadeh. 2004. "Groundnut Policies, Global Trade Dynamics, and the Impact of Trade Liberalization." Policy Research Working Paper 3226. Washington: World Bank. 
Donovan, Graeme, and Frank Casey. 1998. "Soil Fertility Management in SubSaharan Africa." Technical Paper 408. Washington: World Bank.

Easterly, William. 1999. "The Ghost of Financing Gap: Testing the Growth Model of the International Financial Institutions." Journal of Development Economics 60, no. 2: 423-38.

Evenson, Robert E., and Douglas Gollin. 2003. Crop Variety Improvement and Its Effect on Productivity: The Impact of International Research. Wallingford, United Kingdom: CABI Publishing.

Ezzati, Majid, and Daniel M. Kammen. 2002. "Evaluating the Health Benefits of Transitions in Household Energy Technologies in Kenya." Energy Policy 30, no. 10: 815-26.

Food and Agriculture Organisation of the United Nations (FAO). 1995a. "Irrigation in Africa in Figures." Water Reports 7. Rome.

—. 1995b. "Women, Agriculture and Rural Development: A Synthesis Report of the Africa Region." Rome.

- 1996. "Special Feature: Crucial Role of Irrigation Development in Increasing Food Production in Sub-Saharan Africa." Africa Report 05/96. Rome. Available at www.fao.org/docrep/004/w1144e/w1144e54.htm.

. 2001. "Report of the World Food Summit: Five Years Later." Rome. Available at www.fao.org/DOCREP/MEETING/005/Y7106E/Y7106E00. HTM.

2002. "Anti-Hunger Programme: Reducing Hunger through Sustainable Agricultural and Rural Development and Wide Access to Food.” Rome.

Food and Agricultural Policy Research Institute (FAPRI). 2002. "The Doha Round of the World Trade Organization: Liberalization of Agricultural Markets and Its Impact on Developing Economies." Paper presented at the International Agricultural Trade Research Consortium Winter Meetings, San Diego, December.

Foster, Mick. 2002. "Direct Budget Support to Mozambique." Report to the Department for International Development. Mick Foster Economics, Ltd. (November).

Foster, Mick, and Andrew Keith. 2003. "The Case for Increased Aid." Final Report to the Department for International Development of the United Kingdom (December).

Freedom House. 2003. Freedom in the World 2003. New York. Available at www.freedomhouse.org/research/index.htm.

Global Environmental Monitoring and Research Center (GEMS). 1995. Environmental Data Report 1993-1994. London: Blackwell Publishers.

Global Forum for Health Research. 2002. “10/19 Report on Health Research 2001-2002." Geneva. Available at www.globalforumhealth.org/Files Upld/ 36.pdf. 
Global Water Partnership. 2000. "Towards Water Security: A Framework for Action." Paper prepared for the Second World Water Forum, The Hague, March 17-22.

Hamilton, Kirk, and Michael Clemens. 1999. "Genuine Savings Rates in Developing Countries." World Bank Economic Review 13, no. 2: 333-56.

Harrison, Makiko, Jeni Klugman, and Eric Swanson. 2003. "Are Poverty Reduction Strategies Undercutting the Millennium Development Goals? An Empirical Review." Washington: World Bank (September 17).

Henao, Julio, and Carlos Baanante. 1999. "Nutrient Depletion in the Agricultural Soils of Africa." 2020 Brief 62. Washington: International Food Policy Research Institute. Available at www.cgiar.org/ifpri/2020/briefs.

Hine, John L., and Simon D. Ellis. 2001. "Agricultural Marketing and Access to Transport Services." Wokingham, United Kingdom: Transport Research Laboratory.

Hine, John L., and John Rutter. 2000. "Roads, Personal Mobility and Poverty: The Challenge." Transport and Poverty Alleviation Workshop. Wokingham, United Kingdom: Transport Research Laboratory.

Hoekman, Bernard, Francis Ng, and Marcelo Olarreaga. 2002. "Agricultural Tariffs versus Subsidies: What's More Important for Developing Countries?" World Bank Working Paper. Washington: World Bank.

Huan-Niemi, Ellen, and Jyrki Niemi. 2003. “The Impact of Preferential, Regional and Multilateral Trade Agreements: A Case Study of the EU Sugar Regime." Working Paper 1. Brussels: European Network of Agricultural and Rural Policy Research Institutes (September).

Ianchovichina, Elena, Aaditya Mattoo, and Marcelo Olarreaga. 2001. "Unrestricted Market Access for Sub-Saharan Africa: How Much Is It Worth and Who Pays?" Policy Research Working Paper 2595. Washington: World Bank.

Intergovernmental Panel on Climate Change (IPCC). 2001. Climate Change 2001: Impacts, Adaptation and Vulnerability. Contribution of Working Group II to the Third Assessment Report of the Intergovernmental Panel on Climate Change. Cambridge University Press.

International Food Policy Research Institute (IFPRI). 2000. "Women-The Key to Food Security: Looking Within the Household.” IFPRI Policy Brief. Washington. Available at www.ifpri.org/pubs/ib/ib3.pdf.

Jayne, T. S., and others. 2001. "Smallholder Income and Land Distribution in Africa: Implications for Poverty Reduction Strategies." MSU International Development Paper 24. Michigan State University, Department of Agricultural Economics.

Jones, Gareth, and others. 2003. "How Many Child Deaths Can We Prevent This Year?" Lancet 362, no. 9377: 65-71.

Kaufmann, Daniel, Aart Kraay, and Massimo Mastruzzi. 2003. "Governance Matters III: Governance Indicators for 1996-2002.” Policy Research Working 
Paper 3106 (June). Available at www.worldbank.org/wbi/governance/pubs/ govmatters $3 . h t m l$.

Kaufmann, Daniel, Aart Kraay, and Pablo Zoido-Lobaton. 2002. "Governance Matters II-Updated Indicators for 2000/01." Policy Research Department Working Paper 2772. Washington: World Bank (January).

Kay, G. B., ed. 1972. The Political Economy of Colonialism in Ghana: A Collection of Documents and Statistics 1900-1960. Cambridge University Press.

Khan, M. 1982. "Interruption of Shigellosis by Hand Washing. Transactions of the Royal Society of Tropical Medicine and Hygiene 76, no. 2: 164-68.

Kiszewski, Anthony, and others. 2004. "A Global Index Representing the Stability of Malaria Transmission." American Journal of Tropical Medicine and Hygiene 70, no. 5: 486-98.

Kotloff, Karen L., and others. 1999. "Global Burden of Shigella Infections: Implications for Vaccine Development and Implementation of Control Strategies." Bulletin of the World Health Organization 77, no. 8: 651-66.

Kremer, Michael. 2002. "A Purchase Commitment for Vaccines." In Global Public Goods Financing: New Tools for New Challenges, A Policy Dialogue, edited by Inge Kaul, Katell Le Goulven, and Mirjam Schnupf. New York: United Nations Development Programme.

- Forthcoming. "Randomized Evaluations of Educational Programs in Developing Countries: Some Lessons." American Economic Review Papers and Proceedings.

Kuznets, Simon. 1966. Modern Economic Growth: Rate, Structure and Spread. Yale University Press.

Leipziger, Danny, and others. 2003. "Achieving the Millennium Development Goals: The Role of Infrastructure.” Policy Research Working Paper 3163. Washington: World Bank (November).

Lengeler, C. 2004. "Insecticide-Treated Bed Nets and Curtains for Preventing Malaria." In The Cochrane Library, issue 2. Chichester, United Kingdom: John Wiley \& Sons.

Lewis, W. Arthur. 1953. Report on Industrialisation and the Gold Coast. Accra, Ghana: Government Printer.

- 1954. "Economic Development with Unlimited Supplies of Labour." Manchester School 22 (May): 139-91.

Limao, Nuno, and Anthony J. Venables. 1999. "Infrastructure, Geographical Disadvantage and Transport Costs." London School of Economics, Department of Economics.

Loayza, Norman, Klaus Schmidt-Hebbel, and Luis Servén. 2000. "Saving in Developing Countries: An Overview." World Bank Economic Review 14, no. 3: 393-414.

Marsh, David R., and others. 2002. "Advancing Newborn Health and Survival in Developing Countries: A Conceptual Framework." Washington: Save the Children Federation. 
Masters, William A. Forthcoming. "Research Prizes: A New Kind of Incentive for Innovation in African Agriculture. International Journal of Biotechnology.

Maxwell, Caroline A., and others. 2002. "Effect of Community-wide Use of Insecticide Treated Nets for 3-4 Years on Malarial Morbidity in Tanzania." Tropical Medicine and International Health 7, no. 12: 1003-08.

Meade, James E., and others. 1961. The Economic and Social Structure of Mauritius: Report to the Governor of Mauritius. London: Methuen.

Miles, Marc, Edwin Feulner, and Mary O'Grady. 2004. 2004 Index of Economic Freedom. Washington: Heritage Foundation and Wall Street Journal.

Mitchell, Donald. 2004. "Sugar Policies: Opportunity for Change." Policy Research Working Paper 3222. Washington: World Bank.

Musinguzi, Polycarp, and Peter Smith. 2000. "Saving and Borrowing in Rural Uganda." University of Southampton Discussion Papers in Economics and Econometrics 0016. University of Southampton.

Nelson, Richard. 1956. "A Theory of the Low-Level Equilibrium Trap in Underdeveloped Economies." American Economic Review 46, no. 5: 894-908.

New Partnership for Africa's Development (NEPAD). 2004. "Infrastructure Short-Term Action Plan (STAP): Review of Implementation Progress and the Way Forward." Johannesburg. Available at www.nepadst.org/publications/ docs/doc12_032004.pdf.

O'Connell, Stephen A., and Charles C. Soludo. 2001. "Aid Intensity in Africa." World Development 29, no. 9: 1527-52.

Ogaki, Masao, Jonathan Ostry, and Carmen Reinhart. 1996. "Saving Behavior in Low- and-Middle-Income Developing Countries." Staff Papers 43, no. 1: 38-71. Washington: International Monetary Fund.

Okidi, John, Paul Okwi, and John Ddumba. 2000. "Welfare Distribution and Poverty in Uganda 1992-1997.” Occasional Paper 6. Kampala, Uganda: Economic Policy Research Center.

Oxfam. 2002. "Cultivating Poverty: The Impact of US Cotton Subsidies on Africa." Oxfam Briefing Paper 30. Oxford, United Kingdom.

Prati, Alessandro, Ratna Sahay, and Thierry Tressel. 2003. "Is There a Case for Sterilizing Foreign Aid Inflows?" Paper presented at the 18th Annual EEA Congress and the 58th European ESEM meeting, Stockholm, August.

Pritchett, Lant, and Michael Woolcock. 2002. "Solutions When the Solution Is the Problem: Arraying the Disarray in Development." Working Paper 10. Washington: Center for Global Development (September).

PSR Group. 2004. International Country Risk Guide. East Syracuse, N.Y. Available at www.prsgroup.com/icrg/icrg.html.

Quirke, Derek. 2002, Trade Distortions and Cotton Markets: Implications for Global Cotton Producers. Canberra: Cotton Research and Development Corporation, Centre for International Economics.

Quisumbing, Agnes, and John Maluccio. 2000. "Intrahousehold Allocation and Gender Relations: New Empirical Evidence from Four Developing Coun- 
tries.” FCND Discussion Paper 84. Washington: International Food Policy Research Institute.

Radelet, Steve. 2004. "Aid Effectiveness and the Millennium Development Goals." Background Paper for Millennium Project Task Force 1. Working Paper 39. Washington: Center for Global Development (March).

Reinikka, Ritva, and Paul Collier, eds. 2001. Uganda's Recovery: The Role of Farms, Firms, and Government. Washington: World Bank.

Rizet, C., and J. Hine. 1993. "A Comparison of the Costs and Productivity of Road Freight Transport in Africa and Pakistan." Transport Reviews 13, no. 2: $151-65$.

Ross, John A., and William L. Winfrey. 2002. "Unmet Need for Contraception in the Developing World and the Former Soviet Union: An Updated Estimate." International Family Planning Perspectives 28, no. 3: 138-43.

Sachs, Jeffrey D. 2002. "Resolving the Debt Crisis of Low-Income Countries." BPEA, no. 1: 257-86.

- Forthcoming. "Globalization and Patterns of Economic Growth." In Globalization: What's New? edited by Michael M. Weinstein. Columbia University Press/Council on Foreign Relations.

Sanchez, Pedro. 2002. "Soil Fertility and Hunger in Africa." Science 295: 2019-220.

Sasakawa Africa Association. 2000. "About Sasakawa Africa Fund for Extension Education." Available at www.saa-tokyo.org/english/safe/.

Simon, David. 2003. "Official Development Assistance and the Millennium Development Goals." Report prepared for the UN Millennium Project Secretariat. Harvard University.

Smith, Adam. 1776. An Inquiry into the Nature and Causes of the Wealth of Nations. Facsimile of the 1976 Oxford University Press edition. Indianapolis, Ind.: Liberty Fund.

Spencer, Dunstan. 1994. "Infrastructure and Technology Constraints to Agricultural Development in the Humid and Subhumid Tropics of Africa." EPTD Discussion Paper 3. Washington: International Food Policy Research Institute.

Starkey, Paul, and others. 2002. "Improving Rural Mobility—Options for Developing Motorized and Nonmotorized Transport in Rural Areas." World Bank Technical Paper 525. Washington: World Bank.

TAKWIMU. 2000. "Developing a Poverty Baseline in Tanzania." Dar es Salaam: National Bureau of Statistics and OPM Ltd.

Tokarick, Stephen. 2003. "Measuring the Impact of Distortions in Agricultural Trade in Partial and General Equilibrium." Working Paper WP/03/110. Washington: International Monetary Fund.

Torero, Maximo, and Shyamal Chowdhury. 2004. "Infrastructure for Africa: Overcoming Barriers to Development." Paper prepared for the 2020 Africa Conference, Kampala, Uganda, sponsored by the International Food Policy Research Institute, April. 
Transparency International. 2004. Global Corruption Report 2004. London: Pluto Press.

Udry, Christopher, John Hoddinott, and Lawrence Haddad. 1995. “Gender Differentials in Farm Productivity: Implications for Household Efficiency and Agricultural Policy." Food Policy 20, no. 5: 407-23.

United Nations. 2003. World Population Prospects 1950-2050: The 2002 Revision. Department of Economic and Social Affairs, Population Division, New York.

United Nations Conference on Trade and Development (UNCTAD). 2002. The Least Developed Countries Report 2002: Escaping the Poverty Trap. Geneva.

- 2003a. Economic Development in Africa: Trade Performance and Commodity Dependence. New York and Geneva: United Nations.

. 2003b. "Back to Basics: Market Access Issues in the Doha Agenda." New York and Geneva: United Nations. Available at 192.91.247.38/tab/pubs/ itcdtabMisc9_en.pdf.

United Nations Millennium Project. 2004. "Millennium Development Goals Needs Assessment: Background Paper to 'Ending Africa's Poverty Trap.'” Working paper. New York.

United Nations Millennium Project Task Force on Poverty and Economic Development. 2004. "Interim Report: An Enhanced Strategy for Reducing Extreme Poverty by the Year 2015." New York. Available at www.unmillenniumpro ject.org/documents/tfoneinterim.pdf.

U.S. Department of Energy, Energy Information Administration. 1999. Energy in Africa.

World Bank. 2000. Can Africa Claim the 21st Century? Washington.

. 2002. "Achieving Education for All by 2015: Simulation Results for 47 Low Income Countries." Washington: World Bank, Human Development Network, Africa Region and Education Department.

- 2003a. World Development Indicators 2003. Washington.

. 2003b. "Are Poverty Reduction Strategies Undercutting the Millennium Development Goals? An Empirical Review." Washington. Available at www.worldbank.org/poverty/strategies/events/attackpov/nov11_prsp_mdg.pdf.

2003c. "Supporting Sound Policies with Adequate and Appropriate Financing." Staff Paper for the Development Committee. Washington. Available at siteresources.worldbank.org/DEVCOMMINT/Resources/Fall-2003/ DC2003-0016(E)-Financing.pdf.

. 2003d. World Development Report 2004: Making Services Work for Poor People. Oxford University Press.

2004a. World Development Indicators 2004. Washington.

- 2004b. "South Africa: Country Brief." Washington. Available at www. worldbank.org/afr/za/za_ctry_brief.htm. 
World Education Forum. 2000. Dakar Framework for Action: Education for All: Meeting Our Collective Commitments. Paris: UNESCO. Available at www. unesco.org/education/efa/ed_for_all/dakfram_eng.shtml.

World Health Organization. 1992. "World Malaria Situation in 1990, Part II. Weekly Epidemiological Record 67, pp. 167-74.

. 2001. "WHO Technical Consultation. Report on Antimalarial Drug Combination Therapy." Document WHO/CDS/RBM/2001.35. Geneva. Available at rbm.who.int/cmc_upload/0/000/015/082/use_of_antimalarials2.pdf.

World Health Organization and United Nations Children's Fund. 2003. The Africa Malaria Report 2003. Geneva. Available at mosquito.who.int/ amd2003/amr2003/pdf/amr2003.pdf.

World Health Organization, United Nations Children's Fund, and Global Alliance for Vaccines and Immunizations. 2003. "Comprehensive Immunization Strategy Can Greatly Reduce Child Deaths from Measles." Geneva. Available at www.who.int/vaccines/gavi/pr_20030103.shtml. 